\title{
Epidemiologie, Diagnostik und Therapie erwachsener Patienten mit
}

\section{nosokomialer Pneumonie}

S-3 Leitlinie der Deutschen Gesellschaft für Anästhesiologie und Intensivmedizin e.V., der Deutschen Gesellschaft für Infektiologie e.V., der Deutschen Gesellschaft für Hygiene und Mikrobiologie e.V., der Deutschen Gesellschaft für Pneumologie und Beatmungsmedizin e.V. und der Paul-Ehrlich-Gesellschaft für Chemotherapie e.V. ${ }^{1}$

Epidemiology, Diagnosis and Treatment of Adult Patients with Nosocomial Pneumonia

S-3 Guideline of the German Society for Anaesthesiology and Intensive Care Medicine, the German Society

for Infectious Diseases, the German Society for Hygiene and Microbiology, the German Respiratory Society and

the Paul-Ehrlich-Society for Chemotherapy

Autoren

Institute
K. Dalhoff', M. Abele-Horn², S. Andreas ${ }^{3}$, T. Bauer ${ }^{4}$, H. von Baum5 ${ }^{5}$, M. Deja ${ }^{6}$, S. Ewig ${ }^{7}$, P. Gastmeier ${ }^{8}$, S. Gatermann ${ }^{9}$, H. Gerlach ${ }^{10}$, B. Grabein ${ }^{11}$, C. Höffken ${ }^{12}$, W. V. Kern ${ }^{13}$, E. Kramme ${ }^{14}$, C. Lange ${ }^{15}$, J. Lorenz ${ }^{16}$, K. Mayer ${ }^{17}$, I. Nachtigall ${ }^{18}$, M. Pletz ${ }^{19}$, G. Rohde ${ }^{20}$, S. Rosseau ${ }^{21}$, B. Schaaf ${ }^{22}$, R. Schaumann ${ }^{23}$, D. Schreiter ${ }^{24}$, H. Schütte ${ }^{25}$, H. Seifert ${ }^{26}$, H. Sitter ${ }^{27}$, C. Spies ${ }^{28}$, T. Welte ${ }^{29}$

Die Institutsangaben sind am Ende des Beitrags gelistet.
Bibliografie

DOI http://dx.doi.org/

$10.1055 / \mathrm{s}-0032-1325924$

Pneumologie 2012; 66: 707-765

(c) Georg Thieme Verlag KG

Stuttgart · New York

ISSN 0934-8387

\section{Korrespondenzadresse}

Prof. Dr. med. Klaus Dalhoff

Medizinische Klinik III

Universitätsklinikum

Schleswig-Holstein

Campus Lübeck

Ratzeburger Allee 160

23538 Lübeck

klaus.dalhoff@uk-sh.de

\section{Zusammenfassung}

$\nabla$

Die nosokomiale Pneumonie ist eine häufige Komplikation von Krankenhausaufenthalten. Die meisten Daten liegen zur beatmungsassoziierten Pneumonie vor, aber auch auf Normalstationen ist vermehrt mit dieser Erkrankung zu rechnen. Problematisch ist die Zunahme von Infektionen mit multiresistenten Erregern (MRE). Diese erschwert die adäquate Initialtherapie und kann zu unkritischem Einsatz von Breitspektrumantibiotika führen.

Die vorliegende S3-Leitlinie wurde von einer interdisziplinären Arbeitsgruppe auf der Basis einer systematischen Literaturrecherche erarbeitet. Die Empfehlungen zu Diagnostik und Therapie der nosokomialen Pneumonie wurden nach dem GRADE-System abgefasst. Sie berücksichtigen neben der Evidenzqualität auch Nutzen und Risiko bzw. Aufwand der empfohlenen Maßnahmen. Graduierung und Empfehlungsstärke entsprechen der Methodik der Nationalen Versorgungsleitlinien.

Die Leitlinie besteht aus zwei Teilen. Der allgemeine Teil vermittelt einen Überblick zu Epidemiologie, Erregerspektrum und Therapieoptionen der nosokomialen Pneumonie. Handlungsorientierte Empfehlungen werden im zweiten Teil zu zentralen Fragen der Diagnostik und Therapie abgegeben, die Hintergründe hierfür im Fließtext erklärt. Im Diagnostikteil wird besonderer Wert auf eine gezielte mikrobiologische Diagnostik gelegt, da diese die Voraussetzung für die Kenntnis des lokalen Erregerspektrums und der Resistenzraten bildet. Darüber hinaus stellt sie beim individuellen Patienten die beste Grundlage für die Deeskalation dar. Die Intensität der antiinfektiven Therapie ist vorwiegend davon abhängig, ob ein erhöhtes Risiko für Infektionen mit MRE besteht. Strukturierte Deeskalationskonzepte und konsequente Begrenzung der Therapiedauer dienen der Verminderung des Selektionsdrucks.

\section{Abstract \\ $\nabla$}

Nosocomial pneumonia (HAP) is a frequent complication of hospital care. Most data are available on ventilator-associated pneumonia. However infections on general wards are also increasing. A central issue are infections with multi drug resistant (MDR) pathogens which are difficult to treat particularly in the empirical setting potentially leading to inappropriate use of antimicrobial therapy.

This guideline was compiled by an interdisciplinary group on the basis of a systematic literature review. Recommendations are made according to GRADE giving guidance for the diagnosis and therapy of HAP on the basis of quality of evidence and benefit/risk ratio.

The guideline has two parts. First an update on epidemiology, spectrum of pathogens and antiinfectives is provided. In the second part recommendations for the management of diagnosis and treatment are given. Proper microbiologic work up is emphasized for knowledge of the local patterns of microbiology and drug susceptibility. Moreover this is the optimal basis for deescalation in the individual patient. The intensity of antimicrobial therapy is guided by the risk of infections with MDR. Structured deescalation concepts and strict limitation of treatment duration should lead to reduced selection pressure.

\footnotetext{
${ }^{1}$ Unter Mitwirkung der folgenden wissenschaftlichen Fachgesellschaften und Institutionen: Deutsche Gesellschaft für Chirurgie (D. S.) Deutsche Gesellschaft für Innere Medizin e.V. (S. A.) Deutsche Gesellschaft für Internistische Intensivmedizin und Notfallmedizin (T. W.) Deutsche Sepsis-Gesellschaft e.V. (K. M.) und Robert Koch-Institut

Verabschiedet von den Vorständen der beteiligten Fachgesellschaften am 1.10.2012.
} 


\begin{tabular}{|c|c|c|}
\hline \multicolumn{3}{|c|}{ Inhaltsverzeichnis } \\
\hline 1 & Einführung & 708 \\
\hline 2 & Zusammenfassung & 708 \\
\hline 2.1 & Synopsis der Empfehlungen & 708 \\
\hline 3 & Hintergrund und Methoden & 711 \\
\hline 3.1 & Präambel & 711 \\
\hline 3.2 & Ziele der Leitlinie & 711 \\
\hline 3.3 & Struktur des Leitlinienprozesses & 711 \\
\hline 3.4 & GRADE & 712 \\
\hline 3.5 & Literaturrecherche & 712 \\
\hline 3.6 & Finanzierung & 712 \\
\hline 3.7 & Implementierung/Publikation & 712 \\
\hline 3.8 & Planmäßige Überarbeitung & 712 \\
\hline 4 & Definitionen & 712 \\
\hline 5 & Epidemiologie & 713 \\
\hline 5.1 & Epidemiologie der HAP & 713 \\
\hline 5.2 & Inzidenz der VAP/HAP & 713 \\
\hline 5.3 & Letalität der VAP/HAP & 713 \\
\hline 5.4 & Verlängerung der Verweildauer durch VAP & 715 \\
\hline 6 & Erregerspektrum und Resistenz & 715 \\
\hline 6.1 & Interpretation von Daten zum Erregerspektrum & 717 \\
\hline 7 & Antiinfektiva & 720 \\
\hline 7.1 & Aminopenicilline mit Betalaktamaseinhibitor & 720 \\
\hline 7.2 & Ureidopenicilline mit Betalaktamaseinhibitor & 720 \\
\hline 7.3 & Cephalosporine & 720 \\
\hline 7.4 & Carbapeneme & 721 \\
\hline 7.5 & Fluorchinolone & 721 \\
\hline 7.6 & Aminoglykoside & 722 \\
\hline 7.7 & Makrolide & 722 \\
\hline 7.8 & Glykopeptide & 723 \\
\hline 7.9 & Oxazolidinone & 723 \\
\hline 7.10 & Colistin & 723 \\
\hline 7.11 & Cotrimoxazol & 724 \\
\hline 7.12 & Tigecyclin & 724 \\
\hline 8 & Diagnostik & 725 \\
\hline 9 & Antimikrobielle Therapie & 729 \\
\hline Literatı & & 736 \\
\hline Eviden & ztabellen & 743 \\
\hline
\end{tabular}

\section{Einführung}

Die nosokomiale Pneumonie (hospital-acquired pneumonia, international abgekürzt: HAP), besonders die beatmungsassoziierte Pneumonie (ventilator-associated pneumonia: VAP), ist unverändert eine bedrohliche Komplikation im Verlauf einer Krankenhausbehandlung. Die exakte Inzidenz ist aus vielfältigen Gründen schwierig, wenn nicht unmöglich zu bestimmen, ebenso die mit dieser Komplikation verbundene Exzess-Letalität; dennoch besteht kein Zweifel, dass die Erfolge der Intensivmedizin durch diese Erkrankung in erheblichem Umfang eingeschränkt werden. Trotz beeindruckenden Forschungsanstrengungen in den letzten dreißig Jahren bleiben weiterhin viele wichtige Fragen in der Diagnostik und Therapie der nosokomialen Pneumonie offen. Gleichzeitig nimmt die Neigung der öffentlichen Meinung zu, nosokomiale Pneumonien bzw. Infektionen überhaupt für grundsätzlich vermeidbar anzusehen und hiermit indirekt tödliche Ausgänge als nicht hinnehmbar zu werten. Somit ergibt sich die dringende Notwendigkeit, für den deutschsprachigen Raum eine Leitlinie auf hohem Qualitätsniveau zu erarbeiten, die den Klinikern in der Behandlung ihrer Patienten als Orientierung dienen kann.
Die vorliegende Leitlinie, wiewohl auf S3-Niveau erarbeitet, kann nicht mehr als eine solche Orientierung bieten; die Behandlung der nosokomialen Pneumonie bleibt eine Kunst des Umgangs mit Ungewissheiten. Dies gilt besonders hinsichtlich der Diagnostik, aber auch in der Therapie sind zentrale Fragen auf nur geringer Evidenzstufe zu beantworten. Dennoch haben sich alle Autoren bemüht, auf dem Boden einer sorgfältigen Bewertung der vorhandenen Evidenz einen konzeptuellen Rahmen zu beschreiben, der im Ergebnis die beiden großen Gefahren, nämlich eine übermäßige Exposition auf Antibiotika einerseits und eine verspätete adäquate Antibiotika-Therapie andererseits zu vermeiden. Die zentralen Elemente dieses konzeptuellen Rahmens sind: 1) eine hohe Aufmerksamkeit für die Entwicklung einer nosokomialen Pneumonie; 2) eine umfassende mikrobiologische Diagnostik jedes Verdachtsfalls unter Einschluss (semi)quantitativer Kulturen; 3) eine frühzeitige, individuell risikoadaptierte kalkulierte antimikrobielle Therapie; 4) das Deeskalationsprinzip; 5) die weitmöglichste Begrenzung der Therapiedauer; 6) eine systematische Kontrolle des Therapieerfolgs mit klaren Maßgaben in der Definition des Therapieversagens und hinsichtlich der dann notwendigen Diagnostik und Therapie.

Diese Leitlinie löst die bisher für den deutschen Sprachraum gültige von $2003 \mathrm{ab}$. Aufgrund ihrer Qualität darf sie beanspruchen, auch international rezipiert zu werden und wird daher auch in einer englischsprachigen Kurzform erscheinen. Sie unterscheidet sich trotz vieler Gemeinsamkeiten deutlich von der Leitlinie der ATS/IDSA von 2005, vor allem in der Einschätzung der Risiken für multiresistente Erreger. Das Konzept der „Healthcare associated pneumonia“ (HCAP) wurde aufgrund fehlender Evidenz ebensowenig übernommen wie das zuletzt diskutierte Konzept der „Ventilator-associated tracheobronchitis“ (VAT). Dem kundigen Kliniker wird ohnehin auffallen, dass die Empfehlungen überwiegend „konservativ“ in dem Sinne ausfallen, dass nicht jedes aktuell diskutierte und zweifellos interessante Konzept Teil der Empfehlungen geworden ist. Ziel einer Leitlinie sollte nach Auffassung der Autoren sein, evidenzbasierte und in der klinischen Praxis bewährte Aussagen zu treffen, weniger jedoch Frontlinien der Forschung gleich zum Teil der Praxis zu erklären; einige Beispiele der jüngeren Vergangenheit belegen, dass ein solches Vorgehen mit einem erheblichen Risiko späterer Rückzüge behaftet ist. Die Leitliniengruppe hat auf Empfehlungen zur Prävention der nosokomialen Pneumonie bewusst verzichtet und verweist diesbezüglich auf die Empfehlungen des Robert Koch-Instituts.

\section{Zusammenfassung}

\subsection{Synopsis der Empfehlungen}

E1: Wie wird eine HAP klinisch diagnostiziert und welche Differenzialdiagnosen sind zu beachten?

Therapierelevant ist bereits die Verdachtsdiagnose einer HAP, diese soll gestellt werden bei neuem oder progredientem Infiltrat, in Kombination mit zwei von drei weiteren Kriterien: Leukozyten $>10.000$ oder $<4.000 / \mu$ l, Fieber $\geq 38.3^{\circ} \mathrm{C}$, purulentes Sekret. Differenzialdiagnostisch sind u.a. Atelektasen (Sekretverlegung), Herzinsuffizienz/Überwässerung, alveoläre Hämorrhagie, interstitielle Lungenerkrankungen wie eine cryptogen organisierende Pneumonie (COP), ARDS und Lungenarterienembolien abzugrenzen.

Starke Empfehlung, Evidenz C 
E2: Welche bildgebenden Verfahren sind in der Diagnostik der HAP indiziert?

Bei Verdacht auf eine HAP soll eine Thoraxröntgenuntersuchung möglichst in zwei Ebenen in Standardtechnik durchgeführt werden. Bei immobilen Patienten wird eine Röntgenuntersuchung im Liegen durchgeführt.

\section{Starke Empfehlung, Evidenz C}

Bei therapierefraktären Infiltraten und schwieriger Differenzialdiagnose sollte eine erweiterte bildgebende Diagnostik erwogen werden.

Schwache Empfehlung, Evidenz C

\section{E3: Welche Rolle spielen Scores in der Diagnose und Risikobeurteilung der HAP?}

Die klinische Diagnose der HAP wird durch die Verwendung von Pneumonie-Scores wie dem "clinical pulmonary infection score“ (CPIS) nicht verbessert. Bei Patienten mit schwerer Sepsis sollen Sepsis-Scores angewandt werden.

\section{Starke Empfehlung, Evidenz C}

\section{E4: Welche Rolle haben Biomarker für die Diagnose der HAP?}

Der generelle Einsatz von Biomarkern zur Diagnose der HAP ist derzeit nicht zu empfehlen, da keine ausreichende Evidenz für eine zusätzliche, von anderen Parametern unabhängige Aussagekraft vorliegt. Dagegen soll Procalcitonin bei Verdacht auf pneumogene Sepsis im Rahmen der HAP als sensitiver Marker in der initialen Diagnostik eingesetzt werden.

\section{Starke Empfehlung, Evidenz B}

\section{E5: Wann ist die Entnahme von Blutkulturen sinnvoll?}

Blutkulturen sollen bei HAP zur Diagnose der bakteriämischen Pneumonie entnommen werden. Sie tragen darüber hinaus zur Therapiesteuerung und zur Aufdeckung extrapulmonaler Infektionsquellen bei.

\section{Starke Empfehlung, Evidenz C}

E6: Wann ist die Entnahme von Urin zum Antigennachweis sinnvoll?

Die Diagnostik auf Legionellen soll bei Patienten mit HAP insbesondere dann erfolgen, wenn epidemiologische Hinweise auf nosokomiale Akquisition vorliegen. Der Urin-Antigentest stellt in dieser Situation das Verfahren der Wahl dar. Der Antigentest auf Pneumokokken wird wegen fehlender differenzialtherapeutischer Relevanz nicht empfohlen.

Starke Empfehlung, Evidenz C

E7: Welche mikrobiologischen Untersuchungen sollen aus respiratorischen Materialien durchgeführt werden?

Bei nosokomialer Pneumonie sollen quantitative Kulturen aus qualitativ hochwertigen unteren Atemwegsmaterialien wie tracheobronchialem Aspirat (TBAS) oder bronchoalveolärer Lavage (BAL) angelegt werden. Die resultierenden Keimzahlen haben orientierenden Wert und sind nicht als unabhängige Prädiktoren des Vorliegens einer Pneumonie zu betrachten, vielmehr im klinischen Kontext zu interpretieren.

\section{Starke Empfehlung, Evidenz B}

Darüber hinaus sollte eine Ausstrichdiagnostik zur Validierung der Probe erfolgen. Die Ergebnisse eines Gram-Präparats haben keinen prädiktiven Wert hinsichtlich der später isolierten Spezies. Dagegen hat ein negatives Gram-Präparat bei nicht antibiotisch vorbehandelten Patienten einen hohen negativen prädikti- ven Wert. Ein Grampräparat sollte daher insbesondere in Fällen angefertigt werden, in denen eine antibiotische Therapie nicht indiziert erscheint oder frühzeitig abgesetzt werden soll.

\section{Schwache Empfehlung, Evidenz B}

E8: Wann ist eine invasive Diagnostik, wann eine nichtinvasive Materialgewinnung vorzuziehen?

Eine invasive ist einer nichtinvasiven Diagnostik bei VAP nicht überlegen, sodass die Entscheidung für oder gegen eine invasive Diagnostik in Abhängigkeit von der lokalen Logistik, differenzialdiagnostischen Erwägungen, aber auch möglichen therapeutischen Aspekten einer endoskopischen Untersuchung getroffen werden soll. Kontraindikationen zur Durchführung einer Bronchoskopie mit BAL sind zu beachten.

Starke Empfehlung, Evidenz A

E9: Welche Standards werden bei der Materialgewinnung empfohlen?

Die nichtinvasive Materialgewinnung soll mithilfe steriler Katheter und Auffanggefäße erfolgen. Falls eine Bronchoskopie durchgeführt wird, sollen die im Hintergrundtext aufgeführten, auf dem Konsensus erfahrener Untersucher beruhenden Empfehlungen zur Durchführung der Endoskopie bei Pneumonien beachtet werden.

\section{Starke Empfehlung, Evidenz C}

\section{E10: Wann und wie soll eine mykologische Diagnostik} erfolgen?

Auf eine gezielte Candidadiagnostik aus Atemwegsmaterialien soll bei HAP verzichtet werden, da Hefepilzinfektionen als Ursache nosokomialer Pneumonien bei Patienten ohne definiertes Immundefizit extrem selten sind.

\section{Starke Empfehlung, Evidenz B}

Eine Aspergillusdiagnostik soll auch bei Patienten ohne definiertes Immundefizit erwogen werden, wenn Prädispositionen wie eine strukturelle Lungenerkrankung, eine rheumatologische Grunderkrankung oder eine Leberzirrhose vorliegen und/oder hinweisende Infiltrate im CT-Thorax zur Darstellung kommen, die mit einer invasiven Aspergillose assoziiert sein können. Der Nachweis von Galaktomannan-Antigen aus der BAL ist dem Nachweis im Blut überlegen und stellt bei der diagnostischen $\mathrm{Ab}$ klärung eine Ergänzung zur histopathologischen und mikrobiologischen Untersuchung an Lungengewebe dar. Wenn Biopsien nicht durchgeführt werden können, trägt eine positive Aspergilluskultur und/oder ein Galaktomannan-Antigentest aus der BAL zu einer wahrscheinlichen Diagnose bei.

\section{Starke Empfehlung, Evidenz B}

\section{E11: Wann soll die antimikrobielle Therapie begonnen} werden?

Die antibiotische Therapie soll nach Entnahme von adäquatem Untersuchungsmaterial so früh wie möglich erfolgen. Insbesondere bei Patienten mit septischem Schock ist eine Antibiotikatherapie innerhalb der ersten Stunde anzustreben. Nicht sofort verfügbare diagnostische Maßnahmen sollen die Einleitung der Therapie nicht verzögern.

Starke Empfehlung, Evidenz B 
E12: Welche Optionen der kalkulierten Therapie sind bei Patienten mit nosokomialer Pneumonie ohne erhöhtes Risiko für Infektionen mit multiresistenten Erregern (MRE) zu empfehlen?

Bei Patienten ohne erhöhtes Risiko für MRE gehören Cephalosporine der Gruppe 3a, Aminopenicilline/Betalaktamaseinhibitor, Ertapenem oder pneumokokkenwirksame Fluorchinolone zu den empfohlenen Therapieoptionen. Die Substanzauswahl soll vor dem Hintergrund des lokalen Erregerspektrums und Resistenzprofils getroffen werden.

Starke Empfehlung, Evidenz C

E13: Welche Optionen der kalkulierten Therapie sind bei Patienten mit nosokomialer Pneumonie und erhöhtem Risiko für Infektionen mit multiresistenten Erregern (MRE) zu empfehlen?

Bei Patienten mit erhöhtem Risiko für MRE gehören Piperacillin/ Tazobactam oder pseudomonaswirksame Carbapeneme bzw. Cephalosporine, initial in Kombination mit einem Aminoglykosid oder einem pseudomonaswirksamen Fluorchinolon zu den empfohlenen Therapieoptionen. Ceftazidim soll nur in Kombination eingesetzt werden. Die Substanzauswahl soll vor dem Hintergrund des lokalen Erregerspektrums und Resistenzprofils getroffen werden.

\section{Starke Empfehlung, Evidenz B}

Bei Verdacht auf eine MRSA-Infektion soll eine gegenüber MRSA wirksame Substanz hinzugefügt werden.

\section{Starke Empfehlung, Evidenz B}

\section{E14: Wann soll eine Kombinationstherapie gewählt} werden?

Eine initiale Kombinationstherapie soll ausschließlich bei Patienten mit erhöhtem Risiko für das Vorliegen multiresistenter Gramnegativer Erreger sowie bei septischem Schock eingesetzt werden. Nach drei Tagen soll die Erfordernis der Kombinationstherapie überprüft und bei Nachweis eines empfindlichen Erregers bzw. Stabilisierung des Patienten auf eine Monotherapie deeskaliert werden (Einzelheiten s. E17). Die Substanzauswahl soll vor dem Hintergrund des lokalen Erregerspektrums und Resistenzprofils getroffen werden.

Starke Empfehlung, Evidenz B

\section{E15: Wann soll eine vorzeitige Beendigung der Therapie} erwogen werden?

Besteht trotz neu aufgetretener Infiltrate klinisch eine niedrige Wahrscheinlichkeit für eine HAP, soll die antibiotische Therapie nach drei Tagen beendet werden. Ergibt die Diagnostik eine schwere Sepsis/einen septischen Schock mit anderem Fokus, ist die Therapie anzupassen.

Starke Empfehlung, Evidenz B

E16: Wann und nach welchen Kriterien soll der Therapieerfolg evaluiert werden?

Eine Reevaluation des Patienten soll 48 - 72 Stunden nach Beginn der Therapie erfolgen. Hierzu gehört die Beurteilung des klinischen Verlaufs, der Ergebnisse der initialen mikrobiologischen Diagnostik, der Röntgenverlaufsuntersuchung und von Biomarkern.

Starke Empfehlung, Evidenz B
E17: Wann und wie soll eine Deeskalation der Initialtherapie erfolgen?

Die Deeskalation soll 48-72 Stunden nach Therapiebeginn anhand der Ergebnisse der Reevaluation erfolgen. Bei klinischer Besserung, aber fehlendem Nachweis eines respiratorischen Pathogens, soll die Deeskalation auf eine Monotherapie mit dem in der Initialkombination enthaltenen Betalaktamantibiotikum oder Fluorchinolon erfolgen.

\section{Starke Empfehlung, Evidenz B}

Bei Nachweis eines respiratorischen Pathogens soll auf eine gezielte Monotherapie mit schmalem Spektrum umgesetzt werden. Eine initiale kalkulierte Therapie gegen MRSA soll beendet werden, falls ein solcher Erreger nicht nachgewiesen wurde.

\section{Starke Empfehlung, Evidenz B}

\section{E18: Wie lange sollen nosokomiale Pneumonien behan-} delt werden?

Die Therapiedauer soll im Regelfall acht Tage betragen. Bei speziellen Ätiologien ist eine längere Behandlung zu erwägen, um die Rezidivrate zu senken.

\section{Starke Empfehlung, Evidenz A}

Biomarker können zur Steuerung der Therapiedauer eingesetzt werden. Eine relevante Verkürzung der Therapiedauer über empfohlene Zeiten hinaus oder eine Verbesserung gegenüber Standardmethoden ist nicht belegt.

Keine Empfehlung, Evidenz B

\section{E 19: Welches Vorgehen sollte bei einem Therapie- versagen gewählt werden?}

Bei Therapieversagen sollte eine erneute, wenn möglich invasive Diagnostik zur Klärung der Ätiologie erfolgen. In Abhängigkeit vom differenzialdiagnostischen Spektrum ist darüber hinaus eine erweiterte bildgebende Diagnostik zu erwägen.

\section{Schwache Empfehlung, Evidenz B}

E20: Sollte eine „Ventilator-assoziierte Tracheobronchitis“ (VAT) antimikrobiell therapiert werden?

Bei beatmeten Patienten stellt eine VAT möglicherweise einen Risikofaktor für die Entwicklung einer VAP dar. Eine AntibiotikaTherapie kann nicht empfohlen werden, da hierfür keine ausreichende Evidenz besteht.

\section{Keine Empfehlung, Evidenz C}

In Ausnahmefällen sollte bei Risikopatienten und/oder Kolonisation mit MRE bei zunehmendem purulentem Atemwegssekret oder rezidivierenden bronchopulmonalen Infektionen eine Antibiotika-Therapie erwogen werden.

Schwache Empfehlung, Evidenz C

E21: Wann ist eine inhalative antimikrobielle Therapie der VAP (allein/in Kombination mit systemischer Therapie) indiziert?

Eine inhalative Antibiotika-Therapie kann derzeit nicht generell empfohlen werden. In ausgewählten Fällen, wie bei Vorliegen multiresistenter Erreger, sollte die Gabe von aerosoliertem Colistin oder Tobramycin zusätzlich zu einer systemischen Antibiotika-Therapie erwogen werden.

\section{Schwache Empfehlung, Evidenz C}


E22: Wie sieht die adäquate gezielte Therapie aus bei Nachweis von Infektionen mit: MRSA-Pseudomonas aeruginosa - Acinetobacter baumannii-Stenotrophomonas maltophilia-ESBL-bildenden Enterobakterien - Carbapenem-resistenten Enterobakterien?

Bei der gezielten Therapie der HAP soll die Substanzauswahl nach den folgenden Kriterien erfolgen:

- MRSA-Stämme: Geprüfte Antiinfektiva in der Monotherapie sind Vancomycin, Teicoplanin und Linezolid. Bei schwerer Erkrankung stellt die Kombination von Vancomycin mit Rifampicin eine weitere Option dar.

- P. aeruginosa: Ceftazidim, Cefepim, Piperacillin, die Carbapeneme Doripenem, Imipenem und Meropenem sowie Ciprofloxacin und Levofloxacin sind wirksame Therapieoptionen.

Die Kombination eines pseudomonaswirksamen BetalaktamAntibiotikums mit einem Aminoglykosid (Gentamicin, Tobramycin, Amikacin) oder einem Fluorchinolon ist im Einzelfall zu erwägen (schwere Infektion). Eine Überlegenheit gegenüber der Monotherapie ist aber nicht sicher belegt. Bei Resistenz gegenüber allen Standardsubstanzen ist eine Therapie mit Colistin indiziert; eine Kombinationstherapie ist hierbei anzustreben, möglichst in Rücksprache mit einem Infektiologen/ Mikrobiologen.

- ESBL-Stämme: Carbapeneme sind wirksam. Bei zusätzlicher Resistenz gegen Carbapeneme kommt Colistin zum Einsatz, möglichst in Kombinationstherapie nach Rücksprache mit einem Infektiologen/Mikrobiologen.

- Stenotrophomonas maltophilia: Bei In-vitro-Empfindlichkeit ist Cotrimoxazol indiziert. Bei Resistenz gegenüber Cotrimoxazol soll eine Sensibilitätsprüfung auf Ceftazidim, Moxifloxacin, Levofloxacin, Tigecyclin und Ticarcillin/Clavulansäure erfolgen und auf eine dieser Substanzen zurückgegriffen werden. Zuvor ist die klinische Relevanz des Isolates zu prüfen.

- Acinetobacter spp.: Imipenem oder Meropenem sind am häufigsten wirksam. Bei Panresistenz ist Colistin indiziert, möglichst in Kombination mit einer weiteren in vitro wirksamen Substanz. Tigecyclin stellt eine zusätzliche Option für die Salvage-Therapie dar.

Zur Therapiedauer s. Empfehlung E18. Die Notwendigkeit einer generellen Kombinationstherapie ist nicht etabliert. Angaben zur Dosierung finden sich im Kapitel Antiinfektiva.

Starke Empfehlung, Evidenz B

\section{Hintergrund und Methoden}

$\nabla$

\subsection{Präambel}

Die letzte deutsche Leitlinie zur nosokomialen Pneumonie (hospital-acquired pneumonia, international abgekürzt: HAP) wurde 2003 publiziert [1]. In der Zwischenzeit wurden internationale Empfehlungen u.a. von US-amerikanischen Fachgesellschaften [2], der kanadischen Critical Care Trials Group [3], der britischen Gesellschaft für antimikrobielle Chemotherapie [4] sowie ein Konsensuspapier einer europäischen Expertengruppe [5] veröffentlicht. Hierbei wurden teils neue Definitionen eingeführt unter Einbeziehung von nicht direkt im Krankenhaus erworbenen Infektionen (healthcare-associated pneumonia, HCAP). Auch in Deutschland haben sich in der letzten Dekade wichtige Änderungen hinsichtlich Erregerspektrum, Resistenzmuster, diagnostischen und therapeutischen Optionen sowie Versorgungsaspekten ergeben. Die beteiligten Fachgesellschaften haben daher vereinbart, erneut eine interdisziplinäre Leitlinie zur Epidemiologie,
Diagnostik und Therapie der nosokomialen Pneumonie zu erstellen. Hierzu wurde eine Leitliniengruppe etabliert, die sich aus Vertretern der beteiligten Fachgesellschaften sowie der Arbeitsgemeinschaft wissenschaftlicher Medizinischer Fachgesellschaften (AWMF) zusammensetzte. Die Mitglieder repräsentieren die Fächer Anästhesiologie, Innere Medizin, Chirurgie, Intensivmedizin, Klinische Infektiologie, Klinische Mikrobiologie, Hygiene und Pneumologie.

\subsection{Ziele der Leitlinie}

Diese Leitlinie verfolgt das Ziel, nationale Standards in der Diagnostik und Therapie der nosokomialen Pneumonie zu etablieren und die Versorgungsqualität der von dieser Erkrankung betroffenen Patienten zu optimieren. Insbesondere soll ein hohes Niveau adäquater Therapie sichergestellt werden. Gleichzeitig soll durch einen rationalen Antibiotikaeinsatz ein unnötiger Verbrauch von Antiinfektiva vermieden und damit die Selektion resistenter Erreger vermindert werden. Hierzu ist eine zielgerichtete Diagnostik erforderlich, die auch die Generierung von Daten über das lokale Erregerspektrum einschließt. Zur Prävention nosokomialer Pneumonien, dem Umgang mit kontagiösen, vorwiegend ambulant erworbenen respiratorischen Virusinfektionen wie der Influenza sowie zur Intensivtherapie schwerer Infektionen einschließlich des auf dem Boden einer Pneumonie entstandenen ARDS verweisen wir auf die entsprechenden Leitlinien bzw. Empfehlungen des Robert Koch-Instituts, der Deutschen Gesellschaft für Pneumologie und Beatmungsmedizin und der Deutschen Sepsisgesellschaft.

Die Leitlinie wendet sich an alle im Krankenhaus tätigen Ärzte, die mit der Diagnostik und Therapie nosokomialer Pneumonien konfrontiert sind. Zugleich soll sie als Orientierung für Personen und Organisationen dienen, die direkt oder indirekt mit diesem Thema befasst sind.

\subsection{Struktur des Leitlinienprozesses}

Die Erstellung dieser Leitlinie erfolgte nach den Kriterien der AWMF, um dem Nutzer der Leitlinie evidenzbasierte Kriterien für eine rationale Entscheidungsfindung und gute ärztliche Praxis an die Hand zu geben. Es handelte sich um einen zweistufigen Prozess. Die für das Management nosokomialer Pneumonien wichtigen Fragen wurden vorab innerhalb der gesamten Leitliniengruppe identifiziert. Daraufhin wurde in mehreren Arbeitsgruppen die Literatur nach Themenschwerpunkten gesichtet und bewertet. Auf der Basis der vorhandenen Evidenz wurde dann von jeweils einem Mitglied ein Entwurf für Empfehlungen zu einzelnen Fragen unterbreitet, der innerhalb der Leitliniengruppe diskutiert und überarbeitet wurde. Das aus diesem Prozess hervorgegangene Manuskript wurde vier Wochen vor der ersten Konsensuskonferenz mit Zugang zu der zitierten Literatur an alle Konferenzteilnehmer versandt. Auf zwei Konsensuskonferenzen unter Leitung eines unabhängigen Moderators wurden die Empfehlungen ausführlich unter Einbeziehung von Sachverständigen aus weiteren Fachgesellschaften und Organisationen mit Expertise auf dem Gebiet der HAP diskutiert und überarbeitet. Sie wurden nach Änderungen und Ergänzungen durch die Konferenz in einem nominalen Gruppenprozess, der durch den Vertreter der AWMF geleitet wurde, angenommen. Das Manuskript besteht aus einem deskriptiven Teil, der die nationale Epidemiologie, das Erregerspektrum und die Eigenschaften der empfohlenen Antiinfektiva beschreibt, und einem handlungsorientierten Teil, in dem Empfehlungen zur Diagnostik und Therapie nach dem GRADE-System abgegeben werden. 
Tab.1 Klassifizierung der Evidenz und Empfehlungsgrade nach GRADE [6, 7]. RCT: randomized clinical trial.

\begin{tabular}{|c|c|c|}
\hline Empfehlungsgrad & Abwägung des Nutzens gegen Risiko/Aufwand & Evidenzbewertung \\
\hline \multicolumn{3}{|l|}{ „soll“ oder „soll nicht“ } \\
\hline \multirow[t]{2}{*}{ 1A: Starke Empfehlung, hohe Evidenz } & Erwünschte Effekte überwiegen eindeutig & Konsistente Evidenz aus RCTs ohne methodische \\
\hline & Risiken/Zusatzaufwand oder vice versa & $\begin{array}{l}\text { Schwächen oder außergewöhnlich starke Evidenz aus } \\
\text { Beobachtungsstudien }\end{array}$ \\
\hline 1B: Starke Empfehlung, moderate Evidenz & & $\begin{array}{l}\text { Evidenz aus RCTs mit methodischen Limitationen oder } \\
\text { überzeugende Evidenz aus Beobachtungsstudien }\end{array}$ \\
\hline $\begin{array}{l}\text { 1C: Starke Empfehlung, schwache oder } \\
\text { sehr schwache Evidenz }\end{array}$ & & $\begin{array}{l}\text { Evidenz für wenigstens einen zentralen Outcome- } \\
\text { parameter aus Beobachtungsstudien, Fallserien oder } \\
\text { methodisch stark limitierten RCTs }\end{array}$ \\
\hline \multicolumn{3}{|l|}{ "sollte“ oder „sollte nicht" } \\
\hline \multirow[t]{2}{*}{ 2A: Schwache Empfehlung, hohe Evidenz } & Erwünschte Effekte überwiegen vermutlich & Konsistente Evidenz aus RCTs ohne methodische \\
\hline & Risiken/Zusatzaufwand oder vice versa & $\begin{array}{l}\text { Schwächen oder außergewöhnlich starke Evidenz aus } \\
\text { Beobachtungsstudien }\end{array}$ \\
\hline 2B: Schwache Empfehlung, moderate Evidenz & & $\begin{array}{l}\text { Evidenz aus RCTs mit methodischen Limitationen oder } \\
\text { überzeugende Evidenz aus Beobachtungsstudien }\end{array}$ \\
\hline $\begin{array}{l}\text { 2C: Schwache Empfehlung, schwache oder } \\
\text { sehr schwache Evidenz }\end{array}$ & & $\begin{array}{l}\text { Evidenz für wenigstens einen zentralen Outcome- } \\
\text { parameter aus Beobachtungsstudien, Fallserien oder } \\
\text { methodisch stark limitierten RCTs }\end{array}$ \\
\hline \multicolumn{3}{|l|}{ "kann" oder „kann nicht" } \\
\hline 3: Keine Empfehlung & $\begin{array}{l}\text { Kein ausreichender Anhalt für überwiegenden } \\
\text { Nutzen/Risiko der Intervention }\end{array}$ & $\begin{array}{l}\text { Keine Evidenz für Überlegenheit/Unterlegenheit der } \\
\text { Intervention }\end{array}$ \\
\hline
\end{tabular}

\subsection{GRADE}

Die Evidenzbewertung der herangezogenen Literatur orientierte sich an GRADE; die Graduierung und Formulierung der Empfehlungsstärke wurde an die Methodik der Nationalen Versorgungsleitlinien angepasst ( Tab.1). Dieses Bewertungssystem ist dadurch charakterisiert, dass die Empfehlungsstärke nicht nur von der Qualität der Evidenz abhängig ist, sondern auch eine Abwägung von Nutzen und Risiko bzw. Nutzen und Aufwand einschließt. Hieraus ergibt sich, dass auch Kombinationen von starker Empfehlung bei schwacher Evidenz und umgekehrt möglich sind. Empfehlungen werden ausschließlich für definierte diagnostische oder therapeutische Interventionen abgegeben. Details der Evidenzbewertung können den zu jeder Empfehlung hinterlegten Evidenztabellen entnommen werden. Es können mit gleicher Graduierung sowohl positive (do it) als auch negative (don't do it) Empfehlungen abgegeben werden.

\subsection{Literaturrecherche}

Die Literaturrecherche wurde in PubMed und in The Cochrane Library mithilfe des vom Institut für Lungenforschung $\mathrm{GmbH}$ zur Verfügung gestellten Scientific Guideline Manager durchgeführt und auf deutsch- und englischsprachige Originalartikel während des Zeitraums vom 1.1.1990 bis zum 31.12.2009, für das Kapitel Erregerspektrum und Resistenz vom 1.1.2000 bis zum 31.12. 2009 begrenzt. Zusätzlich wurden die Literaturverzeichnisse von systematischen Reviews, Metaanalysen und Originalarbeiten durchsucht. Aktuellere Studien, insbesondere zu Epidemiologie oder Erregerspektrum im deutschsprachigen Raum sowie zum Management, wurden berücksichtigt, soweit sie Einfluss auf Diagnostik und Therapie der HAP haben. Diese Studien sind im Literaturverzeichnis gesondert mit * gekennzeichnet. Insgesamt wurden 9097 Einträge gefunden, die zuerst in der Vorselektion von jeweils zwei Teilnehmern nach dem Abstract gesichtet wurden. 808 potenziell relevante Arbeiten wurden identifiziert und analysiert.

\subsection{Finanzierung}

Die Erstellung dieser Leitlinie wurde von den beteiligten Fachgesellschaften ohne Sponsoring durch Dritte finanziert. Organisatorische Unterstützung sowie Unterstützung bei der Literaturrecherche erfolgte durch das Institut für Lungenforschung $\mathrm{GmbH}$. Die Mitglieder der Arbeitsgruppe waren ausnahmslos ehrenamtlich tätig, es erfolgte keine Einflussnahme von außen.

\subsection{Implementierung/Publikation}

Die Publikation erfolgt in der Zeitschrift Pneumologie im Dezember 2012, Online-Versionen werden auch auf den Websites bzw. in Online-Journalen weiterer beteiligter Fachgesellschaften abrufbar sein. Eine englischsprachige Kurzfassung ist Anfang 2013 vorgesehen.

\subsection{Planmäßige Überarbeitung}

Diese Leitlinie ist bis zum 31.12.2014 gültig. Bei neuen, das Management wesentlich beeinflussenden Erkenntnissen erfolgt zwischenzeitlich eine Aktualisierung der Online-Version.

\section{Definitionen}

Nosokomiale Pneumonien (HAP) sind Pneumonien, die frühestens 48 Stunden nach Krankenhausaufnahme auftreten und sich bei Hospitalisation nicht in der Inkubation befanden. International akzeptierte Diagnosekriterien für epidemiologische Fragestellungen wurden von den Centers for Disease Control and Prevention (CDC) erarbeitet (s. Kapitel Epidemiologie). Unabhängig hiervon haben sich in der Patientenversorgung klinische Diagnosekriterien etabliert (s. Empfehlung E1), die sich an den Erfordernissen einer rationalen Diagnostik und adäquaten Therapie orientieren. Pneumonien, die in den ersten Wochen bis Monaten nach Krankenhausentlassung auftreten, werden ebenfalls als nosokomiale Infektionen gewertet, da häufig noch eine Kolonisation mit Hospitalerregern nachweisbar ist; ein allgemein akzeptierter zeitlicher Rahmen existiert hierfür nicht. Auch wenn der weit überwiegende Teil der wissenschaftlichen Literatur sich auf 
Tab.2 Mediane (Q1 - Q3) der Beatmungsraten und der Inzidenzdichte der Pneumonie in Abhängigkeit von der Beatmung in 400 KISS-Intensivstationen $2005-2007\left[14^{*}\right]$.

\begin{tabular}{|llll} 
& Nichtinvasive Beatmung & Invasive Beatmung & Keine Beatmung \\
\hline $\begin{array}{l}\text { Beatmungsrate } \\
\text { (pro 100 Patiententage) }\end{array}$ & $2,4(0,9-5,1)$ & $35,4(23,1-47,5)$ & 0 \\
\hline Pneumonierate (mean) & 1,6 pro 1000 nichtinvasive & 5,4 pro 1000 invasive & 0,6 pro 1000 Patiententage \\
Letalität auf der Intensivstation (\%) & Beatmungstage & Beatmungstage & 13,3 \\
\hline
\end{tabular}

Pneumonien invasiv beatmeter Patienten (ventilator-associated pneumonia, VAP) bezieht, stellt die HAP bei spontan atmenden oder nichtinvasiv beatmeten Patienten angesichts der zunehmenden Morbidität hospitalisierter Patienten und des vermehrten Einsatzes der nichtinvasiven Ventilation (NIV) ein zunehmend wichtiges Problem dar, sodass sich diese Empfehlung nicht auf die VAP beschränkt.

Unter HCAP (healthcare-associated pneumonia) werden Pneumonien verstanden, die bei Personen auftreten, die sich in regelmäßigem, engem Kontakt mit stationären oder teilstationären Bereichen des Gesundheitssystems befinden oder in Pflegeeinrichtungen untergebracht sind, aber nicht stationär aufgenommen wurden $[2,8,9]$. Es handelt sich um eine heterogene Gruppe von Patienten mit unterschiedlichen Risikofaktoren für nosokomiale Infektionen, deren Validität kontrovers beurteilt wird [10*] und in Deutschland bislang nicht überprüft wurde. HCAP ist daher nicht Teil der Definition der nosokomialen Pneumonie im Sinne dieser Leitlinie.

Pneumonien bei Immundefizit sind durch ein sehr breites Erregerspektrum charakterisiert, das auch opportunistische Pathogene wie Pneumocystis jiroveci, Cytomegalovirus, Schimmelpilze und Mykobakterien umfasst. Da sich hieraus andere diagnostische und therapeutische Konsequenzen als bei immunkompetenten Patienten ergeben, werden in Deutschland Pneumonien unter Immundefizit als eigene Kategorie definiert [11,12] und sind nicht Thema dieser Leitlinie, obwohl der Ort des Erwerbs auch in diesem Kollektiv das Erregerspektrum beeinflusst. Auch wenn viele Grunderkrankungen und Risikofaktoren Funktionen des Immunsystems beeinträchtigen können, erscheint es sinnvoll, den Begriff Immundefizit auf Erkrankungen und Therapien zu begrenzen, bei denen regelmäßig mit Infektionen durch opportunistische Pathogene zu rechnen ist. Als Immundefizit in diesem Sinne werden verstanden: Z.n. Organ- oder Knochenmarktransplantation; Chemotherapie solider oder hämatologischer Neoplasien mit oder ohne Neutropenie; HIV-Infektion im Stadium AIDS; Immunsuppressive oder immunmodulierende Therapie bei Autoimmunopathien; Glukokortikoidtherapie über einen Zeitraum von mindestens vier Wochen mit einer Erhaltungsdosis $\geq 10 \mathrm{mg} / \mathrm{d}$.

\section{Epidemiologie}

\subsection{Epidemiologie der HAP}

Die umfangreichsten Daten zur Epidemiologie der HAP stammen aus den Datenbanken der Surveillance-Systeme von nosokomialen Infektionen. In Deutschland liefert das Krankenhaus-Infektions-Surveillance-System (KISS) die meisten Daten zu diesem Thema. Nationale Surveillance-Systeme verwenden in der Regel Definitionen für die HAP, die vor einem epidemiologischen Hintergrund festgelegt worden sind; d.h. die verwendeten Kriterien müssen in den meisten Krankenhäusern angewendet werden und entsprechende Ergebnisse zur Verfügung stehen. Die international in diesem Sinne am häufigsten angewendeten Definitionen sind die der CDC [13].

\subsection{Inzidenz der VAP/HAP}

KISS erhebt mithilfe der CDC-Definition Daten für die auf der Intensivstation erworbenen HAP, stratifiziert nach Art der Intensivstation und in Abhängigkeit von der Anwendung von Beatmungsgeräten. Bei Patienten mit invasiver Beatmung beträgt die durchschnittliche Pneumonierate 5,4 pro 1000 invasive Beatmungstage, bei Patienten mit nichtinvasiver Beatmung 1,6 pro 1000 nichtinvasive Beatmungstage und bei Patienten ohne Beatmung 0,6 pro 1000 Patiententage ( Tab.2). Dabei unterscheiden sich die Raten beatmungsassoziierter Pneumonien (VAP) nach der Art der Intensivstation ( $\bullet$ Abb. 1 ).

Für außerhalb von Intensivstationen beobachtete Pneumonien existierte bisher keine Surveillance in KISS, und es existieren nur wenige aktuelle prospektive Untersuchungen. In der NIDEP 2-Studie, die in chirurgischen Stationen von acht Krankenhäusern über einen Zeitraum von sechs Monaten durchgeführt wurde, wurde eine durchschnittliche Inzidenz von 0,98 pro $100 \mathrm{~Pa}-$ tienten und eine Inzidenzdichte von 0,95 pro 1000 Patiententage ermittelt $[15,16]$. Eine kürzlich aus einem deutschen Universitätsklinikum publizierte Studie kam mit einer Inzidenz von 1,32 pro 100 Patienten zu einem ähnlichen Ergebnis [17].

Ausgehend von ca. 2,8 Mill. Beatmungstagen auf deutschen Intensivstationen pro Jahr und einer durchschnittlichen beatmungsassoziierten Pneumonierate von 5,4 pro 1000 Beatmungstage kann man pro Jahr von ca. 15500 Pneumonien auf deutschen Intensivstationen ausgehen [18]. Hinzu kommen die bei nicht beatmeten Patienten zu beobachtenden Pneumonien auf Intensivstationen und anderen Stationen mit einem Anteil von ca. $60 \%$ an allen nosokomialen Pneumonien $[15,19]$. Dementsprechend ergeben sich mindestens 40000 nosokomiale Pneumonien pro Jahr auf der Datengrundlage der am KISS beteiligten Einrichtungen.

\subsection{Letalität der VAP/HAP}

Viele Studien haben die Konsequenzen der VAP untersucht. In einer Metaanalyse wurde kürzlich eine Letalität von insgesamt 16\% ermittelt (Bandbreite von 10-47\%) [20*]. Bei diesen Daten ist zu berücksichtigen, dass auch die Grundkrankheiten zur Letalität beitragen. Der Begriff „attributable mortality“ bezeichnet dementsprechend den durch die VAP bedingten Anteil der Letalität. Teilweise wird in Studien die „attributable mortality“ auch als das relative Risiko (RR) der VAP angesehen. Damit ist der Quotient der Letalität von Patienten mit VAP und der Letalität von Patienten ohne VAP gemeint. Zur Bestimmung der VAP-bedingten zusätzlichen Letalität wurden in der Vergangenheit viele Studien durchgeführt, die durch „Matching“ der Patienten nach verschiedenen Risikofaktoren (Alter, Geschlecht, Grundkrankheiten, Schweregrad-Scores) die Unterschiede in der Gruppe der Patien- 


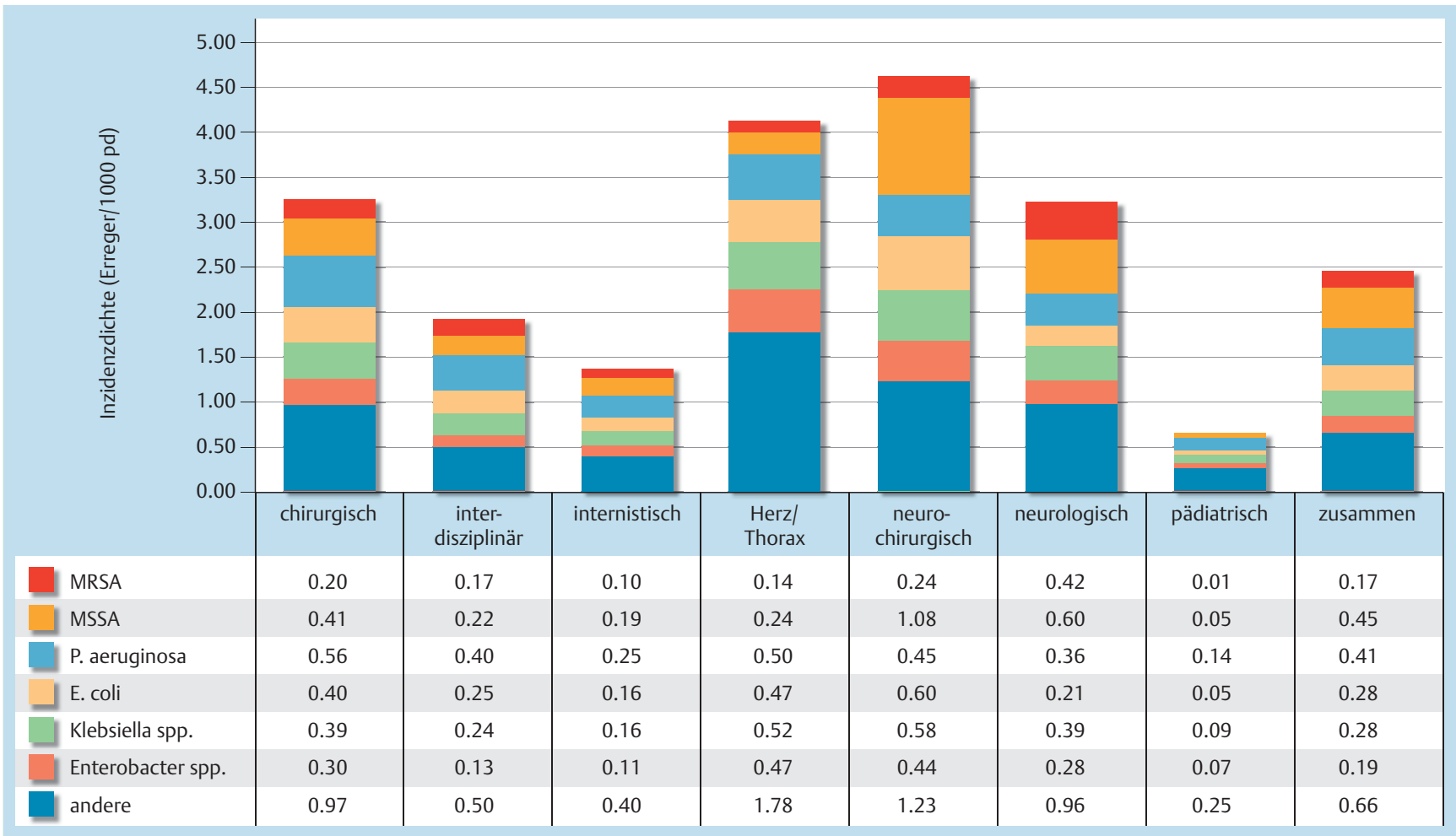

Abb.1 Inzidenzdichte und Erregerspektrum der beatmungsassoziierten Pneumonie nach dem Typ der Intensivstation. Daten aus 586 Intensivstationen 2005-2009 [25*].

Tab. 3 Übersicht über Metaanalysen zur zusätzlichen Letalität wegen VAP (beschränkt auf solche mit großem Umfang eingeschlossener Studien, gutem Design und Aktualität).

\begin{tabular}{|c|c|c|c|c|}
\hline Studie & Design & $\begin{array}{l}\text { Letalität } \\
\text { der Fälle }\end{array}$ & Zusätzliche Letalität & Bemerkungen \\
\hline $\begin{array}{l}\text { Safdar } 2005 \\
{[27]}\end{array}$ & $\begin{array}{l}6 \text { Studien mit Endpunkt Letalität auf der } \\
\text { Intensivstation } \\
4 \text { Studien mit Endpunkt Letalität im } \\
\text { Krankenhaus }\end{array}$ & n.a & $\begin{array}{l}\text { In Intensivstationen: } \\
\text { OR=2,03; } \\
\text { CI95 1,16-3,56 } \\
\text { Im Krankenhaus: } \\
\text { OR=1,64; } \\
\text { CI95 } 0,86-3,14\end{array}$ & $\begin{array}{l}\text { Zeit bis zur Pneumonie nicht berücksichtigt, } \\
\text { signifikante Heterogenität }\end{array}$ \\
\hline $\begin{array}{l}\text { Melsen } 2009 \\
{[28]}\end{array}$ & $\begin{array}{l}52 \text { Studien (gematchte Kohortenstudien } \\
\text { und andere Beobachtungsstudien) } \\
4882 \text { Fälle } \\
4 \text { Studien mit ARDS-Patienten, } 9 \text { Studien } \\
\text { mit Trauma-Patienten }\end{array}$ & $14-70 \%$ & $\begin{array}{l}\mathrm{RR}=1,27 \\
\text { CI95 } 1,15-1,39 \\
\text { Nur ARDS-Patienten: } \\
\mathrm{RR}=1,09 ; \\
\text { CI95 } 0,87-1,37 \text { ) } \\
\text { Nur Trauma-Patienten: } \\
\text { RR }=0,86 ; \\
\text { CI95 } 0,72-1,04\end{array}$ & $\begin{array}{l}\text { Insgesamt erhebliche Heterogenität der Studien } \\
\text { Bei Konzentration auf ARDS- und Trauma-Patien- } \\
\text { ten geringe Heterogenität und keine signifikant } \\
\text { erhöhte Letalität }\end{array}$ \\
\hline $\begin{array}{l}\text { Muscedere } \\
2010\left[20^{*}\right]\end{array}$ & $\begin{array}{l}14 \text { gematchte Studien } \\
9 \text { Studien mit Endpunkt Letalität auf } \\
\text { der Intensivstation } \\
7 \text { Studien mit Endpunkt Letalität im } \\
\text { Krankenhaus } \\
4 \text { Studien zu Traumapatienten }\end{array}$ & $22 \%$ & $\begin{array}{l}\text { absolut: } 13,5 \% \\
\text { OR=1,94; } \\
\text { CI95 1,24-3,03 } \\
\text { absolut: } 1,1 \% \\
\text { OR=1,03; } \\
\text { CI95 } 0,89-1,21 \\
\text { absolut: } 4 \% \\
\text { OR=1,28; } \\
\text { CI95 } 0,7-2,33)\end{array}$ & $\begin{array}{l}\text { Signifikante Heterogenität bei den Studien mit } \\
\text { dem Endpunkt Letalität auf der Intensivstation, } \\
\text { geringe Heterogenität bei denen mit dem End- } \\
\text { punkt Krankenhausletalität } \\
\text { Nach dieser Studie ist die Assoziation zwischen } \\
\text { VAP und Letalität unklar, zumindest scheint sie } \\
\text { nicht zu existieren bezogen auf die Kranken- } \\
\text { hausletalität }\end{array}$ \\
\hline
\end{tabular}

ten mit und ohne VAP berücksichtigen. Dementsprechend existieren auch Metaanalysen, die die Ergebnisse dieser Studien zusammenfassen ( Tab.3).

Die Wahrscheinlichkeit der Entwicklung einer Pneumonie steigt mit der Liegedauer auf der Intensivstation und während der ersten 7-10 Beatmungstage, danach nimmt sie wieder ab $[21,22]$.
Ein Patient mit VAP ändert also seinen Infektionsstatus während des Aufenthaltes, ein Patient ohne VAP behält seinen Status dagegen konstant. Daher sollte die Pneumonie in Analysen der zusätzlichen Letalität als zeitabhängige Variable Berücksichtigung finden $[23,24]$. Die wenigen bislang veröffentlichten Studien, die dies berücksichtigt haben, erbrachten unterschiedliche Ergebnis- 
se in Bezug auf die zusätzliche Letalität durch VAP. In einer Studie auf fünf Intensivstationen in Deutschland war die VAP nicht mit einer zusätzlichen Letalität assoziiert [24].

Eine andere Untersuchung hat bei Anwendung dieser Methode eine zusätzliche Letalität von $8 \%$ ermittelt [ $26^{*}$ ]. In einer kürzlich erschienenen Metaanalyse mit insgesamt 14 Studien, bei denen die Zeit bis zur VAP beim Matching berücksichtigt worden war, wurde eine zusätzliche Letalität von 13,5\% (CI95 4-23\%) für den Aufenthalt auf der Intensivstation, bei allerdings deutlicher Heterogenität der eingeschlossenen Studien, ermittelt. Für die Studien, die den Endpunkt Krankenhaus-Letalität verwendeten, ergab sich dagegen eine absolute zusätzliche Letalität von nur 1,1\% (OR=1,03; CI95 0,89-1,21). Auch wenn die exakte Bestimmung der zusätzlichen Letalität der VAP somit methodisch anspruchsvoll ist, deuten aktuelle Ergebnisse darauf hin, dass sie wahrscheinlich niedriger ist als früher angenommen wurde.

Im Vergleich zur VAP existieren nur wenige Studien, die die Letalität der HAP bei nichtbeatmeten Patienten untersucht haben. Deshalb und wegen des unzureichenden Designs der vorliegenden Studien ist es nicht möglich einzuschätzen, ob die HAP zu einer signifikanten zusätzlichen Letalität führt.

\subsection{Verlängerung der Verweildauer durch VAP}

Die Zusatzkosten der VAP werden vor allem durch die Verlängerung der Verweildauer bedingt. In der Vergangenheit wurden häufig Studien mit verschiedenen systematischen Fehlern publiziert. Neben der Pneumonie können andere Faktoren (z.B. Grundkrankheiten) die Verlängerung der Verweildauer bedingen. In der Regel wird durch „gematchte“ Designs und multivariate Analysen versucht, diese Faktoren zu berücksichtigen. Zusätzlich muss beachtet werden, dass die Verlängerung der Verweildauer erst von dem Tag an berücksichtigt werden darf, an dem die Pneumonie aufgetreten ist. Deshalb müssen longitudinale und Multistadienmodelle angewendet werden. Wird das nicht beachtet, kommt es zu einer deutlichen Überschätzung des Effektes.

Wenn nur Studien berücksichtigt werden, die diese methodischen Aspekte berücksichtigen, resultieren zusätzliche Verweilzeiten von vier bis sechs Tagen auf den Intensivstationen wegen VAP $\left[27,29,30^{*}, 31^{*}\right]$. Für die Verlängerung der Verweildauer wegen HAP außerhalb von Intensivstationen liegen keine aussagekräftigen Studien vor [8]. Wegen der Unterschiede der Gesundheitssysteme anderer Länder sind die Daten aus Studien aus anderen Ländern in der Regel nicht übertragbar.

\section{Erregerspektrum und Resistenz}

Das Erregerspektrum nosokomialer Pneumonien ist vielfältig. Im Vordergrund stehen Bakterien, während Pilze und Viren bei immunkompetenten Patienten nur selten als Pneumonieerreger identifiziert werden. In einem nicht unerheblichen Teil der Fälle handelt es sich um eine polymikrobielle bakterielle Infektion. Die häufigsten Erreger stellen aerobe und fakultativ anaerobe Gramnegative Stäbchenbakterien wie Pseudomonas aeruginosa, Enterobacteriaceae (Escherichia coli, Klebsiella spp. und Enterobacter spp.), Haemophilus influenzae, Acinetobacter baumannii und Stenotrophomonas maltophilia dar. Unter den Gram-positiven Erregern nosokomialer Pneumonien stehen Staphylococcus aureus und Streptococcus pneumoniae im Vordergrund ( Tab.4). Es besteht weitgehender Konsens darüber, dass Bakterien der normalen Schleimhautflora der oberen Luftwege wie vergrünende
Tab.4a Infektionserreger bei nosokomialer Pneumonie, Patienten ohne Risikofaktoren für multiresistente Erreger (MRE).

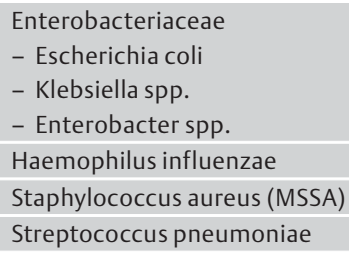

Tab.4b Infektionserreger bei nosokomialer Pneumonie, Patienten mit Risikofaktoren für multiresistente Erreger (MRE).

\begin{tabular}{l} 
zusätzlich: \\
Methicillinresistente Staphylococcus aureus (MRSA) \\
\hline ESBL-bildende Enterobacteriaceae \\
\hline Pseudomonas aeruginosa \\
Acinetobacter baumannii \\
Stenotrophomonas maltophilia
\end{tabular}

Tab. 5 Bakterien und Pilze der oropharyngealen Standortflora ohne therapeutische Relevanz bei nosokomialer Pneumonie.

\begin{tabular}{l} 
Corynebacterium spp. \\
\hline Enterococcus spp. \\
\hline Neisseria spp. \\
\hline$\alpha$-hämolysierende (vergrünende) Streptokokken \\
\hline Koagulase-negative Staphylokokken \\
\hline Candida spp. \\
\hline
\end{tabular}

Streptokokken, Neisseria spp. und Corynebacterium spp., aber auch Bakterienspezies wie Enterococcus faecalis und E. faecium sowie Koagulase-negative Staphylokokken, die als seltenere Kommensalen der oberen Luftwege unter antimikrobieller Therapie selektiert werden können, als Pneumonieerreger keine Bedeutung haben, selbst wenn sie in größerer Menge in einem invasiv gewonnenen Atemwegsmaterial nachgewiesen werden ( Tab.5). Diese Bakterienspezies sollten daher vom mikrobiologischen Labor lediglich auf Genusebene, aber nicht auf Speziesebene, identifiziert und als Schleimhaut- bzw. Atemwegsflora berichtet werden. Auf keinen Fall sollte von diesen Kommensalen eine Resistenzbestimmung durchgeführt werden, die Anlass zu Fehl- und Übertherapie sein könnte. Die Rolle obligat anaerober Bakterien als Erreger nosokomialer Pneumonien ist ungeklärt, da auch bei invasiv gewonnenen Atemwegsmaterialien bei Patienten mit HAP nur selten eine adäquate Anaerobierdiagnostik durchgeführt wird, zumal die üblichen Transportbedingungen dieser Materialien eine qualifizierte Anaerobierdiagnostik verhindern.

Auch Candida spp. werden unter jedweder antibiotischer Therapie, insbesondere aber unter einer Therapie mit Breitspektrumantibiotika, selektiert und daher regelmäßig bei intubierten Intensivpatienten nachgewiesen. Als Erreger einer nosokomialen Pneumonie spielen sie keine Rolle, ihr Nachweis in Atemwegssekreten sollte daher unabhängig von der nachgewiesenen Spezies keinesfalls als Indikation für eine antimykotische Therapie angesehen werden [32]. Demgegenüber sind Aspergillus spp. als Erreger einer nosokomialen Pneumonie zwar selten, sollten aber aufgrund der hohen Letalität bei Risikopatienten berücksichtigt werden (s. Empfehlung E 10). 
Tab.6 Risikofaktoren für multiresistente Infektionserreger bei nosokomialer Pneumonie. Nach [34, 35, 36].

- Antimikrobielle Therapie
- Hospitalisierung>4 Tage (late-onset)
- Invasive Beatmung>4-6 Tage
- Aufenthalt Intensivstation
- Malnutrition
- Strukturelle Lungenerkrankung
- Bekannte Kolonisation durch MRE
- Aufnahme aus Langzeitpflegebereichen, chronische Dialyse,
Tracheostomaträger, offene Hautwunden

In der Leitliniengruppe besteht Konsens darüber, dass die Diagnostik von Erregern der oropharyngealen Standortflora ( $\odot$ Tab.5) auf die Genusebene (Bakterien) bzw. Speziesebene (Hefepilze) beschränkt werden sollte und auf eine Resistenzbestimmung verzichtet werden sollte, um Fehltherapien zu vermeiden.

Das Erregerspektrum und die Frequenz von Infektionen mit multiresistenten Erregern (MRE) hängen von einer Vielzahl von Risikofaktoren ab ( Tab.6). Hierzu gehören insbesondere eine antibiotische Vorbehandlung, ein vorangegangener Krankenhausaufenthalt, das Vorhandensein von Vorerkrankungen in fortgeschrittenen Stadien wie COPD, Bronchiektasie, Leberzirrhose, die Unterbringung in einem Pflegeheim, Aufenthalt auf einer Intensivstation, invasive Beatmung und Dauer der Beatmung. Ein weiterer wichtiger Risikofaktor für Infektionen mit MRE ist die Dauer des stationären Aufenthaltes vor Auftreten der Pneumonie. Dies hat zu dem Konzept der Unterscheidung zwischen einer early-onset und einer late-onset Pneumonie geführt, wobei als Grenze zwischen early-onset und late-onset meist 96 Stunden nach Krankenhausaufnahme definiert werden. Dieses Konzept wurde kürzlich durch die Ergebnisse einer deutschen Studie in- frage gestellt [33]. Daten aus dem Krankenhaus-Infektions-Surveillance-System KISS von über 16000 Patienten mit beatmungsassoziierter Pneumonie aus dem Zeitraum von 1997 bis 2006 haben keinen Unterschied in der Rangfolge der häufigsten Pneumonieerreger zwischen früh und spät auftretender Pneumonie gezeigt. Eine early-onset Pneumonie ist also bei Vorliegen anderer Risikofaktoren nicht selten mit MRE assoziiert. Einschränkend muss gesagt werden, dass in dieser Untersuchung early- und lateonset nicht auf die Zeit nach Krankenhausaufnahme, sondern auf die Zeit nach Beatmungsbeginn bezogen wurde, diese Patienten also durchaus schon länger hospitalisiert gewesen sein und dadurch bereits mit nosokomialen Infektionserregern besiedelt gewesen sein konnten.

Die Mehrzahl prospektiver Studien mit dieser Fragestellung, die allerdings ebenfalls zum Teil den Krankenhausaufenthalt vor der Aufnahme auf die Intensivstation nicht berücksichtigten, demonstrierten eine höhere Prävalenz von MRE als Ursache von Pneumonien ab dem 5. bis 6. Aufenthaltstag ( Tab. 7). Dazu gehörten MRSA (in zwei von vier Studien), P. aeruginosa, A. baumannii und S. maltophilia. Damit zählt das Kriterium „late-onset“, neben anderen Merkmalen, zu den Risikofaktoren für eine $\mathrm{Er}$ krankung durch multiresistente Erreger der HAP.

Insgesamt stehen bei Patienten ohne die obengenannten Risikofaktoren Erreger ambulant erworbener Atemwegsinfektionen wie S. aureus (meist Oxacillin-empfindlich), S. pneumoniae, H. influenzae, seltener Moraxella catarrhalis sowie Enterobacteriaceae aus der patienteneigenen Darmflora im Vordergrund, während bei Patienten mit Risikofaktoren häufiger MRE wie Methicillinresistente S. aureus (MRSA)-Stämme oder multiresistente Gramnegative Erreger wie Enterobacteriaceae mit Extended Spectrum Betalactamases (ESBL), P. aeruginosa, A. baumannii oder seltener S. maltophilia ( Tab.4) die Ursache der HAP darstellen. ESBL-bildende Enterobakterien spielen allerdings trotz rascher Zunahme

Tab. 7 Erregerspektrum bei „früher“ und „später“ beatmungsassoziierter Pneumonie in internationalen Studien.

\begin{tabular}{|c|c|c|c|c|c|c|c|c|}
\hline $\begin{array}{l}\text { Tag nach Beginn der } \\
\text { Beatmung }\end{array}$ & $\leq 5 \mathrm{~d}$ & $\geq 6 \mathrm{~d}$ & $\leq 5 \mathrm{~d}$ & $\geq 6 \mathrm{~d}$ & $\leq 5 \mathrm{~d}$ & $\geq 6 \mathrm{~d}$ & $\leq 4 \mathrm{~d}$ & $\geq 5 \mathrm{~d}$ \\
\hline Author/no. & $\begin{array}{l}\text { Pirrachio } \\
2009[42]\end{array}$ & $\begin{array}{l}\text { Gacouin } \\
2009[43]\end{array}$ & $\begin{array}{l}\text { Rangel } \\
2009[44]\end{array}$ & $\begin{array}{l}\text { Rangel } \\
2009[44]\end{array}$ & $\begin{array}{l}\text { Leone } \\
2007[45]\end{array}$ & $\begin{array}{l}\text { Leone } \\
2007[45]\end{array}$ & $\begin{array}{l}\text { Ibrahim } \\
2000[46]\end{array}$ & $\begin{array}{l}\text { Ibrahim } \\
2000[46]\end{array}$ \\
\hline $\begin{array}{l}\text { Anzahl Patienten/ } \\
\text { Anzahl Erreger }\end{array}$ & $136 / 191$ & $76 / 100$ & $? / 78$ & $? / 97$ & $39 / 50$ & $76 / 90$ & $235 / 247$ & $185 / 223$ \\
\hline Studiendesign & $\begin{array}{l}\text { prospektiv, } \\
1 \text { SICU }\end{array}$ & $\begin{array}{l}\text { prospektiv, } \\
1 \mathrm{ICU}\end{array}$ & $\begin{array}{l}\text { retrospektiv, } \\
1 \text { SICU }\end{array}$ & $\begin{array}{l}\text { retrospektiv, } \\
1 \text { SICU }\end{array}$ & $\begin{array}{l}\text { prospektiv, } \\
1 \mathrm{MSICU}\end{array}$ & $\begin{array}{l}\text { prospektiv, } \\
1 \mathrm{MSICU}\end{array}$ & $\begin{array}{l}\text { prospektiv, } \\
2 \text { ICUs }\end{array}$ & $\begin{array}{l}\text { prospektiv, } \\
2 \text { ICUs }\end{array}$ \\
\hline $\begin{array}{l}\text { Nutzung invasiver } \\
\text { diagnostischer Methoden }\end{array}$ & ja & ja & ja & ja & ja & ja & teilweise & teilweise \\
\hline \multicolumn{9}{|l|}{ Erregerhäufigkeit \% (Rang) } \\
\hline S. aureus & $36.1(1)$ & $21.0(1)$ & $14.1(1)$ & $21.6(1)$ & $34.0(1)$ & $27.8(1)$ & $34.0(1)$ & $26.5(2)$ \\
\hline MSSA & 32.5 & 12.0 & 10.3 & 16.5 & 30.0 & 26.7 & 17.0 & 9.0 \\
\hline MRSA & 3.7 & 9.0 & 3.8 & 5.1 & 4.0 & 1.1 & 17.0 & 17.5 \\
\hline P. aeruginosa & $10.0(4)$ & $21.0(1)$ & 1.3 & $9.3(5)$ & $10.0(3)$ & $10.0(4)$ & $23.9(2)$ & $31.8(1)$ \\
\hline Acinetobacter spp. & $2.6(7)$ & $4.0(8)$ & $11.5(3)$ & $11.3(4)$ & & $6.7(6)$ & $2.4(7)$ & $4.5(6)$ \\
\hline H. influenza & $15.2(2)$ & $3.0(9)$ & $28.2(1)$ & $15.5(2)$ & $26.0(2)$ & $16.7(2)$ & $5.7(5)$ & $2.2(8)$ \\
\hline S. pneumonia & & $1.0(10)$ & $9.0(5)$ & $4.1(7)$ & & & $1.6(10)$ & 0.9 \\
\hline E. coli & & $12.0(3)$ & $6.4(6)$ & $7.2(6)$ & $4.0(6)$ & $4.4(8)$ & $2.4(7)$ & $1.3(10)$ \\
\hline Klebsiella spp. & $5.2(6)$ & $9.0(4)$ & $6.4(6)$ & $2.1(10)$ & $2.0(7)$ & $4.4(8)$ & $5.2(6)$ & $5.4(5)$ \\
\hline Enterobacter spp. & $5.8(5)$ & $8.0(5)$ & $3.8(9)$ & $3.1(9)$ & $8.0(5)$ & $6.7(6)$ & $9.7(3)$ & $8.5(4)$ \\
\hline Proteus spp. & $1.0(10)$ & 1.0 & & $2.1(10)$ & $2.0(7)$ & $10.0(4)$ & $1.6(10)$ & $2.2(8)$ \\
\hline Serratia spp. & $1.6(9)$ & $6.0(7)$ & $5.1(8)$ & $2.1(10)$ & & & $2.4(7)$ & $3.1(7)$ \\
\hline Streptococcus spp. & $11.0(3)$ & & $2.6(10)$ & $4.1(7)$ & $10.0(3)$ & $11.1(3)$ & & \\
\hline S. maltophilia & $2.1(8)$ & $8.0(5)$ & $10.3(4)$ & $14.4(3)$ & & & $6.9(4)$ & $9.4(3)$ \\
\hline polymikrobiell & n.d. & n.d. & n.d. & n.d. & n.d. & n.d. & 20.9 & 27.6 \\
\hline
\end{tabular}

ICU: Intensive Care Unit, MICU: Medical Intensive Care Unit, SICU: Surgical Intensive Care Unit 
Tab. 8 Erregerspektrum beatmungsassoziierter Pneumonien in internationalen Studien.

\begin{tabular}{|c|c|c|c|c|c|c|c|c|c|}
\hline Author/no. & $\begin{array}{l}\text { Koulenti } \\
2009[41]\end{array}$ & $\begin{array}{l}\text { Chastre } \\
2008 \text { [47] }\end{array}$ & $\begin{array}{l}\text { Kollef } \\
2006 \text { [48] }\end{array}$ & $\begin{array}{l}\text { Chastre } \\
2003 \text { [49] }\end{array}$ & $\begin{array}{l}\text { Combes } \\
2002[50]\end{array}$ & $\begin{array}{l}\text { Hayon } \\
2002[51]\end{array}$ & $\begin{array}{l}\text { Ibrahim } \\
2000[46]\end{array}$ & $\begin{array}{l}\text { Rangel } \\
2009 \text { [44] }\end{array}$ & $\begin{array}{l}\text { Fowler } \\
2003 \text { [52] }\end{array}$ \\
\hline $\begin{array}{l}\text { Anzahl Patienten/ } \\
\text { Anzahl Erreger }\end{array}$ & $356 / 491$ & $531 / 725$ & $197 / 184$ & $401 / 625$ & $124 / 207$ & $125 / 220$ & $420 / 470$ & $113 / 175$ & $156 / 117$ \\
\hline Studiendesign & $\begin{array}{l}\text { prospektiv, } \\
\text { multizentrisch }\end{array}$ & $\begin{array}{l}\text { prospektiv, } \\
\text { randomisiert, } \\
\text { multizentrisch }\end{array}$ & $\begin{array}{l}\text { prospektiv, } \\
\text { multizentrisch }\end{array}$ & $\begin{array}{l}\text { prospektiv, } \\
\text { randomisiert, } \\
\text { multizentrisch }\end{array}$ & $\begin{array}{l}\text { prospektiv, } \\
2 \text { ICUs }\end{array}$ & $\begin{array}{l}\text { prospektiv, } \\
\text { monozentrisch }\end{array}$ & $\begin{array}{l}\text { prospektiv, } \\
2 \text { ICUs }\end{array}$ & $\begin{array}{l}\text { retrospektiv, } \\
1 \mathrm{SICU}\end{array}$ & $\begin{array}{l}\text { prospektiv, } \\
2 \mathrm{MSICU}\end{array}$ \\
\hline $\begin{array}{l}\text { Nutzung invasiver } \\
\text { diagnostischer } \\
\text { Methoden }\end{array}$ & $\begin{array}{l}\text { teilweise, } \\
\text { bei } 23 \% \text { der } \\
\text { Patienten }\end{array}$ & teilweise & teilweise & ja & ja & ja & teilweise & ja & nein, TS \\
\hline \multicolumn{10}{|l|}{$\begin{array}{l}\text { Erregerhäufigkeit } \\
\% \text { (Rang) }\end{array}$} \\
\hline S. aureus & $23.6(1)$ & $18.6(1)$ & $51.1(1)$ & $20.0(1)$ & $17.9(3)$ & $20.0(2)$ & $30.4(1)$ & $18.9(2)$ & $25.6(1)$ \\
\hline MSSA & 13.0 & 12.8 & 19.0 & 12.8 & 4.3 & 4.1 & 12.9 & 13.7 & 18.8 \\
\hline MRSA & 10.6 & 5.8 & 32.1 & 7.2 & 13.5 & 15.9 & 17.2 & 5.1 & 6.8 \\
\hline P. aeruginosa & $16.5(2)$ & $7.6(4)$ & $31.0(2)$ & $19.2(2)$ & $26.1(1)$ & $15.9(3)$ & $27.7(2)$ & $5.7(6)$ & $23.9(2)$ \\
\hline Acinetobacter spp. & $14.7(3)$ & $4.3(7)$ & $4.3(6)$ & $1.8(10)$ & $5.3(4)$ & $9.5(4)$ & $3.4(7)$ & $11.4(4)$ & $2.6(10)$ \\
\hline H. influenzae & 5.7 & $12.3(2)$ & & $7.2(5)$ & $3.9(5)$ & $4.5(5)$ & $4.0(6)$ & $21.1(1)$ & $5.1(7)$ \\
\hline S. pneumoniae & 3.7 & $4.1(8)$ & & nd. & & & 1.3 & $6.3(6)$ & 0.9 \\
\hline E. coli & & $5.8(6)$ & $6.5(5)$ & $9.3(4)$ & $3.9(5)$ & $4.1(6)$ & $1.9(9)$ & $6.9(5)$ & $4.3(8)$ \\
\hline Klebsiella spp. & & $8.4(3)$ & $7.1(3)$ & $3.2(8)$ & 1.0 & $0.9(10)$ & $5.3(5)$ & $4.0(7)$ & $8.5(4)$ \\
\hline Enterobacter spp. & & $7.6(4)$ & $7.1(3)$ & $3.8(7)$ & $1.9(10)$ & $0.9(10)$ & $9.1(3)$ & $2.9(8)$ & $12.0(3)$ \\
\hline Proteus spp. & & $2.3(8)$ & & $4.6(6)$ & $3.4(8)$ & $3.6(8)$ & $1.9(9)$ & 0.6 & \\
\hline Serratia spp. & & $2.3(8)$ & & $2.6(9)$ & $2.4(9)$ & $1.4(9)$ & $2.8(8)$ & $2.3(10)$ & $7.7(5)$ \\
\hline Streptococcus spp. & & & & $13.4(3)$ & $21.7(5)$ & $23.2(1)$ & & $2.9(8)$ & $2.7(9)$ \\
\hline S. maltophilia & & $1.7(10)$ & & 0.8 & $3.9(4)$ & $4.1(6)$ & $8.1(4)$ & $12.6(3)$ & $6.0(6)$ \\
\hline Polymikrobiell & 32.0 & n.d. & n.d. & n.d. & 68.6 & n.d. & 21.3 & n.d. & 30.0 \\
\hline Enterobacteriaceae & 31.2 & $\begin{array}{l}\text { random. } \\
\text { Intervent. }\end{array}$ & & $\begin{array}{l}\text { random. } \\
\text { Intervent. } \\
\text { clinical trial }\end{array}$ & & & & & \\
\hline
\end{tabular}

bei abdominellen, urogenitalen und primär bakteriämischen Infektionen als Pneumonieerreger in Deutschland bislang eine untergeordnete Rolle.

In der Leitliniengruppe besteht Konsens darüber, dass im Hinblick auf das Management und die initiale, kalkulierte antimikrobielle Therapie der nosokomialen Pneumonie zwischen Patienten mit und ohne Risikofaktoren für multiresistente Erreger unterschieden werden sollte.

Die Gewichtung dieser Faktoren ist nicht exakt quantifizierbar. Die Präsenz eines einzelnen Merkmals führt nicht notwendigerweise zu einer Infektion mit MRE. Das Risiko hängt von der Suszeptibilität des Patienten, der Dauer und Intensität der Einwirkung einzelner Risikofaktoren (Spektrum der Antibiotikatherapie), dem Zusammenwirken mehrerer Faktoren sowie der lokalen Erregerepidemiologie (Wahrscheinlichkeit der Akquisition von MRE aus der hospitaleigenen Flora) ab. Die Beurteilung des Gesamtrisikos bleibt einer kompetenten klinischen Einschätzung vorbehalten.

\subsection{Interpretation von Daten zum Erregerspektrum}

Die verlässlichsten Daten zur Erreger- und Resistenz-Epidemiologie der HAP liefern prospektive Studien, in denen standardisierte Kriterien für die Diagnose der Pneumonie, invasive Methoden zur Sekretgewinnung, eine optimale Logistik (Probenentnahme vor Beginn der antibiotischen Therapie, sofortiger Transport und sofortige Weiterverarbeitung der Materialien im Labor) und eine standardisierte, qualitätskontrollierte mikrobiologische Diagnostik gewährleistet sind. Weniger zuverlässig sind Daten aus epidemiologischen und mikrobiologischen Surveillancestudien, in denen lediglich klinische Surveillance-Kriterien für die Diagnose der Pneumonie herangezogen werden (KISS) bzw. die Resistenzepidemiologie von Erregern aus Atemwegsmaterialien ausgewertet wird, aber letztlich meist unklar bleibt, ob der nachgewiesene Erreger tatsächlich eine Atemwegsinfektion verursacht hat oder lediglich eine Atemwegsbesiedlung darstellt [37,38].

Die besten verfügbaren Daten zum Erregerspektrum der nosokomialen Pneumonie in Deutschland liefert das KISS. Die häufigsten Erreger nach aktuellen Daten sind demnach S.aureus (26,4 pro 100 VAP-Fälle), P. aeruginosa (15,4 pro 100 Fälle), Klebsiella spp. (10,2 pro 100 Fälle) und E. coli (10,0 pro 100 Fälle) [14*]. Diese Verteilung entspricht den Ergebnissen der SENTRY-Studie aus europäischen Krankenhäusern [39*]. Im Vergleich zu Pneumonien bei invasiv beatmeten Patienten traten in dieser Studie bei Patienten mit nicht invasiver Beatmung und ohne Beatmung signifikant häufiger durch Pneumokokken bedingte Infektionen auf. Alle Gram-negativen Erreger einschließlich P. aeruginosa wurden signifikant häufiger bei beatmeten Patienten beobachtet [14*]. Pneumonie-Fälle, die durch $P$. aeruginosa bedingt sind, zeigen auch ein längeres Intervall zwischen Aufnahme auf die Intensivstation und Pneumonie-Entwicklung im Vergleich mit Fällen, welche durch andere Erreger hervorgerufen werden (13 vs. 9 Tage). Tab. 8 zeigt zum Vergleich Daten zum Erregerspektrum beatmungsassoziierter Pneumonien aus internationalen Studien. Zum Erregerspektrum nicht beatmungsassoziierter nosokomialer Pneumonien liegen lediglich zwei neuere internationale Studien vor $[40,41]$, die ein breites Spektrum bakterieller Pathogene unter Einschluss von MRE und Legionella spp. ergaben.

Nachfolgend werden die wichtigsten Erreger nosokomialer Pneumonien und ihre wichtigsten Resistenzmechanismen im Überblick dargestellt: 
Streptococcus pneumoniae und Haemophilus influenzae S. pneumoniae und $H$. influenzae sind typische Erreger der nosokomialen early-onset Pneumonie bei antibiotisch nicht vorbehandelten Patienten. In den meisten Studien wird S. pneumoniae in einer Häufigkeit zwischen $1 \%$ und $10 \%$ aller beatmungsassoziierten Pneumonien als ursächlicher Erreger nachgewiesen. Bei Patienten mit VAP wurde nach den Daten aus dem KISS S. pneumoniae bei 9,3\% der Patienten, bei denen die Pneumonie innerhalb von vier Tagen nach Beatmungsbeginn, aber auch bei 4,3\% der Patienten nachgewiesen, bei denen die Pneumonie erst mehr als sieben Tage nach Beatmungsbeginn auftrat. In Deutschland sind nur weniger als $1 \%$ der S. pneumoniae-Stämme resistent gegenüber Penicillinen, noch geringer ist die Resistenz gegenüber Drittgenerationscephalosporinen, die Resistenzraten gegenüber Erythromycin und anderen Makrolidantibiotika in Deutschland sind in den letzten Jahren wieder rückläufig und liegen bei Erwachsenen aktuell zwischen 8 und 10\%. H. influenzae trat in Deutschland nach Ergebnissen aus dem KISS bei 6,9\% der Patienten mit Pneumoniebeginn innerhalb von vier Tagen und bei 2,9\% der Patienten mit Pneumoniebeginn nach dem siebten Tag nach Beatmungsbeginn auf. In anderen Studien findet sich $H$. influenzae in bis zu $28 \%$ als Erreger einer VAP, in der Regel sehr viel häufiger bei early-onset Pneumonien. Etwa 10-15\% aller H. influenzae-Isolate sind Betalaktamase-Bildner und daher resistent gegenüber Amino- und Ureidopenicillinen; sie sind jedoch ausnahmslos empfindlich für Betalaktam-Betalaktamase-Inhibitorkombinationen, Cephalosporine der Cefotaximgruppe und Fluorchinolone und stellen daher kein therapeutisches Problem dar. Bei Patienten, die vor Auftreten der Pneumonie bereits wegen einer anderen Infektion antibiotisch behandelt wurden, treten S. pneumoniae und $H$. influenzae aufgrund ihrer guten Antibiotikaempfindlichkeit als Pneumonieerreger praktisch nicht mehr in Erscheinung.

Staphylococcus aureus S. aureus stellt in den meisten Studien den häufigsten oder zweithäufigsten Erreger der HAP dar. Da in Deutschland ambulant erworbene Methicillin-resistente $S$. aureus-Stämme (MRSA) ausgesprochen selten sind, findet man bei der early-onset Pneumonie meist Methicillin-empfindliche S. aureus-Stämme (MSSA), während mit zunehmender Krankenhausverweildauer die Häufigkeit von MRSA zunimmt. So betrug in der Studie von Gastmeier und Kollegen die Häufigkeit von MSSA unter den Erregern der innerhalb von vier Tagen nach Beatmungsbeginn auftretenden Pneumonien 21,4\% gegenüber 4,3\% MRSA, während bei später als sieben Tage nach Beatmungsbeginn auftretenden Pneumonien MSSA bei 14,5\% der Patienten, MRSA bei $6,5 \%$ der Patienten nachgewiesen wurde. Insgesamt lag die Häufigkeit von S. aureus zwischen $21 \%$ und 27\%. In anderen Studien liegt die Häufigkeit von $S$. aureus noch deutlich darüber.Während die meisten MSSA-Stämme neben ihrer Empfindlichkeit gegenüber Penicillinase-festen Betalaktamantibiotika auch empfindlich für Makrolide, Clindamycin und Fluorchinolone mit Resistenzraten von jeweils unter $10 \%$ sind, liegt die Resistenzrate gegenüber diesen Antibiotika bei MRSA-Stämmen über $80 \%$. MRSA-Stämme sind in Deutschland zu 100\% empfindlich für Vancomycin, Teicoplanin und Linezolid. Daptomycin und Tigecyclin sind zur Behandlung der HAP nicht zugelassen. Die Resistenzraten gegenüber Fosfomycin, Fusidinsäure, Cotrimoxazol und Rifampicin sind regional unterschiedlich, liegen aber in der Regel unter 5\%.

Pseudomonas aeruginosa $P$. aeruginosa stellt zusammen mit S. aureus den häufigsten Erreger nosokomialer Pneumonien dar. Die Häufigkeit wird in den meisten Studien zwischen 10 und 30\% angegeben, wobei die Häufigkeitsraten bei Patienten mit Risiko- faktoren für MRE deutlich größer sind. Aus den KISS-Daten ergibt sich eine Häufigkeit von 11,6\% bei Patienten mit Pneumoniebeginn innerhalb von vier Tagen und von 19,9\% bei Patienten mit Pneumoniebeginn nach dem siebten Tag nach Beatmungsbeginn. P. aeruginosa-Stämme weisen eine ausgeprägte intrinsische Resistenz gegenüber einer Vielzahl von Antibiotika auf wie Ampicillin und Cotrimoxazol sowie Drittgenerationcephalosporinen der Cefotaximgruppe. Darüber hinaus hat in den letzten Jahren auch die erworbene Resistenz gegenüber Pseudomonas-wirksamen Antibiotika wie Piperacillin, Ceftazidim, Cefepim, Fluorchinolonen, Aminoglykosiden und Carbapenemen weltweit zugenommen. Hierfür verantwortlich sind eine Vielzahl verschiedener Resistenzmechanismen wie Veränderungen der äußeren Zellmembran (z.B. Porinverlust), Aminoglykosid-modifizierende Enzyme, Betalaktamasen, darunter insbesondere Oxacillinasen und Metallobetalaktamasen, sowie die Hochregulation von Effluxmechanismen. Insbesondere bei Patienten mit strukturellen Lungenerkrankungen und chronischer Besiedlung mit $P$. aeruginosa lassen sich oft mukoide Kulturvarianten mit wechselndem Resistenzphänotyp nachweisen. Somit ist mit Ausnahme von Colistin keine Antibiotikaklasse in der kalkulierten Therapie als sicher wirksam anzusehen.

Enterobacteriaceae Die verschiedenen Spezies der Familie Enterobacteriaceae finden sich in allen Studien unter den zehn häufigsten Erregern der HAP. Hierzu zählen insbesondere E. coli, K. oxytoca und K. pneumoniae, aber auch Enterobacter spp., S. marcescens, Proteus spp. und Citrobacter spp. Die Rangfolge ist von Studie zu Studie verschieden, hier spielen lokale Ausbruchssituationen eine wesentliche Rolle. In Deutschland stehen E. coli und K. pneumoniae im Vordergrund. Die Häufigkeit der einzelnen Spezies wird in den meisten Studien mit unter $10 \%$ angegeben. Fasst man dagegen alle Enterobakterien zusammen, so stellen sie als Gruppe in der Regel den größten Anteil unter den Erregern der HAP dar. In den meisten Studien unterscheidet sich die Häufigkeit von Enterobacteriaceae zwischen früh und spät auftretenden Pneumonien nur unwesentlich, möglicherweise als Hinweis darauf, dass ein Teil der Patienten schon bei Krankenhausaufnahme mit diesen Erregern kolonisiert ist und der Infektionsweg in der Regel endogener Natur ist. Auch bei Enterobakterien ist in den letzten Jahren eine deutliche Resistenzzunahme zu beobachten, wobei hier Resistenzen gegenüber Fluorchinolonen (überwiegend bei $E$. coli, in zunehmendem Maße aber auch bei Klebsiella spp.) sowie gegenüber Cephalosporinen der Cefotaximgruppe und Betalaktam-Betalaktamase-Inhibitorkombinationen im Vordergund stehen. Verantwortlich für Fluorchinolonresistenz bei Enterobakterien sind Mutationen, die zu Veränderungen an Gyrasen und Topoisomerasen führen, sowie Effluxmechanismen. Die Resistenzzunahme gegenüber Penicillinen und Cephalosporinen ist auf meist Plasmid-kodierte Breitspektrumbetalaktamasen (ESBLs) zurückzuführen. Hier lässt sich in Deutschland eine stetige Zunahme ESBL-bildender E. coli- und K. pneumoniae-Stämme beobachten, die oft eine gleichzeitige Resistenz gegenüber Fluorchinolonen und Aminoglykosiden aufweisen. In der Gruppe Enterobacter-Serratia-Citrobacter ist die häufig zu beobachtende Resistenz gegenüber Penicillinen und Cephalosporinen dagegen durch meist chromosomal kodierte AmpC-Betalaktamasen bedingt. Resistenz gegenüber Carbapenemen ist in Deutschland noch sehr selten, stellt allerdings in Griechenland, der Türkei, arabischen Ländern und Israel ein immer häufiger beobachtetes Phänomen dar. Ursächlich sind hierfür verschiedene Betalaktamasen wie Carbapenemasen, Metallo-Betalaktamasen 


\begin{tabular}{|llcc|}
\hline Erreger & $\begin{array}{l}\text { Nicht multiresistente } \\
\text { Erreger (\%) }\end{array}$ & $\begin{array}{l}\text { Multiresistente } \\
\text { Erreger (\%) }\end{array}$ & Resistenzrate $^{2}$ \\
\hline S. aureus & 12,9 & 7,1 & $36 \%$ \\
\hline P. aeruginosa & 15,6 & 1,2 & $7 \%$ \\
\hline $\begin{array}{l}\text { E.coli } \\
+ \text { ESBL }\end{array}$ & 10,4 & 0,2 & $13 \% 4$ \\
\hline Klebsiella spp. & 1,3 & $16 \% 4$ \\
+ ESBL $^{3}$ & 9,9 & 0,5 & $4 \%$ \\
\hline Enterobacter spp. & 7,9 & 1,4 & $10 \%$ \\
\hline S. maltophilia & 3,6 & 0,3 & $19 \%$ \\
\hline A. baumannii & 2,1 & 0,4 & $17 \%$ \\
\hline Summe & 62,4 & 0,5 & 12,9 \\
\hline
\end{tabular}

Tab.9 Auftreten von multiresistenten Erregern bei Patienten mit unteren Atemwegsinfektionen in KISS-Intensivstationen $2005-2009$ [58], bezogen auf 17770 Infektionen, davon $14770(83,1 \%)$ mit Erregernachweis.

${ }^{1}$ Mehrfachnennung möglich

2 Resistenzrate $=$ Anteil multiresistenter Stämme $/$ Gesamtzahl der Isolate des Erregers

${ }^{3}$ trifft für Erreger sowohl die Definition für ESBL als für Multiresistenz zu, ist der Erreger als ESBL zu verkodieren

${ }^{4}$ ESBL und Multiresistenz zusammengefasst.

und Oxacillinasen sowie Veränderungen an der äußeren Zellmembran.

Acinetobacter spp. Zu den Acinetobacter spp. der A. baumanniiGruppe zählen A. baumannii, A. nosocomialis und A. pittii. Sie sind im Rahmen der mikrobiologischen Routinediagnostik nicht sicher zu unterscheiden und werden daher in der Regel als A. baumannii identifiziert. Die A. baumannii-Gruppe hat weltweit als Erreger der VAP an Bedeutung gewonnen. Ihre Häufigkeit liegt zwischen $5 \%$ und $15 \%$ und ist regional sehr unterschiedlich. Dies hängt mit der Tatsache zusammen, dass $A$. baumannii häufig zu Hospitalausbrüchen führt, die nur schwer zu kontrollieren sind. Eine bedeutende Eigenschaft, die auch zur epidemischen Verbreitung von $A$. baumannii beiträgt, ist die hohe intrinsische Resistenz dieser Erreger gegenüber Penicillinen und Cephalosporinen verbunden mit einer Fähigkeit, in rascher Folge weitere Resistenzeigenschaften z. B. gegenüber Fluorchinolonen, Aminoglykosiden und seit einigen Jahren auch gegenüber Carbapenemen zu erwerben. Die Resistenz gegen Carbapeneme ist bedingt durch Oxacillinasen und seltener auch durch Metallobetalaktamasen. Immer häufiger werden panresistente Stämme gefunden, die nur noch gegenüber Colistin empfindlich sind.

Stenotrophomonas maltophilia S. maltophilia, ebenso wie A. baumannii eher für late-onset VAP verantwortlich, zeichnet sich durch eine umfangreiche intrinsische Resistenz gegenüber einer Vielzahl von Antibiotikaklassen aus. Zuverlässig wirksam sind lediglich Cotrimoxazol, welches als Mittel der Wahl gilt, sowie Fluorchinolone. Schwere Pneumonien durch S. maltophilia sind eher selten, meist handelt es sich um eine Besiedlung der Atemwege bei beatmeten Patienten, wobei eine vorausgehende Therapie mit einem Breitspektrumantibiotikum, insbesondere mit Carbapenemen, den entscheidenden Risikofaktor darstellt. Die meisten Studien geben die Häufigkeit von S. maltophilia als Erreger der HAP mit $2 \%$ bis $10 \%$ an.

Legionella pneumophila HAP mit Legionella pneumophila oder anderen Legionella spp.treten insbesondere bei immunkompromittierten Patienten auf. Zur Häufigkeit nosokomialer Legionellenpneumonien außerhalb dieser Risikogruppen gibt es wenig verlässliche Zahlen. Ihr Auftreten ist regional sehr unterschiedlich und hängt einerseits vom Ausmaß der Legionellenbelastung in der Wasserversorgung des jeweiligen Krankenhauses, andererseits von der Exposition beatmeter und nichtbeatmeter Patienten mit kontaminiertem Leitungswasser ab.

Polymikrobielle bakterielle Infektionen Obwohl allgemein akzeptiert ist, dass beatmungsassoziierte Pneumonien oft polymikrobielle Infektionen darstellen, geben die meisten der hier aufgeführten Studien hierzu keine genauen Zahlen an, ihr Anteil wird auf mindestens 30 - $40 \%$ geschätzt.

Aspergillus spp. Nosokomiale Pneumonien durch Aspergillus spp. werden auch bei Patienten außerhalb der klassischen Risikokollektive mit definiertem Immundefizit beobachtet. Die Häufigkeit liegt bei $1-1,4 \%\left[53,46,14^{*}, 54\right]$. Gefährdet sind insbesondere Patienten auf Intensivstationen sowie Patienten mit COPD mit einer über einen längeren Zeitraum durchgeführten Glucocorticoidmedikation. Die Sterblichkeit liegt mit 70-80\% sehr hoch.

Viren Viren treten bei Immunkompetenten selten als Erreger einer HAP in Erscheinung. Allerdings sind Häufungen oder Ausbrüche nosokomialer Pneumonien mit Adenoviren, RSV-Viren, Herpesviren und insbesondere Influenza-Viren beschrieben [55, 56]. In einer kürzlich veröffentlichten Studie wurde über einen hohen Anteil (16\%) von akuter Cytomegalievirusinfektion bei beatmungsassoziierten Pneumonien immunkompetenter Patienten berichtet [57]. Wie bei allen Herpesviren ist die Differenzierung von asymptomatischer Infektion und CMV-Erkrankung insbesondere vor dem Hintergrund der VAP schwierig; quantitative cut-offs der CMV-PCR in der BAL sind für dieses Kollektiv nicht etabliert. Die klinische Relevanz dieses Befundes ist daher nicht gesichert und letztlich nur durch eine kontrollierte Therapiestudie zu klären.

Resistenzepidemiologie Nach aktuellen KISS-Daten liegt die Häufigkeit von MRSA unter allen S. aureus-Stämmen, die im Zusammenhang mit beatmungsassoziierten Pneumonien isoliert wurden, in Deutschland bei 36\%. Bei den Gram-negativen Erregern ist der Anteil von MRE deutlich geringer ( Tab.9). Es ist allerdings darauf hinzuweisen, dass diese Daten nur einen groben Anhaltspunkt zur Häufigkeit des Auftretens resistenter Erreger bei HAP bieten können und nicht als Grundlage therapeutischer Entscheidungen dienen können. Auch nationale oder internationale Daten zur Resistenzepidemiologie können, selbst wenn sie in aktuellen, prospektiven Studien unter Verwendung adäquater mikrobiologischer Methoden gewonnen wurden, für eine individuelle Therapieentscheidung nicht herangezogen werden. Auf eine Veröffentlichung entsprechender Tabellen wird daher in dieser Leitlinie verzichtet. Sowohl die Häufigkeit der verschiedenen Erreger nosokomialer Pneumonien als auch die Häufigkeit des Auftretens von Pneumonieerregern mit bestimmten Antibiotikaresistenzen ist starken regionalen Schwankungen unterworfen, unterscheidet sich von Krankenhaus zu Krankenhaus und auch innerhalb eines Krankenhauses von Abteilung zu Abteilung. Das Vorhandensein einer lokalen Resistenzstatistik möglichst auf 
Tab.10 PK/PD-Studien mit signifikanten Unterschieden bei klinischen Ergebnis-Variablen. Cl: kontinuierliche Infusion; IB (intermittent bolus): Kurzzeitinfusion. PI: prolongierte Infusion. LOS: Length of stay, MV: Mechanische Ventilation.

\begin{tabular}{|c|c|c|c|c|c|c|c|}
\hline Antibiotikum & Dosierungschema & Patienten & Design & Variable & $\mathrm{Cl}(\mathrm{PI})$ & IB & $\mathbf{p}$ \\
\hline Ceftriaxon [79] & $\begin{array}{l}\mathrm{Cl}: 2 \mathrm{~g} / \mathrm{d} \text { über } 24 \mathrm{~h} \\
\text { IB: } 2 \mathrm{~g} \text { als Bolus alle } 24 \mathrm{~h}\end{array}$ & Sepsis $(n=57)$ & RCT & klinische Heilung (\%) & 52 & 20 & $<0,04$ \\
\hline $\begin{array}{l}\text { Piperacillin/Tazobactam } \\
\text { [80] }\end{array}$ & & $\begin{array}{l}\text { Gram-negative VAP } \\
(n=83)\end{array}$ & $\begin{array}{l}\text { retrospektive } \\
\text { Kohorte }\end{array}$ & klinische Heilung (\%) & 89 & 57 & 0,001 \\
\hline $\begin{array}{l}\text { Piperacillin/Tazobactam } \\
\text { [81] }\end{array}$ & $\begin{array}{l}\mathrm{Cl}(\mathrm{PI}): 3.375 \mathrm{~g} \text { über } 4 \mathrm{~h} \\
\text { alle } 8 \mathrm{~h} \\
\mathrm{IB}: 3.375 \mathrm{~g} \text { über } 30 \mathrm{~min} \\
\text { alle } 4-6 \mathrm{~h}\end{array}$ & $\begin{array}{l}\text { Intensivpatienten } \\
\text { mit } P \text {. aeruginosa- } \\
\text { Infektionen }(n=194)\end{array}$ & $\begin{array}{l}\text { retrospektive } \\
\text { Kohorte }\end{array}$ & $\begin{array}{l}\text { Letalität (\%) } \\
\text { Krankenhaus LOS (d) }\end{array}$ & $\begin{array}{l}12 \\
21\end{array}$ & $\begin{array}{l}32 \\
38\end{array}$ & $\begin{array}{l}0,04 \\
0,02\end{array}$ \\
\hline Ceftazidim [82] & $\begin{array}{l}\mathrm{Cl}: 3 \mathrm{~g} \text { über } 24 \mathrm{~h} \\
\mathrm{IB}: 2 \mathrm{~g} \text { alle } 8 \mathrm{~h}\end{array}$ & $\begin{array}{l}\text { Intensivpatienten } \\
\text { mit HAP }(n=35)\end{array}$ & RCT & $\begin{array}{l}\text { klinische Heilung (\%) } \\
\text { Dauer MV (d) } \\
\text { Aufenthalt auf ICU (d) } \\
\text { Dauer des Fiebers (d) }\end{array}$ & $\begin{array}{l}41 \\
7,9 \pm 4,0 \\
8,5 \pm 3,4 \\
3,5 \pm 2,1\end{array}$ & $\begin{array}{l}33 \\
8,3 \pm 4,3 \\
9,3 \pm 4,0 \\
5,2 \pm 4,3\end{array}$ & $\begin{array}{l}\text { NS } \\
\text { NS } \\
\text { NS } \\
0,0015\end{array}$ \\
\hline Meropenem [83] & $\begin{array}{l}\text { Cl: } 1 \mathrm{~g} \text { über } 6 \mathrm{~h} \\
\text { alle } 6 \mathrm{~h} \\
\text { IB: } 1 \mathrm{~g} \text { über } 30 \mathrm{~min} \\
\text { alle } 6 \mathrm{~h}\end{array}$ & $\begin{array}{l}\text { Gram-negative VAP } \\
(n=99)\end{array}$ & $\begin{array}{l}\text { retrospektive } \\
\text { Kohorte }\end{array}$ & klinische Heilung (\%) & 90 & 60 & 0,001 \\
\hline
\end{tabular}

Abteilungsebene ist daher neben einer kompetenten Bewertung individueller Risikofaktoren für die Auswahl einer kalkulierten Antibiotikatherapie von überragender Bedeutung.

In der Leitliniengruppe besteht Konsens darüber, dass in Abständen von 6-12 Monaten das Erregerspektrum und die Resistenzsituation der jeweiligen Station/Einrichtung erhoben und so dargestellt werden sollte, dass diese Daten für Entscheidungen zur kalkulierten Antibiotikatherapie herangezogen werden können. Die Erhebung erfolgt idealerweise bezogen auf die bei HAP nachgewiesenen Erreger, mindestens aber auf solche, die in Atemwegsmaterialien nachgewiesen wurden.

\section{Antiinfektiva}

\subsection{Aminopenicilline mit Betalaktamaseinhibitor}

Zwei verschiedene Kombinationspräparate sind erhältlich, Amoxicillin/Clavulansäure und Ampicillin/Sulbactam. Aminopenicilline sind wirksam gegenüber Streptokokken incl. Pneumokokken sowie gegenüber $H$. influenzae. Vorteil der mit einem Betalaktamase-Inhibitor geschützten Substanzen gegenüber Ampicillin ist das um M. catarrhalis, Klebsiella spp., S. aureus und viele Anaerobier erweiterte Spektrum; die gelegentlich auftretenden Betalaktamase-positiven Haemophilus spp. werden ebenfalls erfasst. $\mathrm{Zu}$ den Nebenwirkungen beider Substanzen gehören gastrointestinale Störungen. Bei Amoxicillin/Clavulansäure wurden Fälle von irreversiblem Leberversagen beschrieben, die sehr wahrscheinlich auf den Clavulansäureanteil zurückzuführen sind. Auch bei Ampicillin/Sulbactam wurden intrahepatische Cholestasen, selten auch Thrombopenie, Leukopenie und Anämie (reversibel) beschrieben. Darüber hinaus sollte an die erhöhte Kaliumzufuhr gedacht werden. Bei beiden Substanzen wird daher eine Kontrolle von Blutbild, Serum-Kreatinin und Leberfunktionsparametern bei längerer Anwendung empfohlen.

\subsection{Ureidopenicilline mit Betalaktamaseinhibitor}

Hierzu gehört Piperacillin/Tazobactam, das klinisch bei HAP gut untersucht ist und eine gute bis sehr gute Aktivität gegenüber $P$. aeruginosa besitzt. Das Wirkspektrum von Piperacillin ähnelt dem der Aminopenicilline, obwohl die In-vitro-Aktivität gegenüber Enterobacteriaceae höher ist. In Kombination mit Sulbactam oder Tazobactam erweitert sich das Wirkspektrum und umfasst zusätzlich eine Reihe Ampicillin-resistenter Enterobacteriaceae, S. aureus (geringere Aktivität als Ampicillin/Sulbactam) und zahlreiche Anaerobier; die Aktivität gegenüber P. aeruginosa ist jedoch nur unwesentlich verbessert. Bei Nachweis AmpC-Betalaktamase-bildender Enterobacteriaceae wie Enterobacter spp., Citrobacter spp., Serratia spp.u.a. ist eine Monotherapie mit Piperacillin/Tazobactam wegen einer Resistenzentwicklung unter Therapie nicht empfehlenswert.

Der als freier Kombinationspartner angebotene Betalaktamaseinhibitor Sulbactam hat mit Piperacillin in vitro eine deutlich geringere Wirksamkeit gegen Enterobacteriaceae als Piperacillin/ Tazobactam; eine Übertragbarkeit der In-vitro-Testergebnisse für Piperacillin/Tazobactam auf Piperacillin/Sulbactam ist daher für Enterobacteriaceae nicht zulässig. Die fixe Kombination mit Tazobactam ist gut untersucht, die Dosierung beträgt 3-4×4,5g. Die Nebenwirkungen sind denen der Aminopenicilline vergleichbar. Piperacillin/Tazobactam ist für die intermittierende Gabe mit verlängerter Infusionsdauer (vier Stunden) und auch als kontinuierliche Infusion untersucht $(\bullet$ Tab. 10).

\subsection{Cephalosporine}

Zu den bei HAP klinisch gut untersuchten Substanzen gehören aus der Gruppe 3a (Drittgenerationscephalosporine der Cefotaxim-Gruppe) Ceftriaxon und Cefotaxim, aus der Gruppe der pseudomonaswirksamen Substanzen Ceftazidim und Cefepim. Ceftriaxon und Cefotaxim haben ein breites Wirkungsspektrum mit ausgeprägter Aktivität gegenüber Gram-negativen Bakterien. Durch die Ausbreitung von ESBL-bildenden Enterobacteriaceae, die auch die Drittgenerationscephalosporine inaktivieren, haben die Substanzen an Bedeutung beim Einsatz gegen diese Erreger verloren. Cefotaxim und Ceftriaxon sind in vitro wirksamer als Cefuroxim gegen $H$. influenzae., M. catarrhalis, Klebsiella spp. und gegen S. pneumoniae. Dies gilt auch für Pneumokokken mit intermediärer Sensitivität gegenüber Penicillin. Penicillinresistente Pneumokokken sind dagegen noch in etwa 90-95\% empfindlich bzw. intermediär empfindlich gegenüber Ceftriaxon und Cefotaxim (MHK $\leq 2 \mathrm{mg} / \mathrm{L}$ ). Die Aktivität der Cephalosporine der Gruppe 3a gegenüber Staphylokokken ist dagegen wesentlich geringer als die der Cephalosporine der 1. oder 2. Generation. Für die Behandlung von Staphylokokkeninfektionen sind diese Substanzen daher nicht geeignet. 
Zu den Cephalosporinen mit Wirksamkeit gegen P. aeruginosa gehören Ceftazidim und Cefepim. Die Aktivität von Ceftazidim wie auch von Cefepim gegenüber Staphylokokken (mittlere MHK-Werte um $2 \mu \mathrm{g} / \mathrm{ml}$ ) ist ähnlich wie die der Cefotaxim-Gruppe unzureichend. Die Aktivität von Ceftazidim gegenüber Pneumokokken (mittlere MHK-Werte um $0.25 \mathrm{mg} / \mathrm{l}$ ) ist etwas geringer als die von Cefepim (mittlere MHK-Werte um $0.125 \mathrm{mg} / \mathrm{l}$ ) und ist der Aktivität von Ceftriaxon/Cefotaxim (mittlere MHK-Werte $<0.05 \mathrm{mg} / \mathrm{l}$ ) unterlegen. Ceftazidim ist daher für die kalkulierte Monotherapie der HAP nicht geeignet. Zum Einsatz von Cefepim bei schweren Infektionen besteht eine kontroverse Diskussion aufgrund von Metaanalysen, die eine Übersterblichkeit bei Therapie mit dieser Substanz fanden [59] bzw. nicht bestätigen konnten [60*]. Die Verfügbarkeit von Cefepim in Deutschland ist limitiert.

Ceftriaxon und Cefotaxim unterscheiden sich durch ihre Halbwertszeit, die bei Cefotaxim ca. eine Stunde beträgt und bei Ceftriaxon mit acht Stunden wesentlich länger ist. Für die kalkulierte Initialtherapie wird eine Tagesdosis von $1 \times 2 \mathrm{~g}$ Ceftriaxon empfohlen. Bei der sehr kurzen Halbwertszeit von Cefotaxim werden Einzeldosen von $2 \mathrm{~g}$ und ein Dosierungsintervall von höchstens acht Stunden empfohlen. Auch Ceftazidim und Cefepim werden bei schweren Infektionen in einer Dosis von $3 \times 2 \mathrm{~g}$ täglich verabreicht. Ceftriaxon wird überwiegend biliär eliminiert, während Cefotaxim, Ceftazidim und Cefepim nahezu vollständig renal ausgeschieden werden. Ihre Dosis muss an die Nierenfunktion angepasst werden. Häufige Nebenwirkungen betreffen gastrointestinale Symptome, Exantheme und Reaktionen an der Injektionsstelle. Für alle aufgeführten Cephalosporine wurde ein erhöhtes Risiko für das Auftreten von Diarrhöen durch Clostridium difficile beschrieben. Cefepim ist bei hohen Tagesdosen und eingeschränkter Nierenfunktion mit Neurotoxizität assoziiert.

\subsection{Carbapeneme}

Carbapeneme besitzen ein breites antimikrobielles Spektrum und sind wirksam gegenüber Gram-positiven und Gram-negativen Bakterien einschließlich ESBL-Bildnern und Anaerobiern. Sie haben eine Wirkungslücke (Primärresistenz) gegenüber S. maltophilia, MRSA und E. faecium. Zur Gruppe der pseudomonaswirksamen Substanzen zählen Imipenem/Cilastatin, Meropenem und Doripenem; Ertapenem ist bei sonst vergleichbarer Aktivität gegenüber Gram-positiven und Gram-negativen Bakterien unwirksam gegenüber P. aeruginosa und A. baumannii. Die MHK-Werte bei Gram-negativen Bakterien liegen für Meropenem um etwa zwei Verdünnungsstufen niedriger als für Imipenem; bei beiden Substanzen ist die Aktivität gegen $P$. aeruginosa relativ gering; die MHK-Werte gruppieren sich um 0,5 (Meropenem) oder $1 \mathrm{mg} / \mathrm{l}$ (Imipenem), die klinische Aktivität ist jedoch meist ausreichend. Die Aktivität von Meropenem bei Streptokokken, Staphylokokken und A. baumannii ist geringer als die des Imipenems. Doripenem ist eine relativ neue Substanz mit etwas höherer In-vitroAktivität gegenüber $P$. aeruginosa im Vergleich zu Meropenem und gegenüber E. coli im Vergleich zu Imipenem.

Die Halbwertszeit bei nierengesunden Patienten liegt bei den Carbapenemen bei ca. einer Stunde mit Ausnahme von Ertapenem, dessen Halbwertszeit (HWZ) ca. vier Stunden ausmacht. Die Ausscheidung erfolgt bei allen Substanzen überwiegend renal. Ertapenem wird einmal täglich in einer Dosis von $1 \mathrm{~g}$ intravenös infundiert. Imipenem und Meropenem werden dreimal täglich in einer Dosis von $1 \mathrm{~g}$, Doripenem mit dreimal 0,5-1 g appliziert, wobei Meropenem auch als Bolus verabreicht werden kann und bei Doripenem eine verlängerte Infusionsdauer von vier Stunden untersucht und zugelassen wurde.

Übelkeit und Erbrechen bei ca. 3-4\% der Patienten sowie Diarrhöen in einer ähnlichen Frequenz sind die häufigsten unerwünschten Wirkungen der Carbapeneme. In seltenen Fällen, insbesondere nach Überdosierung bei Niereninsuffizienz, wurden unter der Therapie mit Imipenem, seltener auch mit anderen Carbapenemen, Krampfanfälle gesehen. Bei gleichzeitiger Gabe von Valproinsäure mit Carbapenemen kann die Plasmakonzentrationen des Antiepileptikums deutlich reduziert sein, sodass es auch dadurch zu Krampfanfällen kommen kann.

\subsection{Fluorchinolone}

Für die Behandlung der HAP sind die Fluorchinolone Ciprofloxacin, Levofloxacin und Moxifloxacin von Bedeutung. Alle Substanzen sind hochaktiv gegen $H$. influenzae, $M$. catarrhalis und häufig auch gegen Enterobacteriaceae einschließlich Klebsiella spp. Die Aktivität gegenüber Legionellen ist besser (MHK90-Werte 0,06 $\mathrm{mg} / \mathrm{l}$ ) als die von Clarithromycin; auch in Zellkulturmodellen wirken sie besser als Makrolide. Ein Argument für die Wahl dieser Substanzen als Kombinationspartner bei HAP kann daher die Spektrumserweiterung gegenüber Legionellen darstellen.

Zu unterscheiden sind Substanzen mit Pneumokokkenaktivität (Moxifloxacin, Levofloxacin) und Substanzen mit Pseudomonasaktivität (Ciprofloxacin, Levofloxacin). Die In-vitro-Aktivität von Moxifloxacin gegenüber S.pneumoniae ist stärker als die von Levofloxacin. Die mittleren MHK90-Werte betragen für Moxifloxacin $\sim 0,125 \mathrm{mg} / \mathrm{l}$ und für Levofloxacin $0,5-1 \mathrm{mg} / \mathrm{l}$. Unter Berücksichtigung pharmakokinetisch-pharmakodynamischer Eigenschaften sind beide Präparate bei Pneumokokkeninfektionen als ähnlich effektiv zu betrachten.

Das Wirkspektrum von Moxifloxacin umfasst auch Anaerobier. Im Unterschied zu Moxifloxacin kann Levofloxacin in der bei HAP untersuchten höheren Dosis von $2 \times 500 \mathrm{mg}$ als für fluorchinolonempfindliche $P$. aeruginosa klinisch ausreichend wirksam betrachtet werden. Bei gesicherter Pseudomonasinfektion sollte allerdings auf Ciprofloxacin gewechselt werden, das eine bessere Wirkung gegenüber $P$. aeruginosa zeigt.

Ciprofloxacin wird aufgrund seiner schwachen Wirkung gegenüber S. pneumoniae (mittlere MHK-Werte 1-2 mg/L) nicht für die kalkulierte Therapie von Infektionen mit Pneumokokken als möglichem Erreger empfohlen (early-onset HAP). Ferner weist die Substanz eine schwächere Wirksamkeit gegen Staphylokokken auf. Dagegen kann es als Kombinationspartner bei VAP mit erhöhtem Risiko von MRE eingesetzt werden. Allerdings muss bei der Auswahl der kalkulierten Therapie beachtet werden, dass Resistenzen wichtiger Enterobacteriaceae wie E. coli oder Klebsiella spp. gegenüber allen Fluorchinolonen in den letzten zehn Jahren deutlich zugenommen haben.

Die Konzentrationen der Fluorchinolone sind aufgrund ihrer guten Gewebegängigkeit in der bronchoalveolären Epithelflüssigkeit deutlich höher als die Serumkonzentrationen. Die Verteilungsvolumina betragen $\sim 1,2 \mathrm{l} / \mathrm{kg}$ (Levofloxacin) bzw. $\sim 2,5 \mathrm{l} / \mathrm{kg}$ (Moxifloxacin). Die Elimination von Levofloxacin erfolgt fast ausschließlich renal und ist daher von der Nierenfunktion abhängig. Moxifloxacin dagegen wird mit einer Halbwertszeit von etwa 13 Stunden überwiegend hepatisch eliminiert und wird unabhängig von der Nierenfunktion mit $1 \times 400 \mathrm{mg} / \mathrm{d}$ dosiert. Nur etwa $20 \%$ lassen sich unverändert im Urin nachweisen. Da der Metabolismus der Substanz unabhängig von der Aktivität hepatischer Monooxygenasen ist, sind entsprechende Interaktionen nicht zu 
erwarten. Die in klinischen Studien getestete Dosierung von Ciprofloxacin bei HAP beträgt $3 \times 400 \mathrm{mg}$ parenteral.

Häufigste unerwünschte Wirkungen der Fluorchinolone sind gastrointestinale Störungen (Übelkeit, Diarrhö, Erbrechen, Bauchschmerzen) sowie Leberfunktionsstörungen. Es sind Fälle von tödlicher Hepatitis im Zusammenhang mit Moxifloxacin berichtet worden, die die Indikation der Substanz bei ambulant erworbenen Atemwegsinfektionen eingeschränkt haben. Für alle Fluorchinolone wurde ein erhöhtes Risiko für das Auftreten von Diarrhöen durch $C$. difficile beschrieben. Gelegentliche bis seltene Nebenwirkungen aller Fluorchinolone sind eine Verlängerung der QTc-Zeit im EKG sowie schmerzhafte Sehnenentzündungen (incl. der seltenen Sehnenruptur, meist bei längerer Anwendung), ZNS-Reaktionen wie Krampfanfälle, Erregungszustände, Verwirrtheit und Halluzinationen, Sehstörungen, Hautreaktionen und Hyperglykämie oder Hypoglykämie. Vorsicht ist geboten bei Hypokaliämie, erworbener QTc-Intervall-Verlängerung, Bradykardie und schwerer Herzinsuffizienz, symptomatischen Herzrhythmusstörungen sowie gleichzeitiger Anwendung von Antiarrhythmika und anderen Arzneimitteln, die das QTc-Intervall verlängern.

\subsection{Aminoglykoside}

Gut untersucht als Kombinationspartner bei schweren Infektionen sind Gentamicin, Tobramycin und Amikacin. Die Substanzen zeigen eine gute Wirkung gegen viele Enterobacteriaceae und gegen $P$. aeruginosa. Ihre Wirkung gegenüber Gram-positiven Bakterien ist weniger ausgeprägt. Unzureichend ist die Aktivität bei Streptokokken und Pneumokokken. Die Konzentrationen im pulmonalen Kompartiment sind nach systemischer Applikation niedrig. Eine Monotherapie mit Aminoglykosiden ist daher nicht indiziert. In der Kombinationstherapie sollten bei pulmonalen Infektionen hohe Einzeldosen bei einmal täglicher Applikation über eine Stunde gewählt werden, um ausreichende Konzentrationen im Alveolarfilm zu erzielen. Aminoglykoside werden renal ausgeschieden. Die Halbwertszeit liegt bei nierengesunden Patienten bei ca. zwei Stunden; bei Patienten mit eingeschränkter Nierenfunktion kann sich die HWZ beträchtlich verlängern. Ein therapeutisches Drug-Monitoring ist erforderlich. Die Dosierung der Aminoglykoside muss an die Nierenfunktion angepasst werden. Talspiegelmessungen zur eventuellen Dosisanpassung sind ab dem dritten Behandlungstag sinnvoll und können Überdosierungen vermeiden helfen. Innerhalb eines 24-Stunden-Dosierungsintervalls werden als therapeutische Zielbereiche Talkonzentrationen von $<1 \mathrm{mg} / \mathrm{l}$ für Gentamicin und Tobramycin und $<5 \mathrm{mg} / \mathrm{l}$ für Amikacin angestrebt. Pharmakologische und klinische Daten sprechen überwiegend dafür, dass durch die tägliche Einmaldosierung bei verbesserter Wirkung das Nebenwirkungsrisiko gesenkt werden kann. Während die zugelassenen Tagesdosen von Gentamicin und Tobramycin bei $3-6 \mathrm{mg} / \mathrm{kg} / \mathrm{d}$ liegen, werden diese Substanzen in der Therapie schwerer Infektionen auch in höheren Dosierungen von $5-7 \mathrm{mg} / \mathrm{kg} / \mathrm{d}$ bei einmal täglicher Applikation eingesetzt. Die Tagesdosis von Amikacin liegt bei normaler Nierenfunktion bei $15-20 \mathrm{mg} / \mathrm{kg} / \mathrm{d}$.

Bei den unerwünschten Wirkungen ist besondere Aufmerksamkeit hinsichtlich der Nephrotoxizität, der Oto- und Vestibulotoxizität und der Hemmung der neuromuskulären Übertragung geboten. Vorschädigungen dieser Organsysteme sollten zu zurückhaltendem Einsatz der Aminoglykoside führen, auch sollte die gleichzeitige Gabe weiterer nephrotoxischer Substanzen vermieden werden. Selten werden schwere Bronchospasmen und anaphylaktoide Reaktionen beobachtet. Im Rahmen der heute üblichen Deeskalationskonzepte werden die ausschließlich in Kombination eingesetzten Aminoglykoside bei klinischem Ansprechen und/oder Nachweis eines auf den Kombinationspartner empfindlichen Erregers nach wenigen Tagen abgesetzt, wodurch das Nebenwirkungsrisiko reduziert wird.

Die inhalative adjunktive Therapie mit Aminoglykosiden wird mit Gentamicin, Amikacin oder Tobramycin durchgeführt. Die Dosierungen sind nicht standardisiert. Für die Anwendung von invasiv beatmeten Patienten wurde u.a. Tobramycin in einer Dosis von $2 \times 200 \mathrm{mg} / \mathrm{d}$ geprüft. Für die Verneblung mit einem Ultraschallvernebler wurde die Substanz mit $\mathrm{NaCl}(0,9 \%)$ auf $10 \mathrm{ml}$ aufgefüllt. Mit diesem Vorgehen ergaben sich bereits erhöhte Serumspiegel bei Patienten mit Niereninsuffizienz [61]. Bisher gibt es keine prospektiven randomisierten Studien, die einen Nutzen der zusätzlichen Gabe von vernebelten Aminoglykosiden bei der VAP belegen und die Art und Weise der Verneblung ist nicht geprüft und/oder standardisiert.

\subsection{Makrolide}

Makrolide haben eine gute Wirkung gegenüber Mykoplasmen, Chlamydien und Legionellen sowie gegenüber Streptokokken. In Deutschland sind neben Erythromycin auch Clarithromycin und Azithromycin zur parenteralen Anwendung verfügbar. Diese Substanzen zeichnen sich im Vergleich zu Erythromycin durch vermehrte Säurestabilität und bessere orale Bioverfügbarkeit aus, teilweise auch durch ein geringeres Potenzial zu Arzneimittel-Interaktionen. Die zeitweise hohen Resistenzraten gegenüber Pneumokokken waren in den letzten Jahren rückläufig. Die Aktivität der „neueren“ Makrolide gegenüber H. influenzae ist mäßig, bei Clarithromycin oft im MHK-Bereich 8-16 mg/l, und die klinische Wirkung entsprechend unsicher. Im Fall von Clarithromycin wirkt in vivo zusätzlich der 14-OH-Metabolit. Die In-vitro-Aktivität von Azithromycin ist vergleichsweise stärker (MHK-Werte $1-2 \mathrm{mg} / \mathrm{l}$ ). Sie wird aber hinsichtlich der klinischen Wirksamkeit ebenfalls nicht als ausreichend betrachtet. Gegenüber Legionella spp. ist Clarithromycin die in vitro wirksamste Substanz $\left(\mathrm{MHK}_{90}\right.$ $\leq 0,004 \mathrm{mg} / \mathrm{l}$ ). Die MHK-Werte von Erythromycin und Azithromycin sind höher $\left(\mathrm{MHK}_{90}\right.$-Werte $\sim 0,125 \mathrm{mg} / \mathrm{l}$ ). Die Wirkung von Clarithromycin auf intrazelluläre Legionellen scheint allerdings nicht besser als die der anderen Makrolide zu sein und ist der Fluorchinolonwirkung unterlegen.

Makrolide werden bei HAP als Kombinationspartner eingesetzt, wenn eine Infektion mit Legionellen, Mykoplasmen oder Chlamydien vermutet wird und Fluorchinolone nicht gegeben werden können. Darüber hinaus wird eine Kombinationstherapie mit Nutzung der antiinflammatorischen Wirkung der Makrolide ähnlich wie bei der schweren ambulant erworbenen Pneumonie diskutiert; hierfür reicht die bisherige Evidenz [62] allerdings nicht aus. Nach Infusion von $1 \mathrm{~g}$ Erythromycin über eine Stunde beträgt die Halbwertszeit zwei Stunden; das empfohlene Dosierungsintervall ist sechs bis acht Stunden. Das Verteilungsvolumen ist $\sim 0,71 / \mathrm{kg}$. Das Verteilungsvolumen von Clarithromycin ist größer, das von Azithromycin mit 23 bis 31 1/kg erheblich größer. Relativ niedrige Serumspiegel dieser Substanzen bei sehr hohen Gewebespiegeln sind die Folge. Die Halbwertszeit von Clarithromycin beträgt $\sim$ drei bis vier Stunden. Charakteristisch für Azithromycin sind die sehr lange Eliminationshalbwertzeit von etwa 20 bis 40 Stunden und die hohen Konzentrationen im Gewebe. Die infolge der langen Halbwertszeit vorkommenden subinhibitorischen Wirkstoffkonzentrationen sind mit einer vermehrten Resistenzselektion bei S. pneumoniae assoziiert worden. 
Die Makrolide werden in der Leber metabolisiert und vorzugsweise biliär ausgeschieden.

Bei allen Substanzen stehen gastrointestinale Beschwerden mit Motilitätssteigerung als unerwünschte Wirkungen im Vordergrund. Im Vergleich zu Erythromycin sind diese unerwünschten Wirkungen bei den neueren Makroliden seltener. Selten kann es zu ZNS-Reaktionen oder Hautreaktionen kommen. Die Venenverträglichkeit bei intravenöser Gabe von Erythromycin und Clarithromycin ist schlecht. Alle Makrolide können eine Verlängerung der QTc-Zeit im EKG verursachen. Vorsicht ist geboten bei Patienten mit koronarer Herzkrankheit, bekannten ventrikulären Arrhythmien, Hypokaliämie, Bradykardie oder gleichzeitiger Anwendung von anderen Substanzen, die die QTc-Zeit verlängern.

\subsection{Glykopeptide}

Glykopeptide sind unwirksam gegenüber allen klinisch relevanten Gram-negativen Bakterien. Aufgrund ihres schmalen Wirkungsspektrums, ihrer klinisch relevanten Toxizität und einer limitierten Gewebegängigkeit gewannen Vancomycin und Teicoplanin erst mit der MRSA-Epidemie an Bedeutung. Fast alle Gram-positiven Bakterien einschließlich MRSA und Penicillin-resistenter Pneumokokken sind gegenüber Glykopeptiden empfindlich. Sie wirken zeitabhängig, d.h. die antibakterielle Wirkung ist abhängig von der Dauer des Serumspiegels oberhalb der MHK der Zielerreger, nicht vom Serumspitzenspiegel. In der Pneumoniebehandlung beschränkt sich ihr Einsatz auf Infektionen durch MRSA-Stämme und auf Fälle, bei denen wegen Allergie kein anderes Antibiotikum eingesetzt werden kann. S. aureus-Pneumonien durch Methicillin-sensible Stämme werden nicht mit Glykopeptiden therapiert, da diese geeigneten Penicillinen in den klinischen Endpunkten unterlegen sind [63].

Vancomycin wird intravenös verabreicht, da es nicht im relevanten Umfang enteral resorbiert wird; die Elimination erfolgt renal. Die Serumhalbwertzeit von Vancomycin beträgt ca. sechs Stunden. Der Talspiegel sollte bei schweren Infektionen auf etwa 15 $\mathrm{mg} / \mathrm{l}$ eingestellt werden. Zwei Varianten der Applikation von Vancomycin können empfohlen werden: 1.) Die Infusion über 1 -2 Stunden von initial $1 \mathrm{~g}$ ( $15 \mathrm{mg} / \mathrm{kg}$ Körpergewicht) im Intervall von 12 Stunden mit nachfolgender Anpassung der Einzeldosis zur Erzielung des erwünschten Talspiegels und 2.) die kontinuierliche Infusion mit Einstellung des Steady-state-Spiegels auf ca. $20 \mathrm{mg} / \mathrm{l}$. Bei Vorliegen einer Niereninsuffizienz sind Messungen des Talspiegels zur Dosissteuerung obligat. Die Regeldosis beträgt unter diesen Umständen $15 \mathrm{mg} / \mathrm{ml}$ glomeruläre Filtrationsrate $(\mathrm{ml} / \mathrm{min}) / \mathrm{d}$. Der Einsatz alternativer Antiinfektiva ist dann zu erwägen. Die Nephrotoxizität von Vancomycin wurde zunächst als hoch eingeschätzt. Sie war jedoch teilweise durch Verunreinigung der frühen Formulierung des Medikamentes bedingt. Es ist aktuell mit einer Vancomycin-induzierten Nephrotoxizität von $5-7 \%$ zu rechnen. Eine Ototoxizität wird bei hohen Serumspiegeln ab $80 \mathrm{mg} / \mathrm{l}$ beobachtet. Im Rahmen der empfohlenen therapeutischen Spiegel kommt sie selten vor. Bei Unterschreiten der empfohlenen Infusionszeit von mindestens $60 \mathrm{Mi}-$ nuten der verdünnten Lösung kann es zu Schmerzen, Thrombophlebitis und einer Erythrodermie („red man syndrome“) kommen.

Teicoplanin zeichnet sich durch eine Serumhalbwertzeit von 70 -100 Stunden aus. Seine Dosierung beträgt am ersten Tag $400 \mathrm{mg}$ im Abstand von 12 Stunden, danach 6 - 12 mg/kg Körpergewicht alle 24 Stunden.

\subsection{Oxazolidinone}

Die neue Klasse der Oxazolidinone (in Deutschland verfügbar: Linezolid p.o. und i.v.) wurde in erster Linie zur Behandlung von MRSA-Infektionen entwickelt. Linezolid ist aktiv gegenüber den meisten aeroben Gram-positiven Kokken. Die orale Bioverfügbarkeit ist sehr hoch. Die Halbwertszeit beträgt fünf bis sieben Stunden, die Substanz wird in Form der Hauptmetaboliten vorwiegend über die Niere eliminiert. Die Dosis beträgt $2 \times 600 \mathrm{mg} / \mathrm{d}$, eine Dosisanpassung bei eingeschränkter Nierenfunktion ist nicht notwendig. Bei den unerwünschten Wirkungen stehen gastrointestinale Beschwerden, teils lang anhaltende Neuropathien (incl. den Sehnerv betreffend) und Myelosuppression im Vordergrund. Blutbildveränderungen wurden v.a. bei längerer Behandlungsdauer gesehen. Aufgrund dieser Nebenwirkung sind wöchentliche Blutbildkontrollen während einer Therapie angezeigt; eine Therapiebegrenzung auf maximal 28 Tage wird empfohlen. Linezolid ist ein Hemmstoff der Monaminoxidase. Aufgrund dieser Wirkung können Interaktionen mit Sympathomimetika und anderen Arzneimitteln vorkommen. Die gleichzeitige Einnahme übermäßiger Mengen tyraminhaltiger Lebensmittel (z.B. Sojasoße, reifer Käse) sollte vermieden werden. Im Tierversuch wurde eine verminderte Fertilität beobachtet; mögliche Auswirkungen auf die reproduktiven Organe beim Menschen sind nicht bekannt.

\subsection{Colistin}

Colistin (Polymyxin E) ist ein kationisches zyklisches PolypeptidAntibiotikum aus der Familie der Polymyxine mit vernachlässigbarer Resorption nach oraler Gabe. Nach der Erstzulassung im Jahr 1959 wurde eine erhebliche Nephrotoxizität beobachtet, die seine Verwendung über lange Zeit stark einschränkte. Deshalb sind viele pharmakologische und klinische Eigenschaften noch unbekannt. Colistin wirkt ausschließlich gegenüber Gramnegativen Bakterien mit Ausnahme von Proteus spp., Providencia spp., Serratia spp., Burkholderia spp. und vielen Stämmen von S. maltophilia. Gegenüber Gram-positiven Kokken zeigt Colistin keine Wirksamkeit. Colistin wirkt konzentrationsabhängig rasch, aber nicht lang anhaltend, durch Destabilisierung der bakteriellen Zellmembran (Interaktion mit $\mathrm{Ca}^{2+}$ und $\mathrm{Mg}^{2+}$-Ionen und Phospholipiden).

Der Einsatz von Colistin in der systemischen Therapie ist auf schwere Infektionen durch multiresistente Stämme von P. aeruginosa, A. baumannii und Carbapenem-resistente Enterobakterien beschränkt. Allerdings ist die klinische Wirksamkeit bei Pneumonien durch multiresistente Gram-negative Erreger nur in kleinen Fallserien belegt, die meisten Studien wurden in Kombinationstherapie mit Carbapenemen, Tetracyclinen, Tigecyclin, Rifampicin u. a. durchgeführt.

Die optimale Dosierung von Colistin in der parenteralen Therapie ist nicht bekannt [64*]. Es existieren verschiedene Formulierungen mit unterschiedlichen Dosierungsempfehlungen; sie sind in Deutschland zur parenteralen Therapie nicht zugelassen. Die aus dem europäischen Ausland über internationale Apotheken erhältlichen Formulierungen beinhalten Colistinmethylsulfonat, das in Milligramm und in internationalen Einheiten (IE) angegeben wird. $1 \mathrm{mg}$ Colistinmethylsulfonat (CMS) entspricht 12500 IE; die in den USA übliche Dosisberechnung anhand der reinen Colistinbase sollte nicht genutzt werden, um Verwechslungen und Fehldosierungen zu vermeiden. Die empfohlene maximale Tagesdosis von CMS für nierengesunde Erwachsene divergiert bei den unterschiedlichen Herstellern erheblich in einem Bereich zwischen $480 \mathrm{mg}$ und $720 \mathrm{mg}$, entsprechend 6-9 Mio IE, verteilt 
auf zwei bis drei Einzeldosen. Die damit erreichbaren Serumkonzentrationen liegen nur gering über der MHK der als empfindlich $(\leq 2 \mathrm{mg} / \mathrm{ml}$ ) geltenden Erreger. Die Elimination erfolgt renal. Bei Nierengesunden treten abhängig von der Definition der Nephrotoxizität in $8 \%$ bis $37 \%$ Störungen der Nierenfunktion unter der Therapie auf $[65,66,67]$. Bei vorbestehender Niereninsuffizienz verschlechtert sich diese in über $30 \%$ der Patienten [68]. Eine tägliche Kontrolle der Nierenfunktion ist deshalb notwendig; die Dosis ist bei Niereninsuffizienz zu reduzieren, eine gleichzeitige Gabe nephrotoxischer Medikamente sollte vermieden werden. Neurotoxische Effekte wurden in Einzelfällen ebenfalls beschrieben. Unklar ist die Notwendigkeit der in Schweden als Standard empfohlenen initialen Loading dose in Höhe von einmalig $720 \mathrm{mg}$ entsprechend 9 Mill. IE. Nach neueren Daten ist damit keine erhöhte Nephrotoxizität verbunden.

Für die inhalative adjunktive Applikation von Colistin existieren keine randomisierten Studien zur Dosisfindung bei intubierten Patienten mit Pneumonie. Die Vorgehensweisen sind denen von Patienten mit Zystischer Fibrose entlehnt [69]. Es wurden Dosierungen von 2-6 Mill. IU entsprechend $160 \mathrm{mg}-480 \mathrm{mg}$, aufgeteilt auf zwei bis drei Gaben, angewendet. Bei Patienten mit einem Körpergewicht von weniger als $50 \mathrm{Kg}$ und/oder Niereninsuffizienz (Serumkreatinin $>2 \mathrm{mg} / \mathrm{dl}$ ) wurden 1,5 Mill. IU, aufgeteilt auf drei Dosierungen, verwendet [70].

\subsection{Cotrimoxazol}

Cotrimoxazol spielt im Indikationsbereich der schweren nosokomialen Infektionen heute nur noch bei der gezielten Therapie von Infektionen mit $S$. maltophilia eine Rolle. Die Dosierung beträgt $2-3 \times 960 \mathrm{mg}$, bei Niereninsuffizienz ist eine Dosisreduktion erforderlich. Die Substanz sollte bei parenteraler Gabe durch einen weitlumigen venösen Zugang appliziert werden. Eine Sulfonamidallergie sollte ausgeschlossen sein und auf Nephrotoxizität, Hyperkaliämie, Lebertoxizität, Leuko- und Thrombozytopenie sollte geachtet werden.

\subsection{Tigecyclin}

Tigecyclin ist ein Glycylcyclin mit erhöhter Stabilität gegenüber Mechanismen der Tetrazyklinresistenz. Die Substanz war gegenüber Imipenem in einer randomisierten Studie bei Patienten mit VAP mit einer geringeren Heilungsrate sowie erhöhten Mortalität assoziiert [71*]. Zudem ergab eine gepoolte Analyse von 13 Therapiestudien zu Tigecyclin im Auftrag der FDA für Patienten mit VAP eine Exzessletalität gegenüber den Komparatoren. Die Substanz wurde daher weder in den USA noch in Europa zur Therapie der HAP zugelassen und wird in dieser Leitlinie nicht empfohlen. Die einzige, in Deutschland bislang sehr seltene Ausnahme hiervon stellt die gezielte Salvage-Therapie von Infektionen mit MRE wie Carbapenemase-bildenden Enterobakterien oder $A$. baumannii dar, wenn keine besser getesteten Alternativen zur Verfügung stehen (s. Empfehlung E22). Tigecyclin sollte in diesem Fall möglichst als Kombinationspartner einer weiteren in vitro aktiven Substanz eingesetzt werden.

\section{Applikation von Antiinfektiva unter Berücksichtigung von phar- makokinetisch/pharmakodynamischen (PK/PD) Prinzipien}

In-vitro- und tierexperimentelle Studien belegen, dass die Wirksamkeit eines Antibiotikums am besten durch die gleichzeitige Betrachtung pharmakodynamischer (=minimale Hemmkonzentration des Erregers) und pharmakokinetischer (z. B. Spitzenkonzentration oder AUC) Parameter vorhergesagt werden kann (Übersicht bei [72]). Diese Studien zeigen, dass Antibiotika nach
PK/PD in zwei Gruppen unterteilt werden können: 1) konzentrationsabhängig wirksame (Aminoglykoside, Fluorchinolone) und 2) zeitabhängig wirksame Substanzen (Betalaktame, Glykopeptide). Während bei konzentrationsabhängig wirksamen Substanzen ein hohes Verhältnis aus Spitzenkonzentration (Cmax) bzw. Area under the curve (AUC) $\mathrm{zu}$ MHK (Cmax/MHK; AUC/MHK) eine gute Wirksamkeit bedingt, ist bei zeitabhängig wirksamen Antibiotika die Zeit, in der der Plasmaspiegel des Antibiotikums oberhalb der MHK liegt ( $\mathrm{T}>\mathrm{MHK}$ ), von vorrangiger Bedeutung. Für Penicilline wurde eine für die Wirksamkeit erforderliche $\mathrm{T}>\mathrm{MHK}$ von mindestens $50 \%$ des Dosisintervalls, für Cephalosporine von 60 - 70\% und für Carbapeneme von mindestens $40 \%$ ermittelt.

In der Praxis bedeutet die Berücksichtigung von PK/PD, eine möglichst hohe Cmax für konzentrationsabhängig wirksame Antibiotika und eine möglichst lange Expositionszeit für zeitabhängig wirksame Antibiotika zu gewährleisten. Während sich in diesem Zusammenhang die einmal tägliche Gabe von Aminoglykosiden in hoher Konzentration durchgesetzt hat [73], gibt es zur Expositionsverlängerung von zeitabhängig wirksamen Antibiotika durch prolongierte Infusionszeiten (z.B. Infusion von Meropenem über drei oder vier Stunden) oder kontinuierliche Infusionen klinische Daten nur aus retrospektiven oder kleinen prospektiven Studien. Diese legen für Meropenem, Ceftazidim, Ceftriaxon und Piperacillin/Tazobactam eine mindestens gleichwertige bis tendenziell bessere Wirksamkeit, insbesondere bei höherer MHK des zugrunde liegenden Erregers, nahe ( Tab.10). Umgekehrt wurde ein signifikant oder tendenziell besseres Ergebnis durch die traditionelle Kurzzeitinfusion bislang in keiner Studie gezeigt. Eine schlechtere Gewebspenetration aufgrund der niedrigeren Spitzenspiegel bei kontinuierlicher Therapie muss offensichtlich nicht befürchtet werden (Review bei $\left[74^{*}\right]$ ). Vorteile der kontinuierlichen Infusion können darüber hinaus bei Substanzen wie Vancomycin in der besseren Steuerbarkeit der Serumspiegel liegen, ein besseres klinisches Ergebnis durch kontinuierliche Gabe wurde allerdings nicht gezeigt [75]. Bei geplanter kontinuierlicher Gabe sollte die erste Dosis als loading dose appliziert werden, um eine schnelle Penetration des Antibiotikums in das Zielgewebe zu gewährleisten.

Bei Patienten mit septischem Schock/schwerer Sepsis legen die wenigen Studien zur Pharmakokinetik von Antibiotika nahe, dass die vom Hersteller angegebenen Dosen sowohl innerhalb der ersten 24 Stunden [76*] als auch im steady state nach drei Tagen häufig in insuffizienten Spiegeln resultieren [77*]. Daher sollte bei eingeschränkter Nierenfunktion zumindest die erste Gabe nicht angepasst werden, und in der Initialphase kann eine höhere Dosierung von Substanzen mit ausreichender therapeutischer Breite sinnvoll sein. Perspektivisch ist bei kritisch kranken Patienten eine individuelle Steuerung der Dosierung durch therapeutisches Drug Monitoring nicht nur aus Gründen der Toxizität, sondern auch der Effektivität zu wünschen. Eine retrospektive Kohortenanalyse an 638 Patienten mit VAP zeigte, dass die individuelle Dosisanpassung zum Erreichen vorab definierter Zielspiegel entsprechend PK/PD im klinischen Alltag realisierbar ist und mit besseren klinischen Ergebnissen einhergeht (Letalität $10 \%$ versus $24 \%$ ) [78].

Das einzige Antibiotikum, für das eine Zulassung mit einem PK/ PD-optimierten Applikationsschema besteht, ist derzeit Doripenem [47]. Bei Piperacillin/Tazobactam sowie Flucloxacillin können die bisherigen klinischen Studien als ausreichender Beleg für antimikrobielle Effektivität und Sicherheit gelten. Bei anderen Substanzen muss bei kontinuierlicher Applikation oder prolon- 
gierter Infusionszeit die Haltbarkeit der Infusionslösung gewährleistet sein. Ggf. muss die Infusionslösung bei kontinuierlicher Infusion in definierten Abständen gewechselt werden. Hierzu sollten die Empfehlungen des Herstellers konsultiert werden.

\section{Diagnostik}

$\nabla$

E1: Wie wird eine HAP klinisch diagnostiziert und welche Differenzialdiagnosen sind zu beachten?

Therapierelevant ist bereits die Verdachtsdiagnose einer HAP, diese soll gestellt werden bei neuem oder progredientem Infiltrat, in Kombination mit zwei von drei weiteren Kriterien: Leukozyten $>\mathbf{1 0 . 0 0 0}$ oder $<4.000 / \mu \mathrm{l}$, Fieber $>38.3^{\circ} \mathrm{C}$, purulentes Sekret. Differenzialdiagnostisch sind u.a. Atelektasen (Sekretverlegung), Herzinsuffizienz/Überwässerung, alveoläre Hämorrhagie, interstitielle Lungenerkrankungen wie eine cryptogen organisierende Pneumonie (COP), ARDS und Lungenarterienembolien abzugrenzen.

\section{Starke Empfehlung, Evidenz C}

Die klinische Diagnose einer HAP ist schwierig. Es gibt keine universell akzeptierten Kriterien auf der Basis randomisierter Studien, sondern lediglich prospektive Kohortenanalysen. Therapierelevant ist die klinisch zu stellende Verdachtsdiagnose einer HAP. In den meisten Leitlinien werden die von Johanson formulierten Kriterien empfohlen: Neues oder progredientes Infiltrat in der Thoraxröntgenuntersuchung in Kombination mit zwei der drei folgenden Kriterien: Leukozyten $>10.000$ /nl bzw. $<4000$ /nl, Fieber $\geq 38.3^{\circ} \mathrm{C}$, purulentes Sekret [84]. Diese Kriterien sind in einer prospektiven Kohortenanalyse an 25 verstorbenen beatmeten Patienten validiert worden. In dieser lag die histologisch überprüfte Sensitivität bei $69 \%$ und die Spezifität bei $75 \%$ [85]. Fagon et al. (1993) [86] konnte in einer Studie an 84 beatmeten Patienten zeigen, dass die klinische Diagnose in $62 \%$ eine VAP vorhersagt und bei $84 \%$ korrekt keine VAP diagnostiziert. In allen Studien liegen Sensitivität und Spezifität dieser Kriterien bei ca. 70\%, sodass etwa 30\% der HAP-Patienten nicht erkannt werden und bei ca. 30\% eine andere Diagnose als eine HAP vorliegt. Der Einsatz mikrobiologischer Kriterien zur Diagnose einer HAP verbessert die Sensitivität und Spezifität nicht [85].

Andere Autoren konnten zeigen, dass postoperative Patienten mit der klinischen Diagnose HAP (beruhend auf diesen Kriterien) eine höhere Mortalität hatten als Patienten ohne Verdacht auf $\operatorname{HAP}$ ( 8 von 46, $17 \%$ vs 16 von 306, 5\%, $\mathrm{p}=0.046$ [87]. Wichtig ist, dass die schwere HAP mit einer Sepsis assoziiert sein kann. Insbesondere bei schwerer HAP sollten daher die klinischen Kriterien der Sepsis beachtet werden [88*]. Zeichen der Sepsis oder des septischen Schocks sind jedoch nicht spezifisch für eine HAP. Insgesamt ist die klinische Diagnose der HAP eine Arbeitsdiagnose, die für die zeitnahe Einleitung einer kalkulierten antimikrobiellen Therapie relevant ist und der regelmäßigen Überprüfung bedarf. In diesem Zusammenhang sind die aufgeführten Differenzialdiagnosen zu bedenken.

\section{E2: Welche bildgebenden Verfahren sind in der Diagnostik der HAP indiziert?}

Bei Verdacht auf eine HAP soll eine Thoraxröntgenuntersuchung möglichst in zwei Ebenen in Standardtechnik durchgeführt werden. Bei immobilen Patienten wird eine Röntgenuntersuchung im Liegen durchgeführt.

Starke Empfehlung, Evidenz C
Bei therapierefraktären Infiltraten und schwieriger Differenzialdiagnose sollte eine erweiterte bildgebende Diagnostik erwogen werden.

\section{Schwache Empfehlung, Evidenz C}

Es existieren nur wenige Untersuchungen zur Bildgebung der HAP. Bei beatmeten Patienten ist die Sensitivität und Spezifität u.a. wegen der Notwendigkeit der Aufnahmetechnik im Liegen deutlich eingeschränkt. Die Sensitivität der Thoraxröntgenuntersuchung liegt in prämortalen und postmortalen Studien bei lediglich 50-70\%, die Spezifität bei 30-50\%. Die akkurate Diagnose einer VAP mittels Röntgenuntersuchung im Liegen ist somit nur in ca. 50\% möglich [89,90]. Ein einzelnes Pneumobronchogramm hat eine Spezifität von $95 \%$, ist aber nur selten zu sehen, die Sensitivität beträgt lediglich $17 \%$. Den höchsten Stellenwert haben multiple Pneumobronchogramme mit einer Prädiktionsrate von ca. $64 \%$. Untersuchungen bei postoperativen Patienten mit Computertomografie als Vergleich zeigen eine Sensitivität von $50-70 \%$ und Spezifität von $80-100 \%$ für die Detektion von Konsolidierungen (Infiltrate und Atelektasen) mittels Aufnahmetechnik im Liegen. In den Unterfeldern, insbesondere retrokardial, werden am häufigsten Konsolidierungen übersehen [91]. Um die bestmögliche Aussage zu erhalten, sollte gerade bei der Bettlungenaufnahme auf die Einhaltung der technischen Standards geachtet werden [92]. Regelmäßige, routinemäßige Verlaufskontrollen des Röntgenbefundes auf Intensivstationen sind nicht erforderlich. Verlaufsaufnahmen sind zunächst einmalig zur Beurteilung des Therapieerfolgs sowie bei neuen klinischen Ereignissen indiziert.

CT und Röntgenuntersuchung differenzieren nicht eindeutig zwischen VAP und anderen Ursachen einer Konsolidierung [91]. Publikationen zur Sensitivität und Spezifität der CT oder MRT in Bezug auf nosokomiale Pneumonien sind kaum zu finden. In einer kleinen Studie an Patienten mit VAP und Nachweis von $P$. aeruginosa konnten bei 13 von 30 Patienten mittels Liegendröntgenuntersuchung Einschmelzungen gezeigt werden, das CT zeigte bei vier von acht Patienten zusätzlich Einschmelzungen oder Pleuraergüsse [93]. Eine CT-Thorax-Untersuchung ist insbesondere bei therapierefraktären Infiltraten aus differenzialdiagnostischen Erwägungen zu begründen. Bei V.a. Lungenarterienembolie sollte eine Angio-CT-Technik genutzt werden. Zudem kann das CT sicherer und schneller Komplikationen wie eine nekrotisierende, abszedierende Pneumonie diagnostizieren. Der schnelle und sichere Nachweis von Pleuraergüssen und größeren Konsolidierungen bis in die Peripherie gelingt mit der Thoraxsonografie. Darüber hinaus kann die Echokardiografie zur Klärung einer kardialen Komorbidität oder akuten Rechtsherzbelastung hilfreich sein.

\section{E3: Welche Rolle spielen Scores in der Diagnose und Risikobeurteilung der HAP?}

Die klinische Diagnose der HAP wird durch die Verwendung von Pneumonie-Scores wie dem „clinical pulmonary infection score“ (CPIS) nicht verbessert. Bei Patienten mit schwerer Sepsis sollen Sepsis Scores angewandt werden.

Starke Empfehlung, Evidenz C

Kohortenuntersuchungen haben gezeigt, dass der „Clinical Pulmonary Infection Score“ (CPIS) bei V.a. HAP nicht besser als klinische Kriterien (Leukozytose, Fieber und purulentes Sekret) abschneidet [85]. Bei Patienten, die Antibiotika erhalten haben, ist die Sensitivität und Spezifität noch schlechter. Der modifizierte CPIS unter Verwendung der Gramfärbung als zusätzlichem Kriterium zeigt eine hohe Sensitivität von 85\% [94]; die Spezifität be- 
trug indes nur 49\%. Der CPIS und andere Scores sollten daher außerhalb von Studien nicht zur Diagnose genutzt werden.

Die Sterblichkeit von Patienten mit HAP ist abhängig von verschiedenen Faktoren (s. auch Kapitel Epidemiologie). Prognostisch negative Einzelfaktoren sind eine initiale Bakteriämie und die Schwere der akuten Lungenschädigung. Bei schwerer Sepsis korreliert die Sterblichkeit mit den Organdysfunktionen. Bei diesen Patienten sollten Scores angewandt werden, welche den Schweregrad der Sepsis und die Organdysfunktion messen, (MODS, SAPS, SOFA) [88*,95]. Als Score zur Risikoeinschätzung bei VAP wurde der VAP-PIRO Score evaluiert [96]. Dieser Score vergibt je einen Punkt für definierte Komorbiditäten, Bakteriämie, systolische Hypotonie und ARDS. Die Datenlage ist begrenzt, in einer Studie war der Score etablierten Intensivscores (APACHE II) überlegen [96]. Allerdings sind hieraus bislang keine Konsequenzen für das Patientenmanagement ersichtlich.

\section{E4: Welche Rolle haben Biomarker für die Diagnose der HAP?}

Der generelle Einsatz von Biomarkern zur Diagnose der HAP ist derzeit nicht zu empfehlen, da keine ausreichende Evidenz für eine zusätzliche, von anderen Parametern unabhängige Aussagekraft vorliegt. Dagegen soll Procalcitonin bei Verdacht auf pneumogene Sepsis im Rahmen der HAP als sensitiver Marker in der initialen Diagnostik eingesetzt werden.

Starke Empfehlung, Evidenz B

Eine Reihe von Biomarkern sind in der Diagnostik der VAP evaluiert worden, darunter Procalcitonin (PCT) [97 - 101], soluble triggering receptor expressed on myeloid cells-1 (sTREM-1) [102107], Interleukin-1ß (IL-1ß), Interleukin-6 (IL-6), Interleukin-8 (IL-8), G-CSF and Macrophage inflammatory protein-1 alpha [108*]. Keiner dieser Biomarker hat bisher eine gegenüber der konventionell mikrobiologischen Diagnostik eigenständige und überlegene Bedeutung erlangen können. Alle Biomarker unterliegen denselben Schwierigkeiten der Evaluation wie konventionelle Methoden (fehlender Goldstandard!). Die bisherigen Studien haben daher meist die zweifelhafte Referenz der quantitativen Kultur herangezogen mit der Folge, dass Fehler potenziert werden können. Darüber hinaus sind die Messmethoden für Biomarker zum Teil noch nicht standardisiert. Aus diesen Gründen ist kurzfristig nicht zu erwarten, dass Biomarker einen Einsatz in der Diagnostik der HAP erreichen werden. PCT hat sich dagegen für die Diagnose der Sepsis als sensitiver und frühzeitiger Marker etabliert und wurde in Studien evaluiert, in denen eine pneumogene Sepsis einen erheblichen Teil des Kollektivs stellte [109, 110]. Es sollte daher zur Etablierung der Diagnose HAP mit schwerer Sepsis oder septischem Schock in der initialen Diagnostik eingesetzt werden.

\section{E5: Wann ist die Entnahme von Blutkulturen sinnvoll?}

Blutkulturen sollen bei HAP zur Diagnose der bakteriämischen Pneumonie entnommen werden. Sie tragen darüber hinaus zur Therapiesteuerung und zur Aufdeckung extrapulmonaler Infektionsquellen bei.

Starke Empfehlung, Evidenz C

Bei HAP nichtbeatmeter Patienten werden insgesamt in 9,3\%, bei S. pneumoniae-Infektionen in $11,4 \%$ positive Blutkulturen gefunden [40]. Bei VAP liegt eine Studie bei 162 Patienten vor [111]. Blutkulturen waren in insgesamt 27 Fällen (16\%) positiv, wobei dies deutlich häufiger der Fall war, wenn die BAL ebenfalls positiv war (22/90 gegen 5/72 Fällen). Allerdings waren Bakterien in der Blutkultur in 6/22 Fällen auf eine extrapulmonale Quelle zurück- zuführen. Insgesamt hatte eine positive Blutkultur damit einen prädiktiven Wert von 73 \% für den Nachweis eines Pneumonieerregers; eine Assoziation mit der Schwere der Erkrankung konnte nicht verifiziert werden. Die Blutkultur bleibt damit der Goldstandard für die Diagnose der bakteriämischen Pneumonie. Darüber hinaus ist sie wertvoll für die Therapiesteuerung und die Diagnose extrapulmonaler Infektionsquellen. Zur Technik der Blutkulturabnahme wird auf die nationale Sepsisleitlinie verwiesen $\left[88^{*}\right]$.

\section{E6: Wann ist die Entnahme von Urin zum Antigen-} nachweis sinnvoll?

Die Diagnostik auf Legionellen soll bei Patienten mit HAP insbesondere dann erfolgen, wenn epidemiologische Hinweise auf nosokomiale Akquisition bestehen. Der Urin-Antigentest stellt in dieser Situation das Verfahren der Wahl dar. Der Antigentest auf Pneumokokken wird wegen fehlender differenzialtherapeutischer Relevanz nicht empfohlen.

Starke Empfehlung, Evidenz C

Die Detektion einer Pneumonie mit Legionella spp. ist bei Verwendung kultureller Techniken außerordentlich schwierig. Bei HAP nicht-beatmeter Patienten gehörte L. pneumophila in einer Studie nach S. pneumoniae zu den häufiger nachgewiesenen Erregern [40]. Demgegenüber spielt dieser Erreger bei Patienten, die bereits invasiv beatmet sind, eine untergeordnete Rolle [112]. Der Urin-Antigentest selbst hat eine sehr hohe Spezifität von $>99 \%$, jedoch eine vergleichsweise niedrige Sensitivität (74\%) [113]. Dabei bestehen zwischen den kommerziell verfügbaren Tests deutliche Unterschiede hinsichtlich der Sensitivität insbesondere bei Isolaten, die nicht zur Serogruppe 1 der Spezies L. pneumophila gehören [114]. Ein negativer Legionellen-Antigentest schließt eine Legionellen-Infektion daher nicht sicher aus. Bei fortbestehendem Verdacht sollte eine weiterführende Diagnostik mittels Kultur oder PCR aus bronchoalveolärer Lavage durchgeführt werden.

Der Urin-Antigentest auf S. pneumoniae hat bei HAP keine differenzialtherapeutische Relevanz; somit kann auf ihn verzichtet werden.

\section{E7: Welche mikrobiologischen Untersuchungen sollten} aus respiratorischen Materialien durchgeführt werden? Bei nosokomialer Pneumonie sollen quantitative Kulturen aus qualitativ hochwertigen unteren Atemwegsmaterialien wie tracheobronchialem Aspirat (TBAS) oder bronchoalveolärer Lavage (BAL) angelegt werden. Die resultierenden Keimzahlen haben orientierenden Wert und sind nicht als unabhängige Prädiktoren des Vorliegens einer Pneumonie zu betrachten, vielmehr im klinischen Kontext zu interpretieren.

Starke Empfehlung, Evidenz B

Darüber hinaus sollte eine Ausstrichdiagnostik zur Validierung der Probe erfolgen. Die Ergebnisse eines Gram-Präparats haben keinen prädiktiven Wert hinsichtlich der später isolierten Spezies. Dagegen hat ein negatives Gram-Präparat bei nicht antibiotisch vorbehandelten Patienten einen hohen negativen prädiktiven Wert. Ein Grampräparat sollte daher insbesondere in Fällen angefertigt werden, in denen eine antibiotische Therapie nicht indiziert erscheint oder frühzeitig abgesetzt werden soll. Schwache Empfehlung, Evidenz B 
Zur Diagnostik der HAP liegen zahlreiche Untersuchungen vor. Diese können nach folgenden Kriterien unterschieden werden:

1. Vergleich quantitativer/semiquantitativer versus qualitativer Kulturen respiratorischer Sekrete

2. Vergleich diagnostischer Indizes invasiv (BAL bzw. protected specimen brush [PSB]) und nichtinvasiv (TBAS) gewonnener Sekrete, jeweils unter Verwendung quantitativer oder qualitativer Kulturen

3. Evaluation nichtkultureller diagnostischer Methoden (Gramfärbung; Giemsafärbung auf intrazelluläre Erreger; Elastinfärbung)

4. Validierung über Referenz aus klinischen Kriterien oder post mortem-Gewebehomogenaten bzw. Histologien

5. Vergleich des klinischen Therapieerfolgs bei Patienten, die invasiv (PSB und BAL) versus nichtinvasiv (TBAS) untersucht worden sind.

Viele dieser Studien sind unter hohem Aufwand und methodisch hochwertig durchgeführt worden. Die Ergebnisse können wie folgt zusammengefasst werden:

1. Nur quantitative (oder semiquantitative) Kulturen erlauben eine Aussage zum Vorliegen einer Pneumonie; zum Nachweis des Erregers sind quantitative und qualitative Kulturen gleichwertig.

2. Nichtkulturelle diagnostische Methoden haben einen sehr begrenzten diagnostischen Wert.

3. Es gibt keinen robusten „Goldstandard“ bei der Evaluation diagnostischer Techniken, auch nicht post mortem gewonnene Gewebshomogenate oder Histologien; dennoch sind letztere aktuell die bestmöglichen „Goldstandards“. Aus klinischen Kriterien gewonnene Referenzen müssen sehr kritisch betrachtet werden.

4. Eine Überlegenheit einer invasiven Diagnostik unter Zugrundelegung quantitativer Kulturen hinsichtlich des klinischen Therapieerfolgs hat sich nicht belegen lassen (s. Empfehlung E8).

Die Untersuchungen bei Verdacht auf HAP werden daher wie folgt bewertet:

\section{Färbungen}

Es sollte die Qualität des TBAS bzw. der BAL validiert werden. Mehr als 25 polymorphkernige Granulozyten sowie weniger als 10 Plattenepithelien/Blickfeld sprechen für ein Material, das repräsentativ für die tiefen Atemwege ist. Aus differenzialdiagnostischen Erwägungen kann ein Zytozentrifugenpräparat der BALF nach Giemsa gefärbt werden, um eine Differenzialzytologie auf der Basis von 300 ausgezählten Zellen zu erhalten.

Darüber hinaus sollte eine Gram-Färbung angefertigt werden, um ggf. eine vorherrschende Bakterienart zu identifizieren. Der prädiktive Wert hinsichtlich der später isolierten Spezies ist allerdings gering. Ein negatives Grampräparat aus TBAS oder BALF spricht bei nicht antibiotisch vorbehandelten Patienten gegen eine bakterielle VAP.

Schließlich kann bei Verdacht auf VAP eine Untersuchung auf intrazelluläre Erreger in phagozytierenden Zellen (,intracellular organisms“, ICO) erfolgen. Es wurden Grenzwerte von 2-15\% positiver Zellen mit unterschiedlichen Resultaten untersucht. Ein Anteil von> 5\% ICO spricht bei nicht antibiotisch vorbehandelten Patienten für das Vorliegen einer VAP. Die Sensitivität dieser Untersuchung unter antimikrobieller Vorbehandlung ist jedoch deutlich reduziert $(<50 \%)$.

\section{Kultur}

- Die kulturelle Aufarbeitung sollte nach den Qualitätsstandards in der mikrobiologisch-infektiologischen Diagnostik (MiQ) mittels serieller Verdünnungstechnik quantitativ erfolgen. Unter einer quantitativen Kultur versteht man die serielle Auftragung zunehmend verdünnten respiratorischen Sekrets auf Kulturplatten. In der Regel werden drei Verdünnungsstufen angelegt (1:10, 1:1000, 1:10.000). Alternativ kann eine semiquantitative Aufarbeitung mit nur zwei Verdünnungsstufen vorgenommen werden. Die Technik der quantitativen Kultur dient der Erfassung der Keimlast und (bei Patienten mit Verdacht auf HAP) der Unterscheidung von Kolonisations- und Infektionserregern.

- Es handelt sich dabei um eine Schätzung, die sich an der Keimlast im Sputum bei Patienten mit Pneumonie orientiert [115]. So finden sich im Sputum etwa $10^{5}$ bis $10^{6}$ koloniebildende Einheiten (KBE)/ml. Die PSB enthält ca. 0,01-0,001 ml, die BALF $1 \mathrm{ml}$ respiratorisches Sekret. Für die Festlegung der Schwellenwerte, die das Vorliegen einer Pneumonie anzeigen, wird bei der PSB der Verdünnungsfaktor der Trägerlösung (100- bis 1000-fach) eingerechnet. Es wird geschätzt, dass bei der BAL 5- bis 10-mal höhere Keimzahlen gewonnen werden als bei der PSB. Als Schwellenwerte zur Unterscheidung zwischen Kolonisation und Infektion ergeben sich somit:

- $10^{5} \mathrm{KBE} / \mathrm{ml}$ für das TBAS (identisch zum Sputum)

- $10^{4} \mathrm{KBE} / \mathrm{ml}$ für die BALF

- $10^{3} \mathrm{KBE} / \mathrm{ml}$ für die PSB (entsprechend $10^{5}$ bis $10^{6} \mathrm{KBE} / \mathrm{ml}$ Sputum)

- Die Keimzahlen beziehen sich in den meisten Arbeiten auf unterscheidbare bakterielle Spezies. Bei Mischinfektionen wurden auch Gesamtkeimzahlen über die Berechnung eines bakteriellen Indexes (logarithmische Umwandlung und Summation der einzelnen Keimzahlen; dies ergibt einen „log BI“) herangezogen.

- Die geschilderten Berechnungen zur Schwellenwertbestimmung von Keimzahlen stellen also Schätzungen dar und ergeben keine exakten Messgrößen. Grundsätzlich führt eine Senkung des Schwellenwertes zu einer höheren Sensitivität auf Kosten der Spezifität und umgekehrt. Störgrößen, die die Keimzahl beeinflussen können, sind mannigfaltig und umfassen die Erregerart, die Transportdauer, die Technik der Materialgewinnung, das Stadium der Infektion und die Wirtsimmunität. Zusätzlich stellen bei der BALF die Menge der instillierten Flüssigkeit sowie die Rückgewinnung Variablen dar, die das Ergebnis beeinflussen können.

- Allein aufgrund dieser Tatsache können Keimzahlen nur orientierenden Wert haben und keine unabhängige Prädiktion des Vorliegens einer Pneumonie darstellen.

- Schließlich ist zu berücksichtigen, dass im Falle einer vorbestehenden Antibiotika-Therapie die Schwellenwerte niedriger angesetzt werden müssen [116].

- Auch wenn eine Überlegenheit einer quantitativen gegenüber der qualitativen Aufarbeitung nicht gezeigt werden konnte [117], ist die quantitative Kultur grundsätzlich vorzuziehen, da sie im Einzelfall eine bessere Abschätzung der Relevanz bakterieller Isolate erlaubt.

- Über die routinemäßige bakteriologische Aufarbeitung hinaus sollte bei entsprechendem klinischem Verdacht eine gezielte Untersuchung auf weitere Erreger wie Mykobakterien, Pilze (s. Empfehlung E10) und Viren erfolgen. 
E8: Wann ist eine invasive Diagnostik, wann eine nichtinvasive Materialgewinnung vorzuziehen?

Eine invasive ist einer nichtinvasiven Diagnostik bei VAP nicht überlegen, sodass die Entscheidung für oder gegen eine invasive Diagnostik in Abhängigkeit von der lokalen Logistik, differenzialdiagnostischen Erwägungen, aber auch möglichen therapeutischen Aspekten einer endoskopischen Untersuchung getroffen werden soll. Kontraindikationen zur Durchführung einer Bronchoskopie mit BAL sind zu beachten.

Starke Empfehlung, Evidenz A

Eine Überlegenheit der invasiven Diagnostik (Bronchoskopie mit BAL und/oder PSB) über die nichtinvasive Diagnostik (TBAS) konnte nicht konsistent gezeigt werden. Drei monozentrische spanische [118 - 120] und zwei französische Arbeiten [121,122] fanden unter Zugrundelegung von post mortem Gewebskulturen und/oder Histologien vergleichbare operative Indizes (Sensitivität und Spezifität) von invasiver und nichtinvasiver Diagnostik, lediglich eine französische Arbeit [123] fand die invasive Diagnostik überlegen. Methodisch weisen diese Arbeiten eine Reihe von z.T. unaufhebbaren Schwächen auf. Hierzu gehört das Fehlen eines eindeutigen Standards. Auch die post mortem Histologie kann diesen Anspruch nicht erheben [124-126]. Darüber hinaus ist die quantitative Kultur respiratorischer Sekrete zur Keimlastbestimmung keine exakte Methode [115,127].

Die Änderung der Perspektive des Vergleichs beider diagnostischer Techniken weg von operativen Indizes hin zu klinischen Endpunkten (Antibiotikatage, Letalität) erbrachte in einer monozentrischen spanischen [118] und einer französischen Studie [123] zwei entgegengesetzte Ergebnisse. Eine große kanadische multizentrische Studie fand keinen Unterschied hinsichtlich des klinischen Therapieerfolgs zwischen quantitativer BAL und nichtinvasivem, qualitativem TBAS unter Standardisierung der initialen kalkulierten antibiotischen Therapie [117], wobei allerdings die genaue Aufarbeitung und Befundübermittlung des TBAS nicht beschrieben wurde. Außerdem wurden Infektionen mit MRSA und $P$. aeruginosa ausgeschlossen, die Ergebnisse sind deshalb nur eingeschränkt übertragbar. Dennoch muss mit dieser Studie die Hypothese einer Überlegenheit der invasiven Diagnostik als unbelegt gelten. Weitere Untersuchungen gleicher Qualität, die diese Ergebnisse infrage stellen könnten, sind bis auf Weiteres nicht zu erwarten.

Somit ist das nichtinvasiv gewonnene und meist problemlos verfügbare TBAS in der Regel ein hinreichendes Medium für die mikrobiologische Erregerdiagnostik.

Differenzialindikationen für eine invasive Diagnostik können darstellen:

1. Verdacht auf mit der Infektion assoziierte Atelektasen, bronchiale Blutungen oder Raumforderungen, die endoskopisch identifiziert und ggf. bereits therapiert werden können.

2. Die Visualisierung distaler purulenter Sekretionen sowie die Persistenz distaler Sekretionen während der Exspiration sind als unabhängige Prädiktoren für eine Pneumonie beschrieben worden [128].

3. Unzureichende Ausbeute bei der Gewinnung von TBAS

4. Therapieversagen (s. Empfehlung E19)

Folgende Kontraindikationen gegen eine invasive Diagnostik sind zu beachten:

1. Spontan atmende Patienten mit schwerer respiratorischer Insuffizienz sollten möglichst nicht einer invasiven Untersuchung unterzogen werden.
2. Eine relative Kontraindikation gegen eine BAL besteht bei abszedierenden Pneumonien wegen der Gefahr der Keimverschleppung während der Untersuchung. Eine Indikation kann dennoch aus differenzialdiagnostischen Erwägungen bestehen.

3. Bei beatmeten Patienten besteht eine relative Kontraindikation gegen eine BAL in der schweren respiratorischen Insuffizienz (PaO2/FIO2 < 100). So konnte gezeigt werden, dass eine BAL unabhängig vom Lavagevolumen zu einer Reduktion der Oxygenierung auch über 24 Stunden hinaus führt, insbesondere dann, wenn tatsächlich eine Pneumonie vorliegt [129]. Kontraindikationen gegen bronchoskopisch gewonnenes Bronchialsekret sowie gegen die Durchführung einer PSB bestehen bei beatmeten Patienten nicht.

\section{E9: Welche Standards werden bei der Material- gewinnung empfohlen?}

Die nichtinvasive Materialgewinnung soll mithilfe steriler Katheter und Auffanggefäße erfolgen. Falls eine Bronchoskopie durchgeführt wird, sollen die im Hintergrundtext aufgeführten, auf dem Konsensus erfahrener Untersucher beruhenden Empfehlungen zur Durchführung der Endoskopie bei Pneumonien beachtet werden.

Starke Empfehlung, Evidenz C

Die hier aufgeführten Empfehlungen sind den Ergebnissen einer Konsensuskonferenz entnommen, bei der die Erfahrungen internationaler Experten zusammengetragen wurden, die an der Entwicklung der BAL-Diagnostik bei VAP maßgeblich beteiligt waren [115]. Für die meisten dargestellten Maßnahmen liegen keine Daten aus kontrollierten Studien vor.

Timing der Untersuchung: Die Probengewinnung sollte grundsätzlich vor Einleitung einer kalkulierten antibiotischen Therapie erfolgen. Auch eine bronchoskopische Untersuchung sollte zum Zeitpunkt des Verdachts auf eine HAP/VAP oder eines Therapieversagens möglichst umgehend erfolgen. Für eine diagnostische Maßnahme darf die Einleitung der Therapie insbesondere bei hämodynamisch instabilen Patienten nicht länger als eine Stunde verschoben werden [130]. Unabhängig vom gewählten Verfahren sollten bei der Materialentnahme Hinweise zur Vermeidung von Kontaminationen beachtet werden ( $\bullet$ Tab. 11).

Vorbestehende Antibiotikatherapie: Falls eine Umstellung der Antibiotika-Therapie geplant ist, sollte die bronchoskopische Diagnostik vor Gabe neuer Antibiotika erfolgen [116]. Ein Vorteil eines sogenannten „diagnostischen Fensters“ mit Antibiotikapause ist nicht nachgewiesen. Die Diagnostik sollte daher umgehend erfolgen und die neue kalkulierte Therapie sollte danach ohne Verzögerungen begonnen werden.

Tab.11 Methodische Voraussetzungen zur Gewinnung qualitativ hochwertiger diagnostischer Proben aus dem unteren Respirationstrakt.

\begin{tabular}{|l|l|}
\hline Probe & Voraussetzungen \\
\hline Tracheobronchialaspirat & $\begin{array}{l}\text { Absaugung des Sekrets aus dem Tubus } \\
\text { tiefes Einführen eines frischen Katheters } \\
\text { mit angeschlossenem Auffanggefäß, } \\
\text { dann erst Absaugung aktivieren }\end{array}$ \\
\hline keine vorherige Instillation von Kochsalz \\
\hline Bronchoskopie & gute Sedierung \\
\hline & keine Anwendung von Lokalanästhetika \\
\hline & $\begin{array}{l}\text { keine Aspiration über den Arbeitskanal } \\
\text { des Bronchoskops vor Gewinnung der } \\
\text { respiratorischen Sekrete }\end{array}$ \\
\hline
\end{tabular}


Techniken der Materialgewinnung: Bei der nichtinvasiven Gewinnung von tracheobronchialem Aspirat (TBAS) müssen bei der Abnahme sterile Katheter und Auffanggefäße verwendet und eine Kontamination mit Material aus dem Oropharynx muss so weit wie möglich vermieden werden. Die bronchoskopische Erregerdiagnostik umfasst heute in der Regel eine bronchoalveoläre Lavage (BAL). Der protected specimen brush (PSB) ist wenig verbreitet, kostenintensiv und im Prinzip entbehrlich.

Probenmenge: Laut MiQ sollen bei Sputum, Bronchialsekret und TBAS mehr als $1 \mathrm{ml}$ eingesandt werden, bei Mini-BAL $10-20 \mathrm{ml}$, bei BAL 30-100 ml. Die Probenmenge ist für die Durchführung mikrobiologischer Analysen i. A. nicht kritisch, die Probe sollte allerdings repräsentativ gewonnen sein.

Bronchoalveoläre Lavage (BAL): Nach Erreichen der Wedge-Position im Segmentostium werden z. B. $6 \times 20 \mathrm{ml}$ körperwarme $\mathrm{NaCl}$ instilliert und sofort reaspiriert. Bei einer Rückgewinnung von $40-50 \mathrm{ml}$ sollte die Lavage beendet werden. Im Falle einer schlechten Rückgewinnung können weitere $40 \mathrm{ml}$ appliziert werden. Die erste rückgewonnene Portion aus der BAL wird verworfen. Die übrigen Portionen werden gepoolt und ggf. aliquotiert.

Mini-Bronchoalveoläre Lavage (Mini-BAL): Eine Minilavage kann unter Verwendung diverser Katheter wie dem Ballard Katheter [131,132] auch nichtbronchoskopisch durchgeführt werden. In diesem Fall werden Lavagevolumina von ca. 30-100 ml gewählt. Die diagnostischen Ergebnisse sind der BAL gleichwertig [131], ein Vorteil dieses Verfahrens ist jedoch weder für den Patienten noch ökonomisch (Verbrauchsmaterial) zu erkennen. Daneben wird auch die bronchoskopische Materialentnahme nach Instillation von geringeren Lavagevolumina von 20-40 ml als Mini-BAL bezeichnet. Dieses Vorgehen kann als Alternative bei Kontraindikationen gegen die Standard-BAL empfohlen werden, die Modalitäten der Materialentnahme sind allerdings deutlich schlechter untersucht.

Verarbeitung nichtinvasiv und invasiv gewonnener Proben: Die Probenverarbeitung sollte innerhalb von spätestens vier Stunden nach Entnahme erfolgen. Lässt sich ein längerer Zeitraum bis zur Verarbeitung nicht vermeiden, muss das Material gekühlt $\left(4-8^{\circ} \mathrm{C}\right)$ gelagert und transportiert werden. Unter diesen Bedingungen verschlechtert sich insgesamt die Aussagekraft der Untersuchungen auch bei 24-stündiger Lagerung nicht wesentlich [133,134]. Andernfalls drohen empfindliche Erreger abzusterben (z.B. Pneumokokken, H. influenzae) und es besteht die Gefahr der Überwucherung durch schnell wachsende Mikroorganismen, die durch ihre Vermehrung eine falsch hohe Keimzahl einer nicht am Geschehen beteiligten Spezies vortäuschen können.

\section{E10: Wann und wie soll eine mykologische Diagnostik erfolgen?}

Auf eine gezielte Candidadiagnostik aus Atemwegsmaterialien soll bei HAP verzichtet werden, da Hefepilzinfektionen als Ursache nosokomialer Pneumonien bei Patienten ohne definiertes Immundefizit extrem selten sind.

Starke Empfehlung, Evidenz B

Eine Aspergillusdiagnostik soll auch bei Patienten ohne definiertes Immundefizit erwogen werden, wenn Prädispositionen wie eine strukturelle Lungenerkrankung, eine rheumatologische Grunderkrankung oder eine Leberzirrhose vorliegen und/oder hinweisende Infiltrate im CT-Thorax zur Darstellung kommen, die mit einer invasiven Aspergillose assoziiert sein können. Der Nachweis von Galaktomannan-Antigen aus der BAL ist dem Nachweis im Blut überlegen und stellt bei der diagnostischen Abklä- rung eine Ergänzung zur histopathologischen und mikrobiologischen Untersuchung an Lungengewebe dar. Wenn Biopsien nicht durchgeführt werden können, trägt eine positive Aspergilluskultur und/oder ein Galaktomannan-Antigentest aus der BAL zu einer wahrscheinlichen Diagnose bei.

Starke Empfehlung, Evidenz B

Candida spp. werden bei beatmeten Patienten mit AntibiotikaVorbehandlungen sehr häufig aus tiefen Atemwegsmaterialien isoliert, ohne dass eine invasive, therapiebedürftige Infektion vorliegt (s. Kapitel Erregerspektrum). In einer prospektiven Autopsiestudie an 232 Patienten, die auf der Intensivstation an einer Pneumonie verstorben waren, wurde kein einziger Fall einer Candidapneumonie identifiziert, obwohl zuvor bei 77 der verstorbenen Patienten Candida spp. aus tracheobronchialen Sekreten isoliert worden waren [32].

Die sichere Diagnose invasiver pulmonaler Aspergillosen beruht auf dem histopathologischen Nachweis von Pilzhyphen im Lungengewebe und dem kulturellen Nachweis der Pilze aus transbronchialen Biopsien oder reseziertem Lungengewebe. Zusammen mit hinweisenden Befunden im CT-Thorax wie Hohlraumbildungen bzw. nodulären Infiltraten mit umgebendem Halo kann auch die Aspergilluskultur und/oder der GalaktomannanAntigentest aus einer gezielt entnommenen BAL zu einer wahrscheinlichen Diagnose führen. In einer prospektiven Beobachtungsstudie bei Patienten auf der Intensivstation mit unterschiedlichen Grunderkrankungen war die diagnostische Genauigkeit des Nachweises von Galaktomannan-Antigen aus der BAL dem Nachweis aus dem Serum deutlich überlegen, der überwiegend bei Patienten mit hämatologischen Neoplasien positiv evaluiert ist [135]. Für den Galaktomannan-Test sind allerdings falsch-positive Ergebnisse bei zum Zeitpunkt der Probenentnahme bestehender Antibiotikatherapie, insbesondere mit Piperacillin/Tazobactam, beschrieben [136]. Weitere Publikationen legen nahe, dass das Problem auch andere Betalaktam-Antibiotika wie z.B. Amoxicillin/Clavulansäure [137] betreffen kann und bei der Verwendung enteraler Ernährungslösungen auftreten kann [138*]. Die Galaktomannan-Bestimmung sollte daher vor der Gabe von ß-Laktamantibiotika durchgeführt werden. Für die Applikation von Antibiotika und die Probennahme sind unterschiedliche Zugänge notwendig. Falsch-positive Galaktomannan-Tests wurden auch in glukonathaltigen kristalloiden Lösungen gefunden, die für die BAL genutzt wurden [139]. Der Galaktomannan-Test ist dem Beta-D-Glucan-Antigentest aus dem Blut überlegen [140], der für eine speziesspezifische Diagnose einer Pilzpneumonie ungeeignet ist. Erregerspezifische Antikörpertiter im Blut sind für die Diagnose invasiver Pilzinfektionen ebenfalls ungeeignet, die erregerspezifische PCR ist bislang nicht ausreichend validiert [ $\left.141^{*}\right]$.

\section{Antimikrobielle Therapie}

$\nabla$

E11: Wann soll die antimikrobielle Therapie begonnen werden?

Die antibiotische Therapie soll nach Entnahme von adäquatem Untersuchungsmaterial so früh wie möglich erfolgen. Insbesondere bei Patienten mit septischem Schock ist eine Antibiotikatherapie innerhalb der ersten Stunde anzustreben. Nicht sofort verfügbare diagnostische Maßnahmen sollen die Einleitung der Therapie nicht verzögern.

Starke Empfehlung, Evidenz B 
Eine verzögerte adäquate antimikrobielle Therapie, definiert als Beginn > 24 Stunden nach Entnahme der Blutkulturen, war bei kritisch kranken Patienten mit P. aeruginosa-Bakteriämie (davon $77 \%$ pneumogener Fokus) ein unabhängiger Risikofaktor für eine erhöhte Sterblichkeit in einer prospektiven Studie [142]. Diese Assoziation wurde erregerunabhängig in einer retrospektiven multizentrischen Kohortenstudie an 2731 Patienten mit schwerer Sepsis bestätigt [130]: eine Verzögerung der Antibiotikatherapie resultierte in einem Anstieg der Letalität um 7,6\% pro Stunde. Die größte Subgruppe (37\%) dieser Patienten hatte einen pneumogenen Focus, eine separate Analyse dieser Patienten wurde allerdings nicht durchgeführt [130]. Die multivariate Analyse von 107 Patienten mit VAP in einer prospektiven Kohortenstudie zeigte ebenfalls eine signifikant erhöhte Letalität (OR 7.7; 95CI 4,5-13; p<0.001) wenn die antibiotische Therapie $>24$ Stunden nach Diagnosestellung erfolgte [143].

E12: Welche Optionen der kalkulierten Therapie sind bei Patienten mit nosokomialer Pneumonie ohne erhöhtes Risiko für Infektionen mit multiresistenten Erregern (MRE) zu empfehlen?

Bei Patienten ohne erhöhtes Risiko für MRE gehören Cephalosporine der Gruppe 3a, Aminopenicilline/Betalaktamaseinhibitor, Ertapenem oder pneumokokkenwirksame Fluorchinolone zu den empfohlenen Therapieoptionen. Die Substanzauswahl soll vor dem Hintergrund des lokalen Erregerspektrums und Resistenzprofils getroffen werden.

Starke Empfehlung, Evidenz C

Die Datenbasis zu Erregerspektrum und Therapie der nosokomialen Pneumonie bei Patienten ohne invasive Beatmung und anderen Risikofaktoren für MRE ist außerordentlich schmal. Die Patientenkollektive sind heterogen und die Erregernachweisrate liegt deutlich niedriger als bei der VAP. Es wurden Piperacillin/ Tazobactam, Cephalosporine der Gruppen 3a und 3b, Carbapeneme und Moxifloxacin geprüft, ohne dass eine Überlegenheit einer Substanz hinsichtlich Sterblichkeit oder klinischem Therapieerfolg gefunden wurde. Langjährige klinische Erfahrungen bestehen darüber hinaus mit der Kombination aus Aminopenicillinen und Betalaktamaseinhibitoren. In zwei Studien wurde mit Erfolg versucht, Patienten nach dem Vorhandensein von Risikofaktoren für Infektionen mit $P$. aeruginosa und anderen Nonfermentern zu stratifizieren $[144,145]$. Hierbei spielen neben einer Beatmungstherapie strukturelle Lungenerkrankungen, Dauer des Hospitalaufenthalts vor Beginn der Pneumonie (early onset vs late onset) und Schweregrad der Pneumonie eine Rolle. In der nach diesen Kriterien durchgeführten Studie von Yakovlev et al. war in einem Kollektiv von Patienten ohne erhöhtes Risiko für MRE eine nicht pseudomonaswirksame Therapie der Gabe eines pseudomonaswirksamen Cephalosporins gleichwertig [144]. Bei niedrigem Risiko für MRE ( Tab.6) erscheint eine Therapie mit begrenztem Wirkspektrum somit möglich und empfehlenswert ( Tab. 12). Bei der Substanzauswahl sollten lokales Erregerspektrum und Resistenzdaten berücksichtigt werden. In Analogie zu anderen Infektionen sollte die Gabe von Antibiotika, für die eine Resistenz relevanter Zielkeime von $>20 \%$ zu erwarten ist, in der Regel vermieden werden. Weiter sollte berücksichtigt werden, dass die Cephalosporine der Gruppe 3 eine unzureichende Aktivität gegenüber $S$. aureus aufweisen.
Tab. 12 Kalkulierte antimikrobielle Therapie bei nosokomialer Pneumonie, Patienten ohne erhöhtes Risiko für multiresistente Erreger.

\begin{tabular}{|l|l|}
\hline Substanz & Dosierung (pro Tag) \\
\hline Aminopenicillin/BLI* & \\
\hline Ampicillin/Sulbactam & $3 \times 3 \mathrm{~g}$ \\
\hline Amoxicillin/Clavulansäure & $3 \times 2.2 \mathrm{~g}$ \\
\hline oder & \\
\hline Cephalosporin Gr. 3a & $1 \times 2 \mathrm{~g}$ \\
\hline Ceftriaxon & $3 \times 2 \mathrm{~g}$ \\
\hline Cefotaxim & \\
\hline oder & $1 \times 1 \mathrm{~g}$ \\
\hline Carbapenem & \\
\hline Ertapenem & $1 \times 400 \mathrm{mg}$ \\
\hline oder & $2 \times 500 \mathrm{mg}$ \\
\hline Fluorchinolon & \\
\hline Moxifloxacin & \\
\hline Levofloxacin & \\
\hline
\end{tabular}

* BLI= Betalaktamaseinhibitor

E13: Welche Optionen der kalkulierten Therapie sind bei Patienten mit nosokomialer Pneumonie und erhöhtem Risiko für Infektionen mit multiresistenten Erregern (MRE) zu empfehlen?

Bei Patienten mit erhöhtem Risiko für MRE gehören Piperacillin/ Tazobactam oder pseudomonaswirksame Carbapeneme bzw. Cephalosporine, initial in Kombination mit einem Aminoglykosid oder einem pseudomonaswirksamen Fluorchinolon zu den empfohlenen Therapieoptionen. Ceftazidim soll nur in Kombination eingesetzt werden. Die Substanzauswahl soll vor dem Hintergrund des lokalen Erregerspektrums und Resistenzprofils getroffen werden.

\section{Starke Empfehlung, Evidenz B}

Bei Verdacht auf eine MRSA-Infektion soll eine gegenüber MRSA wirksame Substanz hinzugefügt werden.

Starke Empfehlung, Evidenz B

Die Evidenz für die Auswahl einer Differenzialtherapie beatmungsassoziierter Pneumonien ist mäßig. Piperacillin/Tazobactam, pseudomonaswirksame Cephalosporine, pseudomonaswirksame Carbapeneme und die Fluorchinolone Ciprofloxacin und Levofloxacin wurden in Mono- bzw. Kombinationstherapie geprüft, ohne dass eine Überlegenheit einer Substanz hinsichtlich der Letalität gefunden wurde. Die meisten Daten wurden im Rahmen von Zulassungsstudien mit dem Ziel der Äquivalenz an begrenzten Kollektiven erhoben. Nur in wenigen Studien waren harte Endpunkte wie Sterblichkeit primärer Zielparameter, meist wurde klinisches oder bakteriologisches Ansprechen als Hauptparameter gewertet. In diesem Zusammenhang ist problematisch, dass nur eine Minderzahl der Studien verblindet war. Mit diesen Einschränkungen ergibt sich, dass ein Vorteil einer Substanz oder eines Regimes hinsichtlich der Sterblichkeit nicht gezeigt werden konnte. Im Hinblick auf Therapieversagen fanden sich in den meisten Studien und in einer Metaanalyse, die über 7000 Patienten mit HAP einschloss, insgesamt ebenfalls keine signifikanten Unterschiede [146]. Allerdings schnitt Ceftazidim in mehreren Studien hinsichtlich des klinischen Ansprechens schlechter ab als Meropenem oder Piperacillin/Tazobactam [146, 147]. Die Substanz weist eine unzureichende Staphylokokkenaktivität auf (s. Kapitel Antiinfektiva) und sollte nicht in Monotherapie verabreicht werden. Resistenz und Superinfektionen spielten in Abhängigkeit vom Erregerspektrum und der lokalen Resistenzsituation eine unterschiedlich große Rolle, waren jedoch in 
einigen Studien von Bedeutung für unterschiedliches Ansprechen unter Therapie mit Fluorchinolonen, Carbapenemen und Cephalosporinen [148-150]. Bei Verdacht auf Infektionen mit ESBL-Bildnern sind Carbapeneme Mittel der Wahl. Die hier gegebenen Empfehlungen ( $\bullet$ Tab. 13) berücksichtigen die aktuellen epidemiologischen und mikrobiologischen Daten in Deutschland (s. Kapitel Epidemiologie, Erregerspektrum). Darüber hinaus sind das lokale Erregerspektrum und Resistenzprofil für die Substanzauswahl von großer Bedeutung.

\section{E14: Wann sollte eine Kombinationstherapie gewählt werden?}

Eine initiale Kombinationstherapie soll ausschließlich bei Patienten mit erhöhtem Risiko für das Vorliegen multiresistenter Gramnegativer Erreger sowie bei septischem Schock eingesetzt werden. Nach drei Tagen soll die Erfordernis der Kombinationstherapie überprüft und bei Nachweis eines empfindlichen Erregers bzw. Stabilisierung des Patienten auf eine Monotherapie deeskaliert werden (Einzelheiten s. E17). Die Substanzauswahl soll vor dem Hintergrund des lokalen Erregerspektrums und Resistenzprofils getroffen werden.

\section{Starke Empfehlung, Evidenz B}

Studien zum Vergleich einer kalkulierten Monotherapie oder Kombinationstherapie der VAP wurden mehrfach mit unterschiedlichen Substanzen in den Studienarmen (divergente Kombination), seltener mit dem gleichen Betalaktamantibiotikum in beiden Studienarmen und einer zweiten Substanz aus einer anderen Klasse im Kombinationsarm (konvergente Kombination), durchgeführt. Geprüft wurden die Carbapeneme Meropenem und Imipenem jeweils allein oder in Kombination mit Ciprofloxacin bzw. Netilmicin sowie das Cephalosporin Cefepim mit oder ohne Amikacin als Partner. Es fand sich insgesamt kein Unterschied zwischen Mono- und Kombinationstherapie hinsichtlich der Sterblichkeit und generell auch kein Vorteil einer Kombinationstherapie hinsichtlich weiterer klinischer Endpunkte. Auch eine rezente Metaanalyse ergab keine Unterschiede zwischen Mono- und Kombinationstherapie [146]. Die Toxizität einer Kombinationstherapie von Betalaktam-Antibiotika mit Aminoglykosiden und der Selektionsdruck sind gegenüber einer Monotherapie erhöht. Eine erhöhte renale Toxizität im Kombinationsarm wurde mehrfach beobachtet und auf die Aminoglykosidkomponente zurückgeführt $[151,152]$. Hieraus ergibt sich die häufig geübte Strategie, die Aminoglykosidkomponente einer Kombinationstherapie bei klinischem Ansprechen nach 3-5 Tagen abzusetzen. Eine erhöhte Rate an Superinfektionen wurde im Kombinationsarm von Croce et al. gefunden [149]. Allerdings zeigte in der Studie von Heyland et al. der Kombinationsarm ein besseres mikrobiologisches Ansprechen in der Subgruppe der Patienten mit Infektionen durch Gram-negative MRE [53]. Eine weitere Studie verglich Cefepim in Monotherapie oder in Kombination mit Amikacin und zeigte einen klinischen Vorteil der Kombinationstherapie, der wesentlich auf ein besseres Ansprechen von Infektionen mit P. aeruginosa zurückzuführen war [153]. Weiterhin fand eine Beobachtungsstudie zur Therapie von $P$. aerugino$s a$-Infektionen bei VAP einen Vorteil der initialen Kombinationstherapie, wenn auf diese Weise das Risiko einer ineffektiven Monotherapie vermieden wurde. Wenn gezielt auf eine wirksame Monotherapie deeskaliert wurde, war kein Nachteil im Vergleich zu einer weiter verabreichten Kombination feststellbar [154]. Diese Befunde sprechen dafür, dass der Wert einer Kombinationstherapie vor allem in der Vermeidung einer inadäquaten Initialtherapie bei hohem Risiko von Infektionen mit MRE be-
Tab.13 Kalkulierte antimikrobielle Therapie bei nosokomialer Pneumonie, Patienten mit erhöhtem Risiko für multiresistente Erreger.

\begin{tabular}{ll}
$\begin{array}{l}\text { Substanz } \\
\text { Pseudomonaswirksames }\end{array}$ & Dosierung (pro Tag) \\
Betalaktam & \\
\hline $\begin{array}{l}\text { Piperacillin/Tazobactam } \\
\text { oder }\end{array}$ & $3-4 \times 4,5 \mathrm{~g}$ \\
\hline Cefepim & $3 \times 2 \mathrm{~g}$ \\
\hline Ceftazidim & $3 \times 2 \mathrm{~g}$ \\
\hline oder & $3 \times 1 \mathrm{~g}$ \\
\hline Imipenem/Cilastatin & $3 \times 1 \mathrm{~g}$ \\
\hline Meropenem & $3 \times 0.5-1 \mathrm{~g}$ \\
\hline Doripenem & \\
\hline plus & $3 \times 400 \mathrm{mg}$ \\
\hline Fluorchinolon & $2 \times 500 \mathrm{mg}$ \\
\hline Ciprofloxacin & \\
\hline Levofloxacin & $2 \times 15 \mathrm{mg} / \mathrm{kg}($ Talspiegel: $15-20 \mu \mathrm{g} / \mathrm{ml})$ \\
\hline oder & $1 \times 3-7 \mathrm{mg} / \mathrm{kg}($ Talspiegel $<1 \mu \mathrm{g} / \mathrm{ml})$ \\
\hline Aminoglykosid & $1 \times 3-7 \mathrm{mg} / \mathrm{kg}($ Talspiegel $<1 \mu \mathrm{g} / \mathrm{ml})$ \\
\hline Gentamicin & $1 \times 15-20 \mathrm{mg} / \mathrm{kg}($ Talspiegel $<4 \mu \mathrm{g} / \mathrm{ml})$ \\
\hline Tobramycin & \\
\hline Amikacin & \\
\hline bei MRSA-Verdacht & \\
\hline $\begin{array}{l}\text { plus Glykopeptid od. } \\
\text { Oxazolidinon } \\
\text { Vancomycin }\end{array}$ & \\
\hline Linezolid & \\
\hline
\end{tabular}

steht. Insbesondere beim septischen Schock wurde eine deutliche Exzessmortalität gefunden, wenn eine adäquate Therapie verzögert eingeleitet wurde [130]. Bei lebensbedrohlichen Infektionen ist das Risiko einer inadäquaten Initialtherapie zu vermeiden. Andererseits besteht das Problem des zunehmenden Selektionsdrucks unter prolongierter breiter Initialtherapie. Ein stringentes Deeskalationskonzept sollte daher Bestandteil jeder Breitspektrumtherapie sein.

Bei der Prüfung divergenter Regime fand sich mehrfach eine Unterlegenheit der Kombination aus Ceftazidim und Aminoglykosid gegenüber der Monotherapie mit Meropenem [147,155]. Dieses Studiendesign erlaubt wegen der Nichtvergleichbarkeit der getesteten Betalaktamantibiotika keine Aussage hinsichtlich der Rolle von Mono- und Kombinationstherapie.

\section{E15: Wann soll eine vorzeitige Beendigung der Therapie erwogen werden?}

Besteht trotz neu aufgetretener Infiltrate klinisch eine niedrige Wahrscheinlichkeit für eine HAP, soll die antibiotische Therapie nach drei Tagen beendet werden. Ergibt die Diagnostik eine schwere Sepsis/einen septischen Schock mit anderem Fokus, ist die Therapie anzupassen.

Starke Empfehlung, Evidenz B

Da eine frühzeitige adäquate antibiotische Therapie prognoseentscheidend, die Diagnose jedoch unter Umständen schwer zu stellen ist, scheint ein gewisser Anteil von Antibiotika-Therapien nichtinfektiös bedingter, neu aufgetretener Infiltrate, die für eine HAP gehalten werden, unvermeidbar. Um den Patienten nicht mit einer unnötigen Therapie zu gefährden und die Selektion resistenter Erreger zu vermeiden, sollte diese Therapie frühestmöglich beendet werden, wenn sich trotz klinischen Anfangsverdachts die Diagnose HAP nicht bestätigt hat. So konnte bei Patienten mit neu aufgetretenen Infiltraten, die klinisch jedoch nur eine moderate Wahrscheinlichkeit für eine VAP aufwiesen 
$(\mathrm{CPIS} \leq 6)$, in einer randomisierten Studie die Antibiotika-Therapie nach drei Tagen beendet werden, wenn sich keine klinische Verschlechterung zeigte. Dieses Vorgehen verminderte das Risiko bakterieller Superinfektionen durch resistente Erreger und verkürzte die Liegezeit auf Intensivstation [156]. Die vorzeitige Beendigung der Antibiotikatherapie in einem solchen Fall ist daher unbedenklich.

\section{E16: Wann und nach welchen Kriterien soll der}

Therapieerfolg evaluiert werden?

Eine Reevaluation des Patienten soll 48-72 Stunden nach Beginn der Therapie erfolgen. Hierzu gehört die Beurteilung des klinischen Verlaufs, der Ergebnisse der initialen mikrobiologischen Diagnostik, der Röntgenverlaufsuntersuchung und von Biomarkern.

\section{Starke Empfehlung, Evidenz B}

Für die Beurteilung eines Therapieerfolges hat die Reevaluation des Patienten am 3.-4. Tag nach Beginn der Therapie eine zentrale Bedeutung. Neben den zu diesem Zeitpunkt meist vorliegenden Ergebnissen der kulturellen Diagnostik sollte eine Verlaufsbeurteilung der klinischen Parameter, des Gasaustausches und der Entzündungsparameter erfolgen. Allerdings zeigt eine prospektive Studie an 27 Patienten, dass bei Therapieerfolg die Abnahme der Körpertemperatur, der Leukozytenzahl und der $\mathrm{KBE} / \mathrm{ml}$ in der BAL sowie ein Anstieg des $\mathrm{paO}$ / $\mathrm{FiO} 2$ bereits 24 Stunden nach Therapiebeginn zu beobachten ist [157]. Bei Patienten, die mit Enterobacteriaceae oder $P$. aeruginosa infiziert waren, zeigte sich ein klinischer Therapieerfolg trotz Persistenz der Pathogene im Tracheobronchialsekret [157].

Eine prospektive Studie an 75 Patienten untersuchte den Verlauf von APACHE II, SOFA, CRP und PCT [158]. In der multivariaten Analyse war nur ein Abfall der Inflammationsparameter C-reaktives Protein (CRP) und PCT an Tag 4 ein unabhängiger Prädiktor für das Überleben. Die prognostische Wertigkeit des Verlaufes proinflammatorischer Parameter, insbesondere für PCT, wurde in mehreren Studien bestätigt $\left[97,98,159^{*}, 160\right]$.

Mehrere Studien haben zeigen können, dass Biomarker wie PCT, aber auch CRP, in der Verlaufskontrolle als Marker eines Therapieansprechens eingesetzt werden können. Sehr niedrige absolute PCT-Werte $(<0,1-<0,25 \mu \mathrm{g} / \mathrm{l})$ oder ein Abfall auf $<90 \%$ des Ausgangswerts zeigen ein Therapieansprechen an [161,162]. Ähnlich war ein CRP-Quotient nach/vor Therapie <0,8 nach 96 Stunden mit einem Therapieansprechen assoziiert [163].

\section{E17: Wann und wie soll eine Deeskalation der Initial- therapie erfolgen?}

Die Deeskalation soll 48-72 Stunden nach Therapiebeginn anhand der Ergebnisse der Reevaluation erfolgen. Bei klinischer Besserung, aber fehlendem Nachweis eines respiratorischen Pathogens soll die Deeskalation auf eine Monotherapie mit dem in der Initialkombination enthaltenen Betalaktamantibiotikum oder Fluorchinolon erfolgen.

Starke Empfehlung, Evidenz B

Bei Nachweis eines respiratorischen Pathogens soll auf eine gezielte Monotherapie mit schmalem Spektrum umgesetzt werden. Eine initiale kalkulierte Therapie gegen MRSA soll beendet werden, falls ein solcher Erreger nicht nachgewiesen wurde. Starke Empfehlung, Evidenz B

Durch die Deeskalation der initial breit gewählten kalkulierten Antibiotikatherapie sollen das Risiko der Selektion multiresistenter Keime mit konsekutiver Superinfektion und/oder Nebenwirkungen der antibiotischen Therapie reduziert werden. Zentraler
Bestandteil der Deeskalation ist die Reevaluation des Patienten nach 48-72 Stunden, da zu diesem Zeitpunkt das klinische Ansprechen beurteilt werden kann und die Ergebnisse der mikrobiologischen Diagnostik vorliegen.

Konnte kein kausales Pathogen identifiziert werden, sollte bei klinischem Ansprechen auf eine Monotherapie mit einem in der Initialkombination enthaltenen Betalaktamantibiotikum oder Fluorchinolon umgestellt werden.

Konnte ein kausales Pathogen identifiziert werden, sollte die Therapie von einer Kombinations- auf eine Monotherapie mit einem resistenzgerechten aber möglichst schmalen Spektrum umgestellt werden. Voraussetzung hierfür ist die korrekte Identifizierung des zugrunde liegenden Pathogens durch quantitative Kulturen aus respiratorischen Materialien, wobei die besten Daten für bronchoskopisch gewonnenes Material vorliegen [164]: In einer randomisierten monozentrischen Studie konnte bei $66 \%$ der Patienten basierend auf Ergebnissen einer quantitativen BAL eine Deeskalation vorgenommen werden, während die Ergebnisse eines semiquantitativen Trachealsekretes nur in $21 \%$ eine Deeskalation ermöglichten. Hinsichtlich Rezidivrate und Sterblichkeit wurden in einer Kohortenstudie an chirurgischen Intensivpatienten mit VAP $(n=138)$ mit stringenter Deeskalationsstrategie basierend auf Ergebnissen einer quantitativen BAL keine signifikanten Unterschiede gegenüber einer nicht deeskalierten Therapie gefunden [165].

Eine neue, durch weitere Studien zu bestätigende Strategie ist die Schnelltestung der Antibiotikaresistenz ohne vorherige Speziesdifferenzierung durch E-Tests, die direkt auf das ausgestrichene Material aufgebracht werden. In einer randomisierten Studie wurden E-Tests an Kulturen blind gewonnener Tracheobronchialsekrete durchgeführt und diese als vorläufiges SchnelltestErgebnis innerhalb von 24 Stunden dem behandelnden Arzt kommuniziert [166]. Diese Strategie verminderte im Vergleich zur konventionellen Diagnostik die Beatmungsdauer, die Anzahl der Fälle von C. difficile-Colitis sowie den Antibiotikaverbrauch.

\section{E18: Wie lange sollten nosokomiale Pneumonien} behandelt werden?

Die Therapiedauer soll im Regelfall acht Tage betragen. Bei speziellen Ätiologien ist eine längere Behandlung zu erwägen, um die Rezidivrate zu senken.

Starke Empfehlung, Evidenz A

Biomarker können zur Steuerung der Therapiedauer eingesetzt werden. Eine relevante Verkürzung der Therapiedauer über empfohlene Zeiten hinaus oder eine Verbesserung gegenüber Standardmethoden ist nicht belegt.

Keine Empfehlung, Evidenz B

Zur optimalen Therapiedauer bei HAP nichtbeatmeter Patienten gibt es keine Daten aus kontrollierten Studien. Eine doppelblinde multizentrische Studie an 401 Patienten mit VAP zeigte keinen Unterschied der Heilungsrate zwischen einer 8- bzw. 15-tägigen Therapie [49]. Lediglich bei nachgewiesener Infektion durch Non-Fermenter (A. baumannii, P. aeruginosa, S. maltophilia) war die längere Therapiedauer mit einer verminderten Rückfallrate assoziiert ( $41 \%$ vs $25 \%$ ). Allerdings war nach 15 -tägiger Therapie im Falle eines Rezidivs der Nachweis resistenter Erreger signifikant höher, sodass jede länger als acht Tage dauernde Therapie kritisch hinterfragt werden sollte. Zudem wurde in einer allerdings retrospektiven Analyse von 154 Patienten mit VAP durch Non-Fermenter die niedrigere Rezidivrate durch eine längere Therapie nicht bestätigt ( $22 \%$ für $<8$ Tage und $34 \%$ für $>8$ Tage, nicht signifikant) [167]. 
Weitere Infektionen, für die eine Therapiedauer von mindestens zwei Wochen diskutiert werden sollte, sind:

- Legionellosen, bei denen eine prolongierte Therapie empfohlen wird, ohne dass hierzu vergleichende Studien vorliegen.

- bakteriämische S. aureus-Infektionen, bei denen Hinweise für eine höhere Erfolgsrate bei einer Therapiedauer von mindestens 14 Tagen vorliegen [168]. Für die Kombination aus Bakteriämie und Pneumonie, die als komplizierte S. aureus-Bakteriämie eingestuft wird, wird überwiegend eine vierwöchige Therapiedauer empfohlen [169*].

- invasive pulmonale Aspergillosen, bei denen eine Therapiedauer von 6-12 Wochen empfohlen wird [170]; diese Empfehlung wurde allerdings von immundefizienten Patientenkollektiven abgeleitet.

$\mathrm{Zu}$ einer fix vorgegebenen Therapiedauer von unter acht Tagen gibt es keine Studien. Allerdings konnte in einem RCT über eine protokollgesteuerte Therapie (Absetzen der Antibiotika, wenn alle folgenden Kriterien erfüllt waren: Fieber $<38,3^{\circ}$, Leukozyten $<10.000 / \mu l$ oder Abfall um 25\%, kein purulentes Sputum, keine Zunahme des radiologischen Infiltrates, pO2/FiO2 > $250 \mathrm{mmHg}$ ) die Therapiedauer signifikant von acht Tagen (Vergleichsgruppe) auf sechs Tage gesenkt werden. Hinsichtlich Rezidivrate und Sterblichkeit wurden keine Unterschiede gefunden [171].

Zur Steuerung und Verkürzung der Therapiedauer durch Biomarker gibt es positive Studien [162]. Ihr Einsatz kann zur Einsparung von Antibiotika und damit zur Reduktion des Selektionsdrucks beitragen. Sie werden dennoch aus folgenden Gründen zurzeit nicht generell empfohlen:

1. Die Standardgruppen, gegen die Biomarker evaluiert wurden, weisen eine sehr hohe Behandlungsdauer auf, die nach klinischen Studien [49], aber auch den Biomarker-Studien selbst, nicht angemessen sind. So sollte die durchschnittliche Dauer der Antibiotikagabe acht Tage nicht überschreiten. Auch unter einer PCT-gesteuerten Therapie wird dieses Ziel nur geringfügig unterschritten.

2. Es liegen keine Kosten-Nutzen-Studien vor.

3. Andere, sehr einfache und kostenfreie Strategien der Reduktion der Therapiedauer $[45,156]$ stehen in Konkurrenz zu biomarkergesteuerten Strategien. Ob Biomarker diesen noch überlegen sind, steht in Zweifel.

\section{E 19: Welches Vorgehen sollte bei einem Therapie- versagen gewählt werden?}

Bei Therapieversagen sollte eine erneute, wenn möglich invasive Diagnostik zur Klärung der Ätiologie erfolgen. In Abhängigkeit vom differenzialdiagnostischen Spektrum ist darüber hinaus eine erweiterte bildgebende Diagnostik zu erwägen.

\section{Schwache Empfehlung, Evidenz B}

Ein Therapieversagen bei HAP stellt eine vital bedrohliche Situation dar, die rasches Handeln und eine zielgerichtete Diagnostik erfordert. Es ist definiert als fehlendes klinisches Ansprechen und/oder Ausbreitung der Röntgeninfiltrate zum Zeitpunkt der Reevaluation nach 48-72 Stunden. Bei Patienten mit HAP und schwerer Sepsis oder septischem Schock ist eine fehlende Besserung oder Verschlechterung des Sepsisstadiums als Anzeichen des Therapieversagens zu werten. Darüber hinaus identifizierte die multivariate Post-hoc-Analyse eines RCT mit 740 Patienten eine fehlende Verbesserung von paO2/FiO2 an Tag 3 als unabhängigen Prädiktor für ein Therapieversagen [172].

Die Ursachen eines Therapieversagens bei HAP sind vielfältig ( Tab. 14). Zum Nachweis einer Infektion mit Erregern, die eine primäre oder sekundär erworbene Resistenz gegenüber der ini-
Tab. 14 Differenzialdiagnose des Therapieversagens bei HAP.

Bei korrekter Diagnose
- Infektion mit primär resistentem bakteriellen oder nichtbakteriellen
Erreger
- Resistenzentwicklung unter Therapie
- Unterdosierung der antimikrobiellen Therapie
- Superinfektion mit „neuem“ Erreger
- einschmelzende/organüberschreitende Infektion
(z. B. Lungenabszess, Pleuraempyem)
Diese Diagnosen können durch adäquate mikrobiologische Diagnostik bzw.
thorakale Bildgebung bestätigt oder ausgeschlossen werden.
Bei Fehldiagnose HAP
- interstitielle Lungenerkrankung (z. B. cryptogen organisierende
Pneumonie [COP], medikamenten-induzierte Pneumonitis)
- kongestive Herzinsuffizienz
- Lungenembolie/Lungeninfarkt
- alveoläre Hämorrhagie
- Aspirationssyndrom
- Atelektase
Die Überprüfung dieser Diagnosen erfordert Echokardiografie, Bronchosko-
pie mit Differenzialzytologie bzw. Angio-CT.

tialen Antibiotika-Therapie aufweisen, oder einer Superinfektion sollte eine erneute mikrobiologische Diagnostik aus respiratorischen Materialien erfolgen. Die in vielen Studien gefundene leicht überlegene Sensitivität einer invasiven Diagnostik kann in dieser Situation eine bronchoskopische Diagnostik begründen $[173,174]$. Es bestehen jedoch grundsätzlich dieselben Limitationen der quantitativen Kultur wie bei primärer Evaluation [175]. Eine Therapiepause („diagnostisches Fenster“) ist nicht indiziert. Die Diagnostik soll vor Gabe neuer Antibiotika erfolgen [116]. Ein weiterer Vorteil der bronchoskopischen Diagnostik ist die Klärung nicht-infektiöser Differenzialdiagnosen wie interstitieller Lungenerkrankungen, alveolärer Hämorrhagien oder Atelektasen. Zur Klärung der dem Therapieversagen zugrunde liegenden Ursache kann eine erweiterte Bildgebung mit Thorax-CT, Echokardiografie oder Thoraxsonografie indiziert sein.

Ein Therapieversagen kann auch bei empfindlichem Erreger vorliegen, wenn sich eine Ausbreitung der Infektion in die Pleura (Pleuraempyem) oder größere pulmonale bzw. extrapulmonale Einschmelzungen entwickelt haben, die die Effektivität der Antibiotika behindern und eine Drainagetherapie erfordern.

\section{E20: Sollte eine „Ventilator-assoziierte Tracheo-} bronchitis“ (VAT) antimikrobiell therapiert werden?

Bei beatmeten Patienten stellt eine VAT möglicherweise einen Risikofaktor für die Entwicklung einer VAP dar. Eine AntibiotikaTherapie kann nicht empfohlen werden, da hierfür keine ausreichende Evidenz besteht.

\section{Keine Empfehlung, Evidenz C}

In Ausnahmefällen sollte bei Risikopatienten und/oder Kolonisation mit MRE bei zunehmendem purulentem Atemwegssekret oder rezidivierenden bronchopulmonalen Infektionen eine Antibiotika-Therapie erwogen werden.

Schwache Empfehlung, Evidenz C

Derzeit existiert keine einheitliche Definition der VAT. In Studien wurden klinische Zeichen der tiefen Atemwegsinfektion (Leukozytose, Fieber, purulentes Sekret) ohne neu aufgetretene oder progrediente Infiltrate zugrundegelegt. Eine exakte radiologische Abgrenzung zwischen VAT und VAP kann im Einzelfall schwierig sein. Bestätigt wird die klinische Diagnose durch mikrobiologische Befunde im Trachealsekret (Gramfärbung, Kultur). Mit den gleichen Einschränkungen wie bei der VAP kann 
hierbei der semiquantitative bzw. quantitative Erregernachweis zur Differenzierung zwischen Kolonisation und Infektion beitragen. Häufig zugrunde gelegte Schwellenwerte liegen bei $10^{5}-10^{6}$ $\mathrm{KBE} / \mathrm{ml}$, sind allerdings nicht systematisch untersucht.

Insgesamt stellt die VAT derzeit noch kein valides diagnostisches Konzept dar. Hieraus ergeben sich auch wesentliche Limitationen der bislang durchgeführten Studien an kleinen Patientenkollektiven zur Therapie der VAT mit systemischen +/- aerosolierten Antibiotika. Palmer et al. [176] fanden unter aerosolierten Antibiotika (Gentamicin und/oder Vancomycin, $n=19$ ) eine Reduktion pulmonaler Infektionszeichen gegenüber Plazebo $(n=24)$. Allerdings lag bei lediglich 11 Patienten eine alleinige VAT vor; bei 32 der insgesamt 43 Patienten bestand zusätzlich eine VAP, die systemisch mit Antibiotika therapiert wurde. Nseir et al. [177] dokumentierten bei Patienten mit VAT unter 8-tägiger intravenöser Antibiotika-Therapie $(n=22)$ eine Abnahme konsekutiver VAP-Episoden, mehr beatmungsfreie Tage und eine niedrigere ICU-Mortalität gegenüber der unbehandelten Kontrollgruppe $(n=36)$. Weitere klinische Studien zur Bestätigung dieser Befunde, aber auch zur Klärung der Diagnosekriterien, des Nutzen-Risiko-Verhältnisses sowie potenzieller Vorteile inhalativer vs. systemischer Antibiotika-Applikation bleiben abzuwarten.

Beim derzeitigen Kenntnisstand kann daher eine antimikrobielle Therapie der VAT nicht generell empfohlen werden. Unabhängig hiervon kann nach Meinung der Leitliniengruppe im Einzelfall bei Risikopatienten mit zunehmend purulentem Atemwegssekret ein Therapieversuch erwogen werden. Hierzu gehören z.B. Patienten mit rezidivierenden Pneumonien unter Beatmung, bekannter tracheobronchialer Kolonisation mit MRE, insuffizienter Sekretelimination durch Hustenschwäche oder Dysphagie mit Aspirationsneigung, insbesondere im Beatmungsentwöhnungsprozess. Für eine antimikrobielle Therapie einer Tracheobronchitis nach thoraxchirurgischen Eingriffen gibt es keine Evidenz.

E21: Wann ist eine inhalative antimikrobielle Therapie der VAP (allein/in Kombination mit systemischer Therapie) indiziert?

Eine inhalative Antibiotika-Therapie kann derzeit nicht generell empfohlen werden. In ausgewählten Fällen, wie bei Vorliegen multiresistenter Erreger, sollte die Gabe von aerosoliertem Colistin oder Tobramycin zusätzlich zu einer systemischen AntibiotikaTherapie erwogen werden.

Schwache Empfehlung, Evidenz C

Inhalative Antibiotika spielen bei der Therapie von Patienten mit cystischer Fibrose und chronischer Infektion durch $P$. aeruginosa eine wichtige Rolle. Zur alleinigen oder adjunktiven inhalativen Therapie der beatmungsassoziierten Pneumonie existieren zwar vielversprechende tierexperimentelle Studien; ihr Stellenwert bei Patienten mit VAP ist hingegen noch ungeklärt. Prospektive, kontrollierte Studien mit relevanten Fallzahlen liegen nicht vor. Korbila et al. untersuchten in einer retrospektiven, zweiarmigen Kohortenstudie 121 Patienten mit VAP, die bei Nachweis von MRE (vornehmlich A. baumannii, sowie P. aeruginosa und K. pneumoniae) mit Colistin i.v. behandelt worden waren. 78 dieser Patienten hatten zusätzlich Colistin inhalativ erhalten und wiesen eine höhere Heilungsrate auf bei unveränderter KrankenhausMortalität [178]. Ghannam et al. fanden in einer retrospektiven Fall-Kontrollstudie an Tumorpatienten mit VAP (69\% P. aeruginosa) Vorteile einer inhalativen Aminoglykosid- oder ColistinTherapie gegenüber einer intravenösen Applikation dieser Medikamente im Hinblick auf klinische und mikrobiologische Infektionszeichen [179]. Eine nicht kontrollierte retrospektive Studie
[180] deutet auf einen möglichen Nutzen von adjunktivem, aerosoliertem Tobramycin, Amikacin oder Colistin bei VAP hin.

Durch die Aerosolierung von Antibiotika lassen sich hohe lokale Konzentrationen erreichen. Dies kann insbesondere bei Infektionen mit MRE vorteilhaft sein, bei denen hohe Konzentrationen am Ort der Infektion erforderlich sind. Zudem vermindert die lokale Applikation den Selektionsdruck auf die Darmflora und bietet Vorteile hinsichtlich systemischer Nebenwirkungen, wie bei vorbestehender Niereninsuffizienz. Andererseits ist die Penetration aerosolierter Antibiotika in das betroffene Lungenparenchym unter klinischen Bedingungen unklar.

Derzeit kann eine Indikation zur inhalativen Antibiotikatherapie der VAP im Einzelfall bei Patienten mit Nachweis von MRE erwogen werden, die systemisch nicht ausreichend oder nur unter Inkaufnahme erheblicher Toxizitäten behandelbar sind. Auf den Einsatz geeigneter Verneblersysteme sollte geachtet werden, um eine ausreichende Deposition und eine optimale Tröpfchengröße zu gewährleisten. Zudem kann die effektive Dosierung unter Beatmung erheblich differieren. Die inhalative Applikation kann ferner in Einzelfällen zu Bronchospasmus und Husten führen.

Der Nutzen einer inhalativen Monotherapie ohne gleichzeitige systemische Antibiotika-Therapie ist ungeklärt.

E22: Wie sieht die adäquate gezielte Therapie aus bei Nachweis von Infektionen mit: MRSA - Pseudomonas aeruginosa - Acinetobacter baumannii - Stenotrophomonas maltophilia - ESBL-bildenden Enterobakterien Carbapenem-resistenten Enterobakterien?

Bei der gezielten Therapie der HAP soll die Substanzauswahl nach den folgenden Kriterien erfolgen:

- MRSA-Stämme: Geprüfte Antiinfektiva in der Monotherapie sind Vancomycin, Teicoplanin und Linezolid. Bei schwerer Erkrankung stellt eine Kombination von Vancomycin mit Rifampicin eine weitere Option dar.

- P. aeruginosa: Ceftazidim, Cefepim, Piperacillin, die Carbapeneme Doripenem, Imipenem und Meropenem sowie Ciprofloxacin und Levofloxacin sind wirksame Therapieoptionen. Die Kombination eines pseudomonaswirksamen BetalaktamAntibiotikums mit einem Aminoglykosid (Gentamicin, Tobramycin, Amikacin) oder einem Fluorchinolon ist im Einzelfall zu erwägen (schwere Infektion). Eine Überlegenheit gegenüber der Monotherapie ist aber nicht sicher belegt. Bei Resistenz gegenüber allen Standardsubstanzen ist eine Therapie mit Colistin indiziert; eine Kombinationstherapie ist hierbei anzustreben, möglichst in Rücksprache mit einem Infektiologen/ Mikrobiologen.

- ESBL-Stämme: Carbapeneme sind wirksam. Bei zusätzlicher Resistenz gegen Carbapeneme kommt Colistin zum Einsatz, möglichst in Kombination.

- Stenotrophomonas maltophilia: Bei In-vitro-Empfindlichkeit ist Cotrimoxazol indiziert. Bei Resistenz gegenüber Cotrimoxazol soll eine Sensibilitätsprüfung auf Ceftazidim, Moxifloxacin, Levofloxacin, Tigecyclin und Ticarcillin/Clavulansäure erfolgen und auf eine dieser Substanzen zurückgegriffen werden. Zuvor ist die klinische Relevanz des Isolates zu prüfen.

- Acinetobacter spp.: Imipenem oder Meropenem sind am häufigsten wirksam. Bei Panresistenz ist Colistin indiziert, möglichst in Kombination mit einer weiteren in vitro wirksamen Substanz. Tigecyclin stellt eine zusätzliche Option für die Salvage-Therapie dar. 
Zur Therapiedauer s. Empfehlung E18. Die Notwendigkeit einer generellen Kombinationstherapie ist nicht etabliert. Angaben zur Dosierung finden sich im Kapitel Antiinfektiva.

\section{Starke Empfehlung, Evidenz B}

Pneumonien durch multiresistente Bakterien wie MRSA oder $P$. aeruginosa gehen häufiger als bei anderen Erregern mit einem Therapieversagen einher $[36,148,151,181]$, vor allem bei inadäquater Therapie [154] oder verzögertem Therapiebeginn [142]. Für MRSA konnte jedoch gezeigt werden, dass bei angemessener Therapie die Letalität im Vergleich zu MSSA nicht erhöht ist [182, 183].

Die Prüfung neuer Substanzen in der Therapie der HAP durch MRSA wie Linezolid und Quinopristin/Dalfopristin gegenüber den Glykopeptiden Vancomycin und Teicoplanin zeigte widersprüchliche Ergebnisse. Eine Metaanalyse über Studien zu Linezolid versus einem Glykopeptid ergab in der empirischen Therapie keine klinische Überlegenheit einer der beiden Substanzen [184*]. Nur in einer methodisch angreifbaren retrospektiven Analyse zweier gepoolter, prospektiver Studien, die ebenfalls jeweils keine Überlegenheit von Linezolid gegenüber Vancomycin aufwiesen, zeigten die Subkollektive von Patienten mit MRSAPneumonie unter Linezolid eine höhere klinische Erfolgsrate und eine geringere Letalität [185]. Bei Patienten mit kulturell gesicherter, vorwiegend nosokomialer MRSA-Pneumonie zeigten sich in einer großen prospektiven, multizentrischen Studie mit dem Ziel, eine Nicht-Unterlegenheit nachzuweisen (non inferiority design), keine Unterschiede zwischen Vancomycin und Linezolid hinsichtlich der 60-Tage-Letalität. In der Per-Protocol-Population zeigte sich unter Linezolid ein besseres klinisches Ansprechen, allerdings mit weiten Konfidenzintervallen der Signifikanz, sodass der tatsächliche Effekt fraglich bleibt [186*]. Risikofaktoren wie invasive Beatmung und Bakteriämie waren nicht gleich verteilt, die erzielten Spiegel für Vancomycin waren nicht in allen Fällen ausreichend. Die Nephrotoxizität war in dieser Studie in der Linezolid-Gruppe signifikant geringer als in der Vancomycin-Gruppe.

Die Bewertung der Ergebnisse dieser Studien wurde in der Leitliniengruppe kontrovers diskutiert. Es bestanden unterschiedliche Auffassungen darüber, ob die insgesamt nicht konsistenten Resultate hinsichtlich der Wirksamkeit und Nephrotoxizität der beiden Vergleichssubstanzen den Schwierigkeiten in der Durchführung von Studien unter Einschluss von Patienten mit nosokomialer MRSA-Pneumonie oder einer tatsächlich fehlenden Überlegenheit von Linezolid zuzuschreiben ist.

Insofern bleibt die bevorzugte Therapie von nosokomialen MRSA-Pneumonien dem Ermessen des Klinikers und seiner Einschätzung der Studienlage überlassen.

Quinopristin/Dalfopristin war äquivalent gegenüber Vancomycin in der Therapie der nosokomialen Pneumonie überwiegend maschinell beatmeter Patienten, sowohl im Gesamtkollektiv wie in der bakteriologisch auswertbaren Patientengruppe [187]. Das Präparat ist in Deutschland nicht verfügbar. Im Hinblick auf die Pharmakokinetik und -dynamik von Vancomycin wurden Patienten mit Bakteriämie oder Pneumonie durch MRSA in zwei Dosierungsmodi untersucht. Die kontinuierliche Infusion mit einem Zielspiegel von $20-25 \mathrm{mg} / \mathrm{l}$ ergab im Vergleich zur Intervallgabe alle 12 Stunden mit einem angestrebten Talspiegel von 10-15 mg/l gleiche klinische und mikrobiologische Erfolgsraten [188]. Das frühere Erreichen des Zielspiegels, geringere Schwankung in der Serumkinetik und die geringeren Kosten für Serumspiegelkontrollen und Medikamente können Argumente für die kontinuierliche Applikation sein. Der Stellenwert einer Kombinations- therapie aus Vancomycin und Rifampicin wurde in einer randomisierten monozentrischen Studie geprüft [189*]. Sie ergab eine Überlegenheit der Kombination im Hinblick auf die klinische Erfolgsrate bei nachgewiesener MRSA-Infektion (primärer Endpunkt), weist allerdings eine Reihe von Limitationen auf wie begrenzte Patientenzahl und inkonsistente Resultate bei verschiedenen Endpunkten. Weitere Antiinfektiva wie Fosfomycin und Cotrimoxazol, die in vitro gegenüber MRSA aktiv sind, wurden in der Indikation HAP nicht geprüft.

Während in der empirischen Initialtherapie die Kombination eines pseudomonaswirksamen Betalaktams mit einem Aminoglykosid oder einem Fluorchinolon höhere Erfolgsraten durch Erfassung von MRE ergibt, zeigen sich in der gezielten Behandlung von Erkrankungen durch $P$. aeruginosa keine sicheren Vorteile der Kombination (s. Empfehlung E14). In einer großen nichtinterventionellen Kohortenstudie war die Monotherapie mit einem pseudomonaswirksamen Betalaktam oder Fluorchinolon der Kombinationstherapie (Betalaktam + Aminoglykosid oder Fluorchinolon) nicht unterlegen [154]. Allerdings ging Meropenem gegenüber der Kombination von Ceftazidim und Tobramycin in einer anderen Prüfung häufiger mit einem Therapieversagen einher, während zugleich die klinische und mikrobiologische Heilungsrate bei Vorliegen anderer Erreger durch Meropenem höher war [147]. Subgruppenanalysen von Studien bei Patienten mit Nachweis von $P$. aeruginosa ergaben für Imipenem eine höhere Rate von Therapieversagen gegenüber Ceftazidim oder Piperacillin/Tazobactam [1901-192]. Im Vergleich zwischen Imipenem und Ciprofloxacin fanden sich keine Unterschiede in der Eradikation von $P$. aeruginosa [148]. Doripenem war gegenüber Imipenem klinisch äquipotent [47]. Bei Nachweis einer Multiresistenz gegenüber pseudomonaswirksamen Antibiotika oder bei Therapieversagen wurde in kleineren Kohortenstudien erfolgreich Polymyxin B und Polymyxin E (Colistin) eingesetzt, meist als Kombinationstherapie mit verschiedenen Partnersubstanzen [65 -67, 193]. Die Bakterizidie von Colistin kann durch die Kombination mit anderen Substanzen erhöht werden [194]. Adjunktiv zur systemischen Therapie wurde Polymyxin B in einer kleinen einarmigen Kohortenstudie erfolgreich inhalativ eingesetzt [195]. Die Evidenz zur Therapie anderer multiresistenter Bakterien beschränkt sich auf kleine monozentrische Beobachtungsserien. Pneumonien durch ESBL-bildende Enterobakterien (vor allem Klebsiella spp. und E. coli) sind der Behandlung mit einem Carbapenem zugänglich [196]. Das nicht pseudomonaswirksame Ertapenem kann die Selektion Carbapenem-resistenter Stämme verhindern. Andere, in vitro wirksam getestete Antiinfektiva sollten wegen ungenügender klinischer Wirksamkeit nur nach Rücksprache mit einem Infektiologen/Mikrobiologen eingesetzt werden [197]. Meist in Kombination mit ESBL finden sich auch Carbapenemase-bildende Gram-negative Bakterien. Sie wurden in Kasuistiken und kleinen Fallserien mit Colistin und Tigecyclin, zum Teil in Kombination mit Aminoglykosiden, behandelt [193, 198*]. Eine gepoolte Analyse von 13 Therapiestudien zu Tigecyclin ergab allerdings für Patienten mit VAP eine Exzessletalität im Vergleich zu den Komparatoren. Die Substanz ist zur Therapie der HAP nicht zugelassen und sollte ausschließlich in der Salvage-Therapie eingesetzt werden. Die entsprechenden FDA-Warnungen sind bei einer Anwendung im Einzelfall zu beachten (s. Kapitel Antiinfektiva).

A. baumannii und S. maltophilia weisen regelmäßig eine Multiresistenz auf. Der Nachweis von S. maltophilia in respiratorischen Isolaten ist häufig die Folge einer prolongierten Therapie mit einem Carbapenem. Die klinische Bedeutung ist oft zweifelhaft 
und sollte immer kritisch geprüft werden [199]. Bei Therapiebedürftigkeit wurden Cotrimoxazol und Tigecyclin [200] eingesetzt. A. baumannii weist sehr unterschiedliche Resistenzmuster auf und wird entsprechend dem Antibiogramm behandelt. Die Isolate sind oft gegen Ampicillin/Sulbactam, Carbapeneme oder Tigecyclin sensibel [201*]. Die Testung auf Ampicillin/Sulbactam in der Routinediagnostik ist allerdings nicht zuverlässig, sodass diese Option von der Leitliniengruppe nicht empfohlen wird. Zur Therapie wurden lediglich kleine Fallserien publiziert. Dabei kamen Tetrazykline [202], Tigecyclin [203,204], Ampicillin/Sulbactam [205 - 207], Meropenem [208] und Imipenem [207] zum Einsatz. Pneumonien durch panresistente Isolate werden mit Colistin behandelt [209,210,65]. Die notwendige Therapiedauer ist nicht bekannt. In einer großen kontrollierten Studie war bei Vorliegen von $P$. aeruginosa und anderen nicht-fermentierenden Gram-negativen Bakterien nach einer Dauer von 15 Tagen ein Rezidiv weniger häufig als nach acht Tagen [49].

\section{AWMF-Registernummer 020/013}

\section{Interessenkonflikt}

$\nabla$

Eine Auflistung der Interessenkonflikte finden Sie im Internet unter http://www.awmf.org/uploads/tx_szleitlinien/020-013m_ S3_Nosokomiale_Pneumonie_Epidemiologie_Diagnostik_Therapie_2012-10_01.pdf.

\section{Institute}

Medizinische Klinik III, Pneumologie und Infektiologie, Universitätsklinikum Schleswig-Holstein, Lübeck

2 Institut für Hygiene und Mikrobiologie der Universität Würzburg, Würzburg

${ }^{3}$ Lungenfachklinik Immenhausen, Immenhausen

${ }^{4}$ Klinik für Pneumologie, Lungenklinik Heckeshorn, HELIOS Klinikum

Emil von Behring, Berlin

${ }^{5}$ Institut für Medizinische Mikrobiologie und Hygiene, Universitätsklinikum Ulm, Ulm

${ }^{6}$ Charité, Universitätsmedizin Berlin, Klinik für Anästhesiologie m. S. operative Intensivmedizin, Campus Virchow Klinikum und Campus Mitte, Berlin ${ }^{7}$ Thoraxzentrum Ruhrgebiet, Klinik für Pneumologie und Infektiologie,

Ev. Krankenhaus Herne, Augusta-Kranken-Anstalt Bochum, Bochum

${ }^{8}$ Institut für Hygiene und Umweltmedizin, Charité, Universitätsmedizin Berlin, Campus Benjamin Franklin, Berlin

${ }^{9}$ Institut für Hygiene und Mikrobiologie, Abteilung für Medizinische Mikrobiologie, Ruhr-Universität Bochum, Bochum

${ }^{10}$ Klinik für Anästhesie, operative Intensivmedizin und Schmerztherapie, Vivantes Klinikum Neukölln, Berlin

${ }^{11}$ Stabsstelle Klinische Mikrobiologie und Krankenhaushygiene am Klinikum der Universität München, München

${ }^{12}$ Medizinische Klinik und Poliklinik $1 \mathrm{~m}$. S. Pneumologie, Universitätsklinikum Carl Gustav Carus an der TU Dresden, Dresden

${ }^{13}$ Zentrum Infektiologie und Reisemedizin Freiburg, Universitätsklinikum Freiburg, Freiburg

${ }^{14}$ Medizinische Klinik III, Pneumologie und Infektiologie, Universitätsklinikum Schleswig-Holstein, Lübeck

${ }^{5}$ Medizinische Klinik, Forschungszentrum Borstel, Borstel

${ }^{16}$ Klinik für Pneumologie, Infektiologie und internistische Intensivmedizin, Klinikum Lüdenscheid, Lüdenscheid

17 Zentrum für Innere Medizin, Medizinische Klinik II, Pneumologie und Intensivmedizin, Universitätsklinikum Gießen und Marburg, Standort Gießen

${ }^{18}$ Charité, Universitätsmedizin Berlin, Klinik für Anästhesiologie m. S. operative Intensivmedizin, Campus Virchow Klinikum und Campus Mitte, Berlin

${ }^{19}$ Zentrum für Infektionsmedizin und Krankenhaushygiene, Universitätsklinikum Jena, Jena

${ }^{20}$ Maastricht University Medical Center, Department of Respiratory Medicine, Maastricht, Niederlande

${ }^{21}$ Charité, Universitätsmedizin Berlin, Medizinische Klinik m. S. Infektiologie und Pneumologie, Campus Charité Mitte, Berlin

${ }^{22}$ Medizinische Klinik, Pneumologie und Infektiologie, Klinikum Dortmund $\mathrm{gGmbH}$, Dortmund

${ }^{23}$ Robert Koch-Institut, Berlin

${ }^{24}$ Klinik und Poliklinik für Viszeral-, Thorax- und Gefäßchirurgie, Universitätsklinikum Carl Gustav Carus, Dresden
${ }^{25}$ Charité, Universitätsmedizin Berlin, Medizinische Klinik m. S. Infektiologie und Pneumologie, Campus Virchow-Klinikum, Berlin

${ }^{26}$ Institut für Medizinische Mikrobiologie, Immunologie und Hygiene, Klinikum der Universität zu Köln, Köln

27 Institut für Chirurgische Forschung, Philipps-Universität Marburg, Marburg

${ }^{28}$ Charité, Universitätsmedizin Berlin, Klinik für Anästhesiologie m. S. operative Intensivmedizin, Campus Virchow Klinikum und Campus Mitte, Berlin

${ }^{29}$ Klinik für Pneumologie, Medizinische Hochschule Hannover, Hannover

\section{Literatur}

1 Lorenz J, Bodmann KF, Bauer TT et al. Nosocomial pneumonia: prevention, diagnosis, treatment. Pneumologie 2003; 57: 532-545

2 American Thoracic Society; Infectious Diseases Society of America. Guidelines for the management of adults with hospital-acquired, ventilator-associated, and healthcare-associated pneumonia. Am J Respir Crit Care Med 2005; 171: 388 - 416

3 Muscedere J, Dodek P, Keenan S et al. VAP Guidelines Committee and the Canadian Critical Care Trials Group. Comprehensive evidence-based clinical practice guidelines for ventilator-associated pneumonia: diagnosis and treatment. J Crit Care 2008; 23: 138 - 147

4 Masterton RG, Galloway A, French $G$ et al. Guidelines for the management of hospital-acquired pneumonia in the UK: report of the working party on hospital-acquired pneumonia of the British Society for Antimicrobial Chemotherapy. J Antimicrob Chemother 2008; 62: 5 34

5 Torres A, Ewig S, Lode $H$ et al. The European HAP working group. Defining, treating and preventing hospital acquired pneumonia: European perspective. Intensive Care Med 2009; 351: 9-29

6 Atkins $D$, Best $D$, Briss PA et al. GRADE Working Group. Grading quality of evidence and strength of recommendations. BMJ 2004; 328: $1490-1494$

7 Schünemann HJ, Jaeschke R, Cook DJ et al. An official ATS statement: grading the quality of evidence and strength of recommendations in ATS guidelines and recommendations. Am J Respir Crit Care Med 2006; 174: 605-614

8 Kollef MH, Shorr A, Tabak YP et al. Epidemiology and outcomes of health-care-associated pneumonia: results from a large US database of culture-positive pneumonia. Chest 2005; 128: $3854-3862$

9 Kollef MH, Morrow LE, Baughman RP et al. Health care-associated pneumonia (HCAP): a critical appraisal to improve identification, management, and outcomes - proceedings of the HCAP Summit. Clin Infect Dis 2008; 46: 296 - 334

* 10 Ewig S, Welte T, Chastre J et al. Rethinking the concepts of communityacquired and health-care-associated pneumonia. Lancet Infect Dis 2010; 10: 279-287

11 Dalhoff K, Ewig S, Höffken $G$ et al. Empfehlungen zur Diagnostik, Therapie und Prävention von Pneumonien bei erworbenem Immundefizit. Pneumologie 2002; 56: 807-831

12 Maschmeyer G, Beinert T, Buchheidt D et al. Diagnosis and antimicrobial therapy of lung infiltrates in febrile neutropenic patients: Guidelines of the infectious diseases working party of the German Society of Haematology and Oncology. Eur J Cancer 2009; 45: 2462 - 2472

13 Horan TC, Andrus M, Dudeck MA. CDC/NHSN surveillance definition of health care-associated infection and criteria for specific types of infections in the acute care setting. Am J Infect Control 2008; 36: 309-332

*14 Kohlenberg A, Schwab F, Behnke M et al. Pneumonia associated with invasive and noninvasive ventilation: an analysis of the German nosocomial infection surveillance system database. Intensive Care Med 2010; 36: 971 - 978

15 Gastmeier P, Bräuer H, Forster D et al. A quality management project in 8 selected hospitals to reduce nosocomial infections: a prospective, controlled study. Infect Control Hosp Epidemiol 2002; 23: 91 -97

16 Rüden H, Daschner F. Nosokomiale Infektionen in Deutschland - Erfassung und Prävention (NIDEP-Studie). Teil 2: Studie zur Einführung eines Qualitätsmanagementprogrammes Baden-Baden: Normos-Verlag; 2000

17 Stausberg J, Azaouagh A. Frequency of hospital-acquired pneumonia in electronic and paper-based patient record. Stud Health Technol Inform 2008; 136: 479-483

18 Meyer E, Sohr D, Gastmeier P et al. New identification of outliers and ventilator-associated pneumonia rates from 2005 to 2007 within the German Nosocomial Infection Surveillance System. J Hosp Infect 2009; 73: 246-252 
19 Gastmeier P, Kampf G, Wischnewski N et al. Prevalence of nosocomial infections in representative German hospitals. J Hosp Infect 1998; 38: $37-49$

*20 Muscedere JG, Day A, Heyland DK. Mortality, attributable mortality, and clinical events as end points for clinical trials of ventilator-associated pneumonia and hospital-acquired pneumonia. Clin Infect Dis 2010; $51: 120-125$

21 Ibrahim EH, Tracy L, Hill C et al. The occurrence of ventilator-associated pneumonia in a community hospital: risk factors and clinical outcomes. Chest 2001; 120: 555-561

22 Cook DJ, Walter SD, Cook RJ et al. Incidence of and risk factors for ventilator-associated pneumonia in critically ill patients. Ann Intern Med 1998; 129: $433-440$

23 Schumacher M, Wangler $M$, Wolkewitz $M$ et al. Attributable mortality due to nosocomial infections. A simple and useful application of multistate models. Methods Inf Med 2007; 46: 595-600

24 Wolkewitz M, Vonberg RP, Grundmann $H$ et al. Risk factors for the development of nosocomial pneumonia and mortality on intensive care units: application of competing risks models. Crit Care 2008; 12: R44

* 25 Meyer E, Schwab F, Gastmeier P. Nosocomial methicillin resistant Staphylococcus aureus pneumonia - epidemiology and trends based on data of a network of 586 German ICUs (2005-2009). Eur J Med Res 2010; 15: $514-524$

*26 Nguile-Makao M, Zahar JR, Français A et al. Attributable mortality of ventilator-associated pneumonia: respective impact of main characteristics at ICU admission and VAP onset using conditional logistic regression and multi-state models. Intensive Care Med 2010; 36: 781 789

27 Safdar N, Dezfulian C, Collard HR et al. Clinical and economic consequences of ventilator-associated pneumonia: a systematic review. Crit Care Med 2005; 33: 2184-2193

28 Melsen WG, Rovers MM, Bonten MJ. Ventilator-associated pneumonia and mortality: a systematic review of observational studies. Crit Care Med 2009; 37: 2709-2718

29 Beyersmann J, Gastmeier P, Grundmann $H$ et al. Use of multistate models to assess prolongation of intensive care unit stay due to nosocomial infection. Infect Control Hosp Epidemiol 2006; 27: 493 - 499

* 30 Eber MR, Laxminarayan R, Perencevich EN et al. Clinical and economic outcomes attributable to health care-associated sepsis and pneumonia. Arch Intern Med 2010; 170: 347-353

* 31 Restrepo MI, Anzueto A, Arroliga AC et al. Economic burden of ventilator-associated pneumonia based on total resource utilization. Infect Control Hosp Epidemiol 2010; 31: 509-515

32 Meersseman W, Lagrou K, Spriet I et al. Significance of the isolation of Candida species from airway samples in critically ill patients: a prospective, autopsy study. Intensive Care Med 2009; 35: 1526 - 1531

33 Gastmeier P, Sohr D, Geffers C et al. Early- and late-onset pneumonia: is this still a useful classification? Antimicrob Agents Chemother 2009; 53: $2714-2718$

34 Trouillet JL, Chastre J, Vuagnat A et al. Ventilator-associated pneumonia caused by potentially drug-resistant bacteria. Am J Respir Crit Care Med 1998: 157: 531-539

35 Ewig S, Torres A, El-Ebiary $M$ et al. Bacterial colonization patterns in mechanically ventilated patients with traumatic and medical head injury. Incidence, risk factors, and association with ventilator-associated pneumonia. Am J Respir Crit Care Med 1999; 159: 188-198

36 Rello J, Torres A, Ricart $M$ et al. Ventilator-associated pneumonia by Staphylococcus aureus. Comparison of methicillin-resistant and methicillin-sensitive episodes. Am J Respir Crit Care Med 1994; 150: $1545-1549$

37 http://www.p-e-g.org/ag_resistenz/main.htm

38 Hoban DJ, Biedenbach DJ, Mutnick AH et al. Pathogen of occurrence and susceptibility patterns associated with pneumonia in hospitalized patients in North America: results of the SENTRY Antimicrobial Surveillance Study. Diagn Microbiol Infect Dis 2003; 45: 279-285

* 39 Jones RN. Microbial etiologies of hospital-acquired bacterial pneumonia and ventilator-associated bacterial pneumonia. Clin Infect Dis 2010; 51: $81-87$

40 Sopena N, Sabrià M. Neunos 2000 Study Group. Multicenter study of hospital-acquired pneumonia in non-ICU patients. Chest 2005; 127: $213-219$

41 Koulenti D, Lisboa T, Brun-Buisson C et al. Spectrum of practice in the diagnosis of nosocomial pneumonia in patients requiring mechanical ventilation in European intensive care units. Crit Care Med 2009; 37: $2360-2368$
42 Pirracchio R, Mateo J, Raskine L et al. Can bacteriological upper airway samples obtained at intensive care unit admission guide empiric antibiotherapy for ventilator-associated pneumonia? Crit Care Med 2009; 37: 2559-2563

43 Gacouin A, Barbarot N, Camus C et al. Late-onset ventilator-associated pneumonia in nontrauma intensive care unit patients. Anesth Analg 2009; 109: 1584 - 1590

44 Rangel EL, Butler KL, Johannigman JA et al. Risk factors for relapse of ventilator-associated pneumonia in trauma patients. J Trauma 2009; 67: $91-95$

45 Leone M, Garcin F, Bouvenot J et al. Ventilator-associated pneumonia: breaking the vicious circle of antibiotic overuse. Crit Care Med 2007; 35: $379-385$

46 Ibrahim EH, Ward S, Sherman G et al. A comparative analysis of patients with early-onset vs late-onset nosocomial pneumonia in the ICU setting. Chest 2000; 117: 1434-1442

47 Chastre J, Wunderink R, Prokocimer P et al. Efficacy and safety of intravenous infusion of doripenem versus imipenem in ventilator-associated pneumonia: a multicenter, randomized study. Crit Care Med 2008; 36: 1089-1096

48 Kollef MH, Morrow LE, Niederman MS et al. Clinical characteristics and treatment patterns among patients with ventilator-associated pneumonia. Chest 2006; 129: 1210-1218

49 Chastre J, Wolff M, Fagon JY et al. Comparison of 8 vs 15 days of antibiotic therapy for ventilator-associated pneumonia in adults: a randomized trial. JAMA 2003; 290: 2588-2598

50 Combes A, Figliolini C, Trouillet JL et al. Incidence and outcome of polymicrobial ventilator-associated pneumonia. Chest 2002; 121: 1618 1623

51 Hayon J, Figliolini C, Combes A et al. Role of serial routine microbiologic culture results in the initial management of ventilator-associated pneumonia. Am J Respir Crit Care Med 2002; 165: 41-46

52 Fowler RA, Flavin KE, Barr J et al. Variability in antibiotic prescribing patterns and outcomes in patients with clinically suspected ventilator-associated pneumonia. Chest 2003; 123: 835-844

53 Heyland DK, Dodek P, Muscedere J et al. Randomized trial of combination versus monotherapy for the empiric treatment of suspected ventilator-associated pneumonia. Crit Care Med 2008; 36: 737-744

54 Garnacho-Montero J, Amaya-Villar R, Ortiz-Leyba C et al. Isolation of Aspergillus spp. from the respiratory tract in critically ill patients: risk factors, clinical presentation and outcome. Crit Care 2005; 9: R191 - 199

55 Luyt CE, Combes A, Deback C et al. Herpes simplex virus lung infection in patients undergoing prolonged mechanical ventilation. Am J Respir Crit Care Med 2007; 175: 935 - 942

56 Gooskens J, Jonges M, Claas EC et al. Morbidity and mortality associated with nosocomial transmission of oseltamivir-resistant influenza A(H1N1) virus. JAMA 2009; 301: 1042 - 1046

57 Chiche L, Forel JM, Roch A et al. Active cytomegalovirus infection is common in mechanically ventilated medical intensive care unit patients. Crit Care Med 2009; 37: 1850 - 1857

58 www.nrz-hygiene.de/surveillance/kiss

59 Yahav D, Paul M, Fraser A et al. Efficacy and safety of cefepime: a systematic review and meta-analysis. Lancet Infect Dis 2007; 7: 338 348

*60 Kim PW, Wu YT, Cooper C et al. Meta-analysis of a possible signal of increased mortality associated with cefepime use. Clin Infect Dis 2010; $51: 381-389$

61 Badia JR, Soy D, Adrover $M$ et al. Disposition of instilled versus nebulized tobramycin and imipenem in ventilated intensive care unit (ICU) patients. J Antimicrob Chemother 2004; 54: 508 - 514

62 Giamarellos-Bourboulis EJ, Pechère JC, Routsi C et al. Effect of clarithromycin in patients with sepsis and ventilator-associated pneumonia. Clin Infect Dis 2008; 46: 1157 - 1164

63 González C, Rubio M, Romero-Vivas J et al. Bacteremic pneumonia due to Staphylococcus aureus: A comparison of disease caused by methicillin-resistant and methicillin-susceptible organisms. Clin Infect Dis 1999; 29: 1171 - 1177

*64 Imberti R, Cusato M, Villani P et al. Steady-state pharmacokinetics and BAL concentration of colistin in critically ill patients after IV colistin methanesulfonate administration. Chest 2010; 138: 1333-1339

65 Reina $R$, Estenssoro $E$, Sáenz $G$ et al. Safety and efficacy of colistin in Acinetobacter and Pseudomonas infections: a prospective cohort study. Intensive Care Med 2005; 31: 1058-1065 
66 Falagas ME, Kasiakou SK, Kofteridis DP et al. Effectiveness and nephrotoxicity of intravenous colistin for treatment of patients with infections due to polymyxin-only-susceptible (POS) gram-negative bacteria. Eur J Clin Microbiol Infect Dis 2006; 25: 596-599

67 Furtado $G H$, d'Azevedo PA, Santos AF et al. Intravenous polymyxin B for the treatment of nosocomial pneumonia caused by multidrug-resistant Pseudomonas aeruginosa. Int J Antimicrob Agents 2007; 30: 315-319

68 Falagas ME, Kasiakou SK. Toxicity of polymyxins: a systematic review of the evidence from old and recent studies. Crit Care 2006; 10: R27

69 Linden PK, Paterson DL. Parenteral and inhaled colistin for treatment of ventilator-associated pneumonia. Clin Infect Dis 2006; 43: 89-94

70 Michalopoulos A, Fotakis D, Virtzili S et al. Aerosolized colistin as adjunctive treatment of ventilator-associated pneumonia due to multidrug-resistant Gram-negative bacteria: a prospective study. Respir Med 2008; 102: 407-412

* 71 Freire AT, Melnyk V, Kim MJ et al. Comparison of tigecycline with imipenem/cilastatin for the treatment of hospital-acquired pneumonia. Diagn Microbiol Infect Dis 2010; 68: 140-151

72 Craig WA. Basic pharmacodynamics of antibacterials with clinical applications to the use of beta-lactams, glycopeptides, and linezolid. Infect Dis Clin North Am 2003; 17: 479-501

73 Murry KR, McKinnon PS, Mitrzyk B et al. Pharmacodynamic characterization of nephrotoxicity associated with once-daily aminoglycoside. Pharmacotherapy 1999; 19: 1252 - 1260

* 74 Mohd Hafiz AA, Staatz CE, Kirkpatrick CM et al. Continuous infusion vs. bolus dosing: implications for beta-lactam antibiotics. Minerva Anestesiol 2012; 78: 94-104

75 Rybak M, Lomaestro B, Rotschafer JC et al. Therapeutic monitoring of vancomycin in adult patients: a consensus review of the American Society of Health-System Pharmacists, the Infectious Diseases Society of America, and the Society of Infectious Diseases Pharmacists. Am J Health Syst Pharm 2009; 66: 82 -98

* 76 Taccone FS, Laterre PF, Dugernier T et al. Insufficient $\beta$-lactam concentrations in the early phase of severe sepsis and septic shock. Crit Care 2010; 14: R126

* 77 Pletz MW, Bloos F, Burkhardt 0 et al. Pharmacokinetics of moxifloxacin in patients with severe sepsis or septic shock. Intensive Care Med 2010; 36: $979-983$

78 Scaglione F, Esposito S, Leone $S$ et al. Feedback dose alteration significantly affects probability of pathogen eradication in nosocomial pneumonia. Eur Respir J 2009; 34: 394 - 400

79 Roberts JA, Boots R, Rickard CM et al. Is continuous infusion ceftriaxone better than once-a-day dosing in intensive care? A randomized controlled pilot study. J Antimicrob Chemother 2007; 59: 285 - 291

80 Lorente L, Jiménez A, Martín MM et al. Clinical cure of ventilator-associated pneumonia treated with piperacillin/tazobactam administered by continuous or intermittent infusion. Int J Antimicrob Agents 2009; 33: $464-468$

81 Lodise TPJr, Lomaestro B, Drusano GL. Piperacillin-tazobactam for Pseudomonas aeruginosa infection: clinical implications of an extended-infusion dosing strategy. Clin Infect Dis 2007; 44: 357 - 363

82 Nicolau DP, McNabb J, Lacy MK et al. Continuous versus intermittent administration of ceftazidime in intensive care unit patients with nosocomial pneumonia. Int J Antimicrob Agents 2001; 17: 497 - 504

83 Lorente L, Lorenzo L, Martín MM et al. Meropenem by continuous versus intermittent infusion in ventilator-associated pneumonia due to gram-negative bacilli. Ann Pharmacother 2006; 40: 219-223

84 Johanson WG Jr, Pierce AK, Sanford JP et al. Nosocomial respiratory infections with gram-negative bacilli. The significance of colonization of the respiratory tract. Ann Intern Med 1972; 77: 701 - 706

85 Fábregas N, Ewig S, Torres A et al. Clinical diagnosis of ventilator associated pneumonia revised: comparative validation using immediate post-mortem lung biopsies. Thorax 1999; 54: 867-873

86 Fagon JY, Chastre J, Hance AJ et al. Evaluation of clinical judgment in the identification and treatment of nosocomial pneumonia in ventilated patients. Chest 1993; 103: $547-553$

87 Helling TS, Van Way C, Krantz S et al. The value of clinical judgment in the diagnosis of nosocomial pneumonia. Am J Surg 1996; 171: 570 575

*88 Reinhart K, Brunkhorst FM, Bone HG et al. Prevention, diagnosis, therapy and follow-up care of sepsis: 1 st revision of S-2k guidelines of the German Sepsis Society (Deutsche Sepsis-Gesellschaft e.V. (DSG)) and the German Interdisciplinary Association of Intensive Care and Emer- gency Medicine (Deutsche Interdisziplinäre Vereinigung für Intensivund Notfallmedizin (DIVI)). Ger Med Sci 2010; 28: 14

89 Winer-Muram HAT, Rubin SA, Ellis JV et al. Pneumonia and ARDS in patients receiving mechanical ventilation: diagnostic accuracy of chest radiography. Radiology 1993; 188: 479-485

90 Wunderink RG, Woldenberg LS, Zeiss J et al. The radiologic diagnosis of autopsy-proven ventilator-associated pneumonia. Chest 1992; 101: 458-463

91 Beydon L, Saada M, Liu N et al. Can portable chest X-ray examination accurately diagnose lung consolidation after major abdominal surgery? A comparison with computed tomography scan. Chest 1992 ; 102: $1697-1703$

92 Schäfer-Prokop C. Aufnahmetechnik der Bettlungenaufnahme. In: Radiologische Diagnostik in der Intensivmedizin. Stuttgart: Thieme; 2009: 15 - 19

93 Winer-Muram HAT, Jennings SG, Wunderink RG et al. Ventilator-associated Pseudomonas aeruginosa pneumonia: radiographic findings. Radiology 1995; 195: 247 - 252

94 Fartoukh M, Maitre B, Honoré $S$ et al. Diagnosing pneumonia during mechanical ventilation: the clinical pulmonary infection score revisited. Am J Respir Crit Care Med 2003; 168: 173 - 179

95 Combes A, Luyt CE, Fagon JY et al. Early predictors for infection recurrence and death in patients with ventilator-associated pneumonia. Crit Care Med 2007; 35: 146-154

96 Lisboa T, Diaz E, Sa-Borges $M$ et al. The ventilator-associated pneumonia PIRO score: a tool for predicting ICU mortality and health-care resources use in ventilator-associated pneumonia. Chest 2008; 134 : $1208-1216$

97 Duflo F, Debon R, Monneret G et al. Alveolar and serum procalcitonin: diagnostic and prognostic value in ventilator-associated pneumonia. Anesthesiology 2002; 96: 74-79

98 Ramirez P, Garcia MA, Ferrer M et al. Sequential measurements of procalcitonin levels in diagnosing ventilator-associated pneumonia. Eur Respir J 2008; 31: 356-362

99 Luyt CE, Combes A, Reynaud C et al. Usefulness of procalcitonin for the diagnosis of ventilator-associated pneumonia. Intensive Care Med 2008; 34: 1434-1440

100 Linssen CF, Bekers $O$, Drent $M$ et al. C-reactive protein and procalcitonin concentrations in bronchoalveolar lavage fluid as a predictor of ventilator-associated pneumonia. Ann Clin Biochem 2008; 45: 293 298

101 Oppert M, Reinicke A, Müller C et al. Elevations in procalcitonin but not C-reactive protein are associated with pneumonia after cardiopulmonary resuscitation. Resuscitation 2002; 53: 167-170

102 Gibot S, Cravoisy A, Levy B et al. Soluble triggering receptor expressed on myeloid cells and the diagnosis of pneumonia. N Engl J Med 2004; 350: $451-458$

103 Determann RM, Millo JL, Gibot S et al. Serial changes in soluble triggering receptor expressed on myeloid cells in the lung during development of ventilator-associated pneumonia. Intensive Care Med 2005; 31: $1495-1500$

104 Horonenko G, Hoyt JC, Robbins RA et al. Soluble triggering receptor expressed on myeloid cell-1 is increased in patients with ventilatorassociated pneumonia: a preliminary report. Chest 2007; 132: 58 63

105 Huh JW, Lim CM, Koh Y et al. Diagnostic utility of the soluble triggering receptor expressed on myeloid cells-1 in bronchoalveolar lavage fluid from patients with bilateral lung infiltrates. Crit Care 2008; 12: R6

106 Anand NJ, Zuick S, Klesney-Tait J et al. Diagnostic implications of soluble triggering receptor expressed on myeloid cells- 1 in BAL fluid of patients with pulmonary infiltrates in the ICU. Chest 2009; 135 : $641-647$

107 Oudhuis GJ, Beuving J, Bergmans D et al. Soluble Triggering Receptor Expressed on Myeloid cells-1 in bronchoalveolar lavage fluid is not predictive for ventilator-associated pneumonia. Intensive Care Med 2009; 35: 1265 - 1270

*108 Conway Morris A, Kefala K, Wilkinson S et al. Diagnostic importance of pulmonary interleukin-1beta and interleukin-8 in ventilator-associated pneumonia. Thorax 2010; 65: $201-207$

109 Uzzan B, Cohen R, Nicolas P et al. Procalcitonin as a diagnostic test for sepsis in critically ill adults and after surgery or trauma: a systematic review and meta-analysis. Crit Care Med 2006; 34: 1996-2003

110 Nakamura A, Wada $H$, Ikejiri $M$ et al. Efficacy of procalcitonin in the early diagnosis of bacterial infections in a critical care unit. Shock 2009; $31: 586-591$ 
111 Luna CM, Videla A, Mattera J et al. Blood cultures have limited value in predicting severity of illness and as a diagnostic tool in ventilatorassociated pneumonia. Chest 1999; 116: 1075-1084

112 Park DR. The microbiology of ventilator-associated pneumonia. Respir Care 2005; 50: 742 - 763

113 Shimada T, Noguchi Y, Jackson JL et al. Systematic review and metaanalysis: urinary antigen tests for Legionellosis. Chest 2009; 136: $1576-1585$

114 Olsen CW, Elverdal P, Jørgensen CS et al. Comparison of the sensitivity of the Legionella urinary antigen EIA kits from Binax and Biotest with urine from patients with infections caused by less common serogroups and subgroups of Legionella. Eur J Clin Microbiol Infect Dis 2009; 28: 817-820

115 Baselski VS, el-Torky M, Coalson JJ et al. The standardization of criteria for processing and interpreting laboratory specimens in patients with suspected ventilator-associated pneumonia. Chest 1992; 102: 571S-579S

116 Souweine B, Veber B, Bedos JP et al. Diagnostic accuracy of protected specimen brush and bronchoalveolar lavage in nosocomial pneumonia: impact of previous antimicrobial treatments. Crit Care Med 1998; 26: $236-244$

117 The Canadian Critical Care Trials Group. A randomized trial of diagnostic techniques for ventilator-associated pneumonia. N Engl J Med 2006; 355: 2619-2630

118 Ruiz M, Torres A, Ewig $S$ et al. Noninvasive versus invasive microbial investigation in ventilator-associated pneumonia: evaluation of outcome. Am J Respir Crit Care Med 2000; 162: 119-125

119 Sanchez-Nieto JM, Torres A, Garcia-Cordoba $F$ et al. Impact of invasive and noninvasive quantitative culture sampling on outcome of ventilator-associated pneumonia: a pilot study. Am J Respir Crit Care Med 1998; 157: $371-376$

120 Solé-Violán J, Rodríguez de Castro F, Rey A et al. Usefulness of microscopic examination of intracellular organisms in lavage fluid in ventilator-associated pneumonia. Chest 1994; 106: 889-894

121 Papazian L, Thomas P, Garbe L et al. Bronchoscopic or blind sampling techniques for the diagnosis of ventilator-associated pneumonia. Am J Respir Crit Care Med 1995; 152: 1982 - 1991

122 Marquette $\mathrm{CH}$, Copin MC, Wallet $\mathrm{F}$ et al. Diagnostic tests for pneumonia in ventilated patients: prospective evaluation of diagnostic accuracy using histology as a diagnostic gold standard. Am J Respir Crit Care Med 1995; 151: 1878-1888

123 Fagon JY, Chastre J, Wolff $M$ et al. Invasive and noninvasive strategies for management of suspected ventilator-associated pneumonia. A randomized trial. Ann Intern Med 2000; 132: 621 - 630

124 Fàbregas N, Torres A, El-Ebiary $M$ et al. Histopathologic and microbiologic aspects of ventilator-associated pneumonia. Anesthesiology 1996; 84: $760-771$

125 Kirtland SH, Corley DE, Winterbauer RH et al. The diagnosis of ventilator-associated pneumonia: a comparison of histologic, microbiologic, and clinical criteria. Chest 1997; 112: 445-457

126 Torres A, Fàbregas N, Ewig $S$ et al. Sampling methods for ventilatorassociated pneumonia: validation using different histologic and microbiological references. Crit Care Med 2000; 28: 2799-2804

127 Wermert $D$, Marquette $C H$, Copin $M C$ et al. Influence of pulmonary bacteriology and histology on the yield of diagnostic procedures in ventilator-acquired pneumonia. Am J Respir Crit Care Med 1998; 158: $139-147$

128 Timsit JF, Misset B, Azoulay E et al. Usefulness of airway visualization in the diagnosis of nosocomial pneumonia in ventilated patients. Chest 1996; 110: $172-179$

129 Bauer TT, Torres A, Ewig $S$ et al. Effects of bronchoalveolar lavage volume on arterial oxygenation in mechanically ventilated patients with pneumonia. Intensive Care Med 2001; 27: 384-393

130 Kumar A, Roberts D, Wood KE et al. Duration of hypotension before initiation of effective antimicrobial therapy is the critical determinant of survival in human septic shock. Crit Care Med 2006; 34: $1589-1596$

131 Levy H. Comparison of Ballard catheter bronchoalveolar lavage with bronchoscopic bronchoalveolar lavage. Chest 1994; 106: 1753-1756

132 Kollef $M H$, Bock KR, Richards RD et al. The safety and diagnostic accuracy of minibronchoalveolar lavage in patients with suspected ventilator-associated pneumonia. Ann Intern Med 1995; 122: 743 - 748

133 de Lassence A, Joly-Guillou ML, Martin-Lefevre L et al. Accuracy of delayed cultures of plugged telescoping catheter samples for diagnosing bacterial pneumonia. Crit Care Med 2001; 29: 1311-1317
134 de Lassence A, Joly-Guillou ML, Salah A et al. Accuracy of delayed (24 hours) processing of bronchoalveolar lavage for diagnosing bacterial pneumonia. Crit Care Med 2004; 32: 680-685

135 Meersseman W, Lagrou K, Maertens J et al. Galactomannan in bronchoalveolar lavage fluid: a tool for diagnosing aspergillosis in intensive care unit patients. Am J Respir Crit Care Med 2008; 177: 27-34

136 Sulahian A, Touratier S, Ribaud P. False positive test for aspergillus antigenemia related to concomitant administration of piperacillin and tazobactam. N Engl J Med 2003; 349: 2366 - 2367

137 Mattei $D$, Rapezzi $D$, Mordini $N$ et al. False-positive Aspergillus galactomannan enzyme-linked immunosorbent assay results in vivo during amoxicillin-clavulanic acid treatment. J Clin Microbiol 2004; 42: $5362-5363$

* 138 Girmenia C, Santilli S, Ballarò D et al. Enteral nutrition may cause falsepositive results of Aspergillus galactomannan assay in absence of gastrointestinal diseases. Mycoses 2011; 54: e883-884

139 Racil $Z$, Kocmanova I, Lengerova $M$ et al. Intravenous PLASMA-LYTE as a major cause of false-positive results of platelia Aspergillus test for galactomannan detection in serum. J Clin Microbiol 2007; 45: $3141-3142$

140 Senn L, Robinson JO, Schmidt S et al. 1,3-Beta-D-glucan antigenemia for early diagnosis of invasive fungal infections in neutropenic patients with acute leukemia. Clin Infect Dis 2008; 46: 878-885

*141 Torelli R, Sanguinetti M, Moody A et al. Diagnosis of invasive aspergillosis by a commercial real-time PCR assay for Aspergillus DNA in bronchoalveolar lavage fluid samples from high-risk patients compared to a galactomannan enzyme immunoassay. J Clin Microbiol 2011; 49: 4273-4278

142 Kang CI, Kim SH, Kim HB et al. Pseudomonas aeruginosa bacteremia: risk factors for mortality and influence of delayed receipt of effective antimicrobial therapy on clinical outcome. Clin Infect Dis 2003; 37: $745-751$

143 Iregui $M$, Ward S, Sherman $G$ et al. Clinical importance of delays in the initiation of appropriate antibiotic treatment for ventilator-associated pneumonia. Chest 2002; 122: 262-268

144 Yakovlev SV, Stratchounski LS, Woods GL et al. Ertapenem versus cefepime for initial empirical treatment of pneumonia acquired in skilled-care facilities or in hospitals outside the intensive care unit. Eur J Clin Microbiol Infect Dis 2006; 25: 633-641

145 Höffken G, Barth J, Rubinstein $E$ et al. A randomized study of sequential intravenous/oral moxifloxacin in comparison to sequential intravenous ceftriaxone/oral cefuroxime axetil in patients with hospitalacquired pneumonia. Infection 2007; 35: 414-420

146 Aarts MA, Hancock JN, Heyland D et al. Empiric antibiotic therapy for suspected ventilator-associated pneumonia: a systematic review and meta-analysis of randomized trials. Crit Care Med 2008; 36: 108 117

147 Sieger B, Berman SJ, Geckler RW et al. Empiric treatment of hospitalacquired lower respiratory tract infections with meropenem or ceftazidime with tobramycin: a randomized study. Meropenem Lower Respiratory Infection Group. Crit Care Med 1997; 25: 1663-1670

148 Fink MP, Snydman DR, Niederman MS et al. Treatment of severe pneumonia in hospitalized patients: results of a multicenter, randomized double-blind trial comparing intravenous ciprofloxacin with imipenem-cilastatin. The Severe Pneumonia Study Group. Antimicrob Agents Chemother 1994; 38: 547-557

149 Croce MA, Fabian TC, Stewart RM et al. Empiric monotherapy versus combination therapy of nosocomial pneumonia in trauma patients. J Trauma 1993; 35: $303-309$

150 Brun-Buisson C, Sollet JP, Schweich $H$ et al. Treatment of ventilatorassociated pneumonia with piperacillin-tazobactam/amikacin versus ceftazidime/amikacin: a multicenter, randomized controlled trial. VAP Study Group. Clin Infect Dis 1998; 26: 346 - 354

151 Cometta A, Baumgartner JD, Lew D et al. Prospective randomized comparison of imipenem monotherapy with imipenem plus netilmicin for treatment of severe infections in nonneutropenic patients. Antimicrob Agents Chemother 1994; 38: 1309-1313

152 Rubinstein E, Lode H, Grassi C. Ceftazidime monotherapy vs. ceftriaxone/tobramycin for serious hospital-acquired gram-negative infections. Antibiotic Study Group. Clin Infect Dis 1995; 20: 1217-1228

153 Chaudhary M, Shrivastava SM, Varughese $L$ et al. Efficacy and safety evaluation of fixed dose combination of cefepime and amikacin in comparison with cefepime alone in treatment of nosocomial pneumonia patients. Curr Clin Pharmacol 2008; 3: 118-122 
154 Garnacho-Montero J, Sa-Borges M, Sole-Violan J et al. Optimal management therapy for Pseudomonas aeruginosa ventilator-associated pneumonia: an observational, multicenter study comparing monotherapy with combination antibiotic therapy. Crit Care Med 2007; 35: $1888-1895$

155 Alvarez-Lerma F, Insausti-Ordeñana J, Jordá-Marcos $R$ et al. Efficacy and tolerability of piperacillin/tazobactam versus ceftazidime in association with amikacin for treating nosocomial pneumonia in intensive care patients: a prospective randomized multicenter trial. Intensive Care Med 2001; 27: 493 - 502

156 Singh N, Rogers P, Atwood CW et al. Short-course empiric antibiotic therapy for patients with pulmonary infiltrates in the intensive care unit. A proposed solution for indiscriminate antibiotic prescription. Am J Respir Crit Care Med 2000; 162: 505 - 511

157 Dennesen PJ, van der Ven AJ, Kessels AG et al. Resolution of infectious parameters after antimicrobial therapy in patients with ventilatorassociated pneumonia. Am J Respir Crit Care Med 2001; 163: 1371 1375

158 Seligman R, Meisner M, Lisboa TC et al. Decreases in procalcitonin and C-reactive protein are strong predictors of survival in ventilator-associated pneumonia. Crit Care 2006; 10: R125

* 159 Hillas G, Vassilakopoulos T, Plantza P et al. C-reactive protein and procalcitonin as predictors of survival and septic shock in ventilatorassociated pneumonia. Eur Respir J 2010; 35: 805 - 811

160 Luyt CE, Guérin V, Combes A et al. Procalcitonin kinetics as a prognostic marker of ventilator-associated pneumonia. Am J Respir Crit Care Med 2005; 171: $48-53$

161 Nobre V, Harbarth S, Graf JD et al. Use of procalcitonin to shorten antibiotic treatment duration in septic patients: a randomized trial. Am J Respir Crit Care Med 2008; 177: 498-505

162 Stolz D, Smyrnios N, Eggimann $P$ et al. Procalcitonin for reduced antibiotic exposure in Ventilator Associated Pneumonia - a randomized study. Eur Respir J 2009; 34: 1364-1375

163 Lisboa T, Seligman $R$, Diaz E et al. C-reactive protein correlates with bacterial load and appropriate antibiotic therapy in suspected ventilator-associated pneumonia. Crit Care Med 2008; 36: 166-171

164 Giantsou E, Liratzopoulos N, Efraimidou E et al. De-escalation therapy rates are significantly higher by bronchoalveolar lavage than by tracheal aspirate. Intensive Care Med 2007; 33: 1533 - 1540

165 Eachempati SR, Hydo LJ, Shou J et al. Does de-escalation of antibiotic therapy for ventilator-associated pneumonia affect the likelihood of recurrent pneumonia or mortality in critically ill surgical patients? J Trauma 2009; 66: $1343-1348$

166 Bouza E, Torres MV, Radice C et al. Direct E-test (AB Biodisk) of respiratory samples improves antimicrobial use in ventilator-associated pneumonia. Clin Infect Dis 2007; 44: $382-387$

167 Hedrick TL, McElearney ST, Smith RL et al. Duration of antibiotic therapy for ventilator-associated pneumonia caused by non-fermentative gram-negative bacilli. Surg Infect 2007; 8: 589-597

168 Cosgrove SE, Fowler VG Jr. Management of methicillin-resistant Staphylococcus aureus bacteremia. Clin Infect Dis 2008; 46: 386- 393

* 169 Liu C, Bayer A, Cosgrove SE et al. Clinical practice guidelines by the infectious diseases society of america for the treatment of methicillinresistant Staphylococcus aureus infections in adults and children: executive summary. Clin Infect Dis 2011; 52: 285-292

170 Walsh TJ, Anaissie EJ, Denning DW et al. Infectious Diseases Society of America. Treatment of aspergillosis: clinical practice guidelines of the Infectious Diseases Society of America. Clin Infect Dis 2008; 46: 327 360

171 Micek ST, Ward S, Fraser VJ et al. A randomized controlled trial of an antibiotic discontinuation policy for clinically suspected ventilatorassociated pneumonia. Chest 2004; 125: 1791 - 1799

172 Shorr AF, Cook D, Jiang X et al. Correlates of clinical failure in ventilator-associated pneumonia: insights from a large, randomized trial. J Crit Care 2008; 23: 64-73

173 El-Solh AA, Aquilina AT, Dhillon RS et al. Impact of invasive strategy on management of antimicrobial treatment failure in institutionalized older people with severe pneumonia. Am J Respir Crit Care Med 2002; 166: 1038 - 1043

174 el-Ebiary M, Torres A, González J et al. Quantitative cultures of endotracheal aspirates for the diagnosis of ventilator-associated pneumonia. Am Rev Respir Dis 1993; 148: 1552 - 1557

175 Wu CL, Yang DL, Wang NY et al. Quantitative culture of endotracheal aspirates in the diagnosis of ventilator-associated pneumonia in patients with treatment failure. Chest 2002; 122: 662-668
176 Palmer LB, Smaldone GC, Chen JJ et al. Aerosolized antibiotics and ventilator-associated tracheobronchitis in the intensive care unit. Crit Care Med 2008; 36: 2008-2013

177 Nseir S, Favory R, Jozefowicz E et al. Antimicrobial treatment for ventilator-associated tracheobronchitis: a randomized, controlled, multicenter study. Crit Care 2008; 12: R62

178 Korbila IP, Michalopoulos A, Rafailidis PI et al. Inhaled colistin as adjunctive to intravenous colistin for the treatment of microbiologically documented VAP: a comparative cohort study. Clin Microbiol Infect 2009; 16: $1230-1236$

179 Ghannam DE, Rodriguez GH, Raad II et al. Inhaled aminoglycosides in cancer patients with ventilator-associated Gram-negative bacterial pneumonia: safety and feasibility in the era of escalating drug resistance. Eur J Clin Microbiol Infect Dis 2009; 28: 253-259

180 Czosnowski QA, Wood GC, Magnotti LJ et al. Adjunctive aerosolized antibiotics for treatment of ventilator-associated pneumonia. Pharmacotherapy 2009; 29: 1054-1060

181 West M, Boulanger BR, Fogarty $C$ et al. Levofloxacin compared with imipenem/cilastatin followed by ciprofloxacin in adult patients with nosocomial pneumonia: a multicenter, prospective, randomized, open-label study. Clin Ther 2003; 25: 485-506

182 Combes A, Luyt CE, Fagon JY et al. Impact of methicillin resistance on outcome of Staphylococcus aureus ventilator-associated pneumonia. Am J Respir Crit Care Med 2004; 170: 786-792

183 Zahar JR, Clec'h C, Tafflet $M$ et al. Is methicillin resistance associated with a worse prognosis in Staphylococcus aureus ventilator-associated pneumonia? Clin Infect Dis 2005; 41: 1224-1231

*184 Kalil AC, Murthy MH, Hermsen ED et al. Linezolid versus vancomycin or teicoplanin for nosocomial pneumonia: a systematic review and meta-analysis. Crit Care Med 2010; 38: 1802-1808

185 Wunderink RG, Rello J, Cammarata SK et al. Linezolid vs vancomycin: analysis of two double-blind studies of patients with methicillin-resistant Staphylococcus aureus nosocomial pneumonia. Chest 2003; 124: $1789-1797$

*186 Wunderink RG, Niederman MS, Kollef MH et al. Linezolid in methicillin-resistant Staphylococcus aureus nosocomial pneumonia: a randomized, controlled study. Clin Infect Dis 2012; 54: 621 - 629

187 Fagon $J-Y$, Patrick $H$, Haas DW et al. The Nosocomial Pneumonia Group. Treatment of gram-positive nosocomial pneumonia: Prospective randomized comparison of quinupristin/dalfopristin versus vancomycin. Am J Respir Crit Care Med 2000; 161: 753 - 762

188 Wysocki M, Delatour F, Faurisson F et al. Continuous versus intermittent infusion of vancomycin in severe Staphylococcal infections: prospective multicenter randomized study. Antimicrob Agents Chemother 2001; 45: 2460-2467

*189 Jung YJ, Koh Y, Hong SB et al. Effect of vancomycin plus rifampicin in the treatment of nosocomial methicillin-resistant Staphylococcus aureus pneumonia. Crit Care Med 2010; 38: 175-180

190 Jaccard C, Troillet $N$, Harbarth $S$ et al. Prospective randomized comparison of imipenem-cilastatin and piperacillin-tazobactam in nosocomial pneumonia or peritonitis. Antimicrob Agents Chemother 1998; 42: $2966-2972$

191 Hartenauer U, Weilemann LS, Bodmann KF et al. Comparative clinical trial of ceftazidime and imipenem/cilastatin in patients with severe nosocomial pneumonias and septicaemias. J Hosp Infec 1990; 15: $61-64$

192 Norrby SR, Finch RG, Glauser M. Monotherapy in serious hospitalacquired infections: a clinical trial of ceftazidime versus imipenem/ cilastatin. European Study Group. J Antimicrob Chemother 1993; 31: 927-937

193 Michalopoulos AS, Tsiodras S, Rellos K et al. Colistin treatment in patients with ICU-acquired infections caused by multiresistant Gramnegative bacteria: the renaissance of an old antibiotic. Clin Microbiol Infect 2005; 11: 115-121

194 MacGowan AP, Rynn C, Wootton $M$ et al. In vitro assessment of colistin's antipseudomonal antimicrobial interactions with other antibiotics. Clin Microbiol Infect 1999; 5: $32-36$

195 Hamer $\mathrm{DH}$. Treatment of nosocomial pneumonia and tracheobronchitis caused by multidrug-resistant Pseudomonas aeruginosa with aerosolized colistin. Am J Respir Crit Care Med 2000; 162: 328 - 330

196 Bassetti M, Righi E, Fasce R et al. Efficacy of ertapenem in the treatment of early ventilator-associated pneumonia caused by extendedspectrum beta-lactamase-producing organisms in an intensive care unit. J Antimicrob Chemother 2007; 60: 433-435 
197 Paterson DL, Ko WC, Von Gottberg A et al. Outcome of cephalosporin treatment for serious infections due to apparently susceptible organisms producing extended-spectrum beta-lactamases: implications for the clinical microbiology laboratory. J Clin Microbiol 2001; 39: $2206-2212$

*198 Hirsch EB, Tam VH. Detection and treatment options for Klebsiella pneumoniae carbapenemases (KPCs): an emerging cause of multidrug-resistant infection. J Antimicrob Chemother 2010; 65: 11191125

199 Looney WJ, Narita M, Mühlemann K. Stenotrophomonas maltophilia: an emerging opportunist human pathogen. Lancet Infect Dis 2009; 9: $312-323$

200 Blanquer D, De Otero J, Padilla E et al. Tigecycline for treatment of nosocomial-acquired pneumonia possibly caused by multi-drug resistant strains of Stenotrophomonas maltophilia. J Chemother 2008; 20: $761-763$

*201 Wadl M, Heckenbach K, Noll I et al. Increasing occurrence of multidrug-resistance in Acinetobacter baumannii isolates from four German University Hospitals, 2002-2006. Infection 2010; 38: 47-51

202 Wood GC, Hanes SD, Boucher BA et al. Tetracyclines for treating multidrug-resistant Acinetobacter baumannii ventilator-associated pneumonia. Intensive Care Med 2003; 29: 2072-2076

203 Curcio D, Fernández F, Vergara J et al. Late onset ventilator-associated pneumonia due to multidrug-resistant Acinetobacter spp.: experience with tigecycline. J Chemother 2009; 21: 58-62

204 Schafer JJ, Goff DA, Stevenson KB et al. Early experience with tigecycline for ventilator-associated pneumonia and bacteremia caused by multidrug-resistant Acinetobacter baumannii. Pharmacotherapy 2007; 27: 980-987

205 Levin AS, Levy CE, Manrique AE et al. Severe nosocomial infections with imipenem-resistant Acinetobacter baumannii treated with ampicillin/sulbactam. Int J Antimicrob Agents 2003; 21: 58-62

206 Betrosian AP, Frantzeskaki F, Xanthaki A et al. Efficacy and safety of high-dose ampicillin/sulbactam vs. colistin as monotherapy for the treatment of multidrug resistant Acinetobacter baumannii ventilator-associated pneumonia. J Infect 2008; 56: 432-436

207 Wood GC, Hanes SD, Croce MA et al. Comparison of ampicillin-sulbactam and imipenem-cilastatin for the treatment of acinetobacter ventilator-associated pneumonia. Clin Infect Dis 2002; 34: 1425 1430

208 Wang $D$. Experience with extended-infusion meropenem in the management of ventilator-associated pneumonia due to multidrug-resistant Acinetobacter baumannii. Int J Antimicrob Agents 2009; 33: 290-291

209 Levin AS, Barone AA, Penço J et al. Intravenous colistin as therapy for nosocomial infections caused by multidrug-resistant Pseudomonas aeruginosa and Acinetobacter baumannii. Clin Infect Dis 1999; 28: $1008-1011$

210 Bassetti M, Repetto E, Righi $E$ et al. Colistin and rifampicin in the treatment of multidrug-resistant Acinetobacter baumannii infections. J Antimicrob Chemother 2008; 61: 417-420

211 Garnacho-Montero J, Ortiz-Leyba C, Jiménez-Jiménez FJ et al. Treatment of multidrug-resistant Acinetobacter baumannii ventilatorassociated pneumonia (VAP) with intravenous colistin: a comparison with imipenem-susceptible VAP. Clin Infect Dis 2003; 36: 1111 1118

212 Almirall J, Mesalles E, Klamburg J et al. Prognostic factors of pneumonia requiring admission to the intensive care unit. Chest 1995; 107 : $511-516$

213 Luna CM, Blanzaco D, Niederman MS et al. Resolution of ventilatorassociated pneumonia: prospective evaluation of the clinical pulmonary infection score as an early clinical predictor of outcome. Crit Care Med 2003; 31: 676-682

214 Lauzier F, Ruest A, Cook D et al. Canadian Critical Care Trials Group. The value of pretest probability and modified clinical pulmonary infection score to diagnose ventilator-associated pneumonia. J Crit Care 2008; 23: 50-57

215 Mongardon N, Lemiale V, Perbet S et al. Value of procalcitonin for diagnosis of early onset pneumonia in hypothermia-treated cardiac arrest patients. Intensive Care Med 2010; 36: 92 -99

216 Bouadma L, Luyt CE, Tubach $F$ et al. Use of procalcitonin to reduce patients' exposure to antibiotics in intensive care units (PRORATA trial): a multicentre randomised controlled trial. Lancet 2010; 375: $463-$ 474
217 Taylor GD, Buchanan-Chell M, Kirkland T et al. Bacteremic nosocomial pneumonia. A 7-year experience in one institution. Chest 1995; 108: $786-788$

218 Campbell SG, Marrie TJ, Anstey R et al. The contribution of blood cultures to the clinical management of adult patients admitted to the hospital with community-acquired pneumonia: a prospective observational study. Chest 2003; 123: $1142-1150$

219 Gupta SK, Imperiale TF, Sarosi GA. Evaluation of the Winthrop-University Hospital criteria to identify Legionella pneumonia. Chest 2001; 120: $1064-1071$

220 Clec'h C, Jauréguy F, Hamza L et al. Agreement between quantitative cultures of postintubation tracheal aspiration and plugged telescoping catheter, protected specimen brush or BAL for the diagnosis of nosocomial pneumonia. Chest 2006; 130: 956-961

221 Solé Violán J, Fernández JA, Benítez $A B$ et al. Impact of quantitative invasive diagnostic techniques in the management and outcome of mechanically ventilated patients with suspected pneumonia. Crit Care Med 2000; 28: 2737-2741

222 Timsit JF, Chevret S, Valcke J et al. Mortality of nosocomial pneumonia in ventilated patients: influence of diagnostic tools. Am J Respir Crit Care Med 1996; 154: 116-123

223 Chastre J, Fagon JY, Bornet-Lecso M et al. Evaluation of bronchoscopic techniques for the diagnosis of nosocomial pneumonia. Am J Respir Crit Care Med 1995; 152: 231 - 240

224 Papazian L, Martin C, Meric B et al. A reappraisal of blind bronchia sampling in the microbiologic diagnosis of nosocomial bronchopneumonia. A comparative study in ventilated patients. Chest 1993; 103: $236-242$

225 Croce MA, Fabian TC, Mueller EW et al. The appropriate diagnostic threshold for ventilator-associated pneumonia using quantitative cultures. J Trauma 2004; 56: 931 - 934

226 Sirvent JM, Vidaur L, Gonzalez S et al. Microscopic examination of intracellular organisms in protected bronchoalveolar mini-lavage fluid for the diagnosis of ventilator-associated pneumonia. Chest 2003; 123: $518-523$

227 Torres A, el-Ebiary M, Padró $L$ et al. Validation of different techniques for the diagnosis of ventilator-associated pneumonia. Comparison with immediate postmortem pulmonary biopsy. Am J Respir Crit Care Med 1994; 149: 324-331

228 Shorr AF, Sherner JH, Jackson WL et al. Invasive approaches to the diagnosis of ventilator-associated pneumonia: a meta-analysis. Crit Care Med 2005; 33: 46-53

229 Heyland DK, Cook DJ, Marshall J et al. The clinical utility of invasive diagnostic techniques in the setting of ventilator-associated pneumonia. Canadian Critical Care Trials Group. Chest 1999; 115: 1076 - 1084

230 Corley DE, Kirtland SH, Winterbauer RH et al. Reproducibility of the histologic diagnosis of pneumonia among a panel of four pathologists: analysis of a gold standard. Chest 1997; 112: $458-465$

231 Zedtwitz-Liebenstein K, Schenk P, Apfalter P et al. Ventilator-associated pneumonia: Increased bacterial counts in bronchoalveolar lavage by using urea as an endogenous marker of dilution. Crit Care Med 2005: 33: $756-759$

232 Musher B, Fredricks D, Leisenring $W$ et al. Aspergillus galactomannan enzyme immunoassay and quantitative PCR for diagnosis of invasive aspergillosis with bronchoalveolar lavage fluid. J Clin Microbiol 2004; 42: 5517-5522

233 Becker MJ, Lugtenburg EJ, Cornelissen JJ et al. Galactomannan detection in computerized tomography-based broncho-alveolar lavage fluid and serum in haematological patients at risk for invasive pulmonary aspergillosis. Br J Haematol 2003; 121: 448 - 457

234 Odabasi Z, Mattiuzzi G, Estey E et al. Beta-D-glucan as a diagnostic adjunct for invasive fungal infections: validation, cutoff development, and performance in patients with acute myelogenous leukemia and myelodysplastic syndrome. Clin Infect Dis 2004; 39: 199-205

235 Ostrosky-Zeichner L, Alexander BD, Kett DH et al. Multicenter clinical evaluation of the $(1->3)$ beta-D-glucan assay as an aid to diagnosis of fungal infections in humans. Clin Infect Dis 2005; 41: 654-659

236 el-Ebiary $M$, Torres A, Fàbregas $N$ et al. Significance of the isolation of Candida species from respiratory samples in critically ill, non-neutropenic patients. An immediate postmortem histologic study. Am J Respir Crit Care Med 1997; 156: 583-590

237 Pittet D, Monod M, Suter PM et al. Candida colonization and subsequent infections in critically ill surgical patients. Ann Surg 1994; 220: $751-758$ 
238 Wood GC, Mueller EW, Croce MA et al. Candida sp. isolated from bronchoalveolar lavage: clinical significance in critically ill trauma patients. Intensive Care Med 2006; 32: 599-603

239 Rello J, Esandi ME, Díaz E et al. The role of Candida sp isolated from bronchoscopic samples in nonneutropenic patients. Chest 1998; 114: $146-149$

240 Réa-Neto A, Niederman M, Lobo SM et al. Efficacy and safety of doripenem versus piperacillin/tazobactam in nosocomial pneumonia: a randomized, open-label, multicenter study. Curr Med Res Opin 2008; 24: $2113-2126$

241 Siempos II, Vardakas KZ, Manta KG et al. Carbapenems for the treatment of immunocompetent adult patients with nosocomial pneumonia. Eur Respir J 2007; 29: 548 - 560

242 Joshi M, Metzler M, McCarthy M et al. Comparison of piperacillin/tazobactam and imipenem/cilastatin, both in combination with tobramycin, administered every $6 \mathrm{~h}$ for treatment of nosocomial pneumonia. Respir Med 2006; 100: 1554-1565

243 Shorr AF, Zadeikis $N$, Jackson WL et al. Levofloxacin for treatment of ventilator-associated pneumonia: a subgroup analysis from a randomized trial. Clin Infect Dis 2005; 40: $123-129$

244 Shorr AF, Susla GB, Kollef MH. Quinolones for treatment of nosocomial pneumonia: a meta-analysis. Clin Infect Dis 2005; 40: 115-122

245 Zanetti G, Bally F, Greub G et al. Cefepime versus imipenem-cilastatin for treatment of nosocomial pneumonia in intensive care unit patients: a multicenter, evaluator-blind, prospective, randomized study. Antimicrob Agents Chemother 2003; 47: 3442 - 3447

246 Torres A, Bauer TT, León-Gil C et al. Treatment of severe nosocomial pneumonia: a prospective randomised comparison of intravenous ciprofloxacin with imipenem/cilastatin. Thorax 2000; 55: 10331039

247 Bassetti M, Righi E, Rosso R et al. Efficacy of the combination of levofloxacin plus ceftazidime in the treatment of hospital-acquired pneumonia in the intensive care unit. Int J Antimicrob Agents 2006; 28: $582-585$

248 Berman SJ, Fogarty CM, Fabian T et al. Meropenem monotherapy for the treatment of hospital-acquired pneumonia: results of a multicenter trial. J Chemother 2004; 16: 362 - 371

249 Wolff $M$. Comparison of strategies using cefpirome and ceftazidime for empiric treatment of pneumonia in intensive care patients. The Cefpirome Pneumonia Study Group. Antimicrob Agents Chemother 1998; $42: 28-36$

250 Ahmed S, Choudhary J, Ahmed M et al. Treatment of ventilator-associated pneumonia with piperacillin-tazobactum and amikacin vs cefepime and levofloxacin: A randomized prospective study. Indian J Crit Care Med 2007; 11: 117-121

251 Saginur R, Garber G, Darling G et al. Prospective, randomized comparison of intravenous and oral ciprofloxacin with intravenous ceftazidime in the treatment of nosocomial pneumonia. Can J Infect Dis 1997; 8: 89-94
252 Magnotti LJ, Schroeppel TJ, Clement LP et al. Efficacy of monotherapy in the treatment of Pseudomonas ventilator-associated pneumonia in patients with trauma. J Trauma 2009; 66: 1052-1058

253 Alvarez-Lerma F. Serious Infection Study Group. Efficacy of meropenem as monotherapy in the treatment of ventilator-associated pneumonia. J Chemother 2001; 13: 70-81

254 Vidaur L, Gualis B, Rodriguez A et al. Clinical resolution in patients with suspicion of ventilator-associated pneumonia: a cohort study comparing patients with and without acute respiratory distress syndrome. Crit Care Med 2005; 33: 1248 - 1253

255 Rotstein C, Evans G, Born A et al. Clinical practice guidelines for hospital-acquired pneumonia and ventilator-associated pneumonia in adults. Can J Infect Dis Med Microbiol 2008; 19: 19-53

256 Alvarez-Lerma F, Alvarez B, Luque $P$ et al. Empiric broad-spectrum antibiotic therapy of nosocomial pneumonia in the intensive care unit: a prospective observational study. Crit Care 2006; 10: R78

257 Kopelman TR. Can empiric broad-spectrum antibiotics for ventilatorassociated pneumonia be narrowed based on Gram's stain results of bronchoalveolar lavage fluid. Am J Surg 2006; 192: 812 - 816

258 Rello J, Vidaur L, Sandiumenge A et al. De-escalation therapy in ventilator-associated pneumonia. Crit Care Med 2004; 32: 2183-2190

259 Craven DE, Chroneou A, Zias $N$ et al. Ventilator-associated tracheobronchitis: the impact of targeted antibiotic therapy on patient outcomes. Chest 2009; 135: 521-528

260 De Cock E, Krueger WA, Sorensen S et al. Cost-effectiveness of linezolid vs vancomycin in suspected methicillin-resistant Staphylococcus aureus nosocomial pneumonia in Germany. Infection 2009; 37: 123 132

261 Radhakrishnan M, Jaganath A, Rao GS et al. Nebulized imipenem to control nosocomial pneumonia caused by Pseudomonas aeruginosa. J Crit Care 2008; 23: 148-150

262 Estes L, Orenstem R. Cost-effectiveness analysis of linezolid compared with vancomycin for the treatment of nosocomial pneumonia caused by methicillin-resistant Staphylococcus aureus. Clin Ther 2007; 29: $759-760$

263 Pereira GH, Muller PR, Levin AS. Salvage treatment of pneumonia and initial treatment of tracheobronchitis caused by multidrug-resistant Gram-negative bacilli with inhaled polymyxin B. Diagn Microbiol Infect Dis 2007; 58: 235-240

264 Salerno D, Vahid B, Marik PE. Methicillin-resistant Staphylococcus aureus pneumonia after thoracic surgery: successful treatment with linezolid after failed vancomycin therapy. Ann Thorac Surg 2007; 83: $1888-1891$

265 Karageorgopoulos DE, Kelesidis T, Kelesidis I et al. Tigecycline for the treatment of multidrug-resistant (including carbapenem-resistant) Acinetobacter infections: a review of the scientific evidence. J Antimicrob Chemother 2008; 62: 45-55 

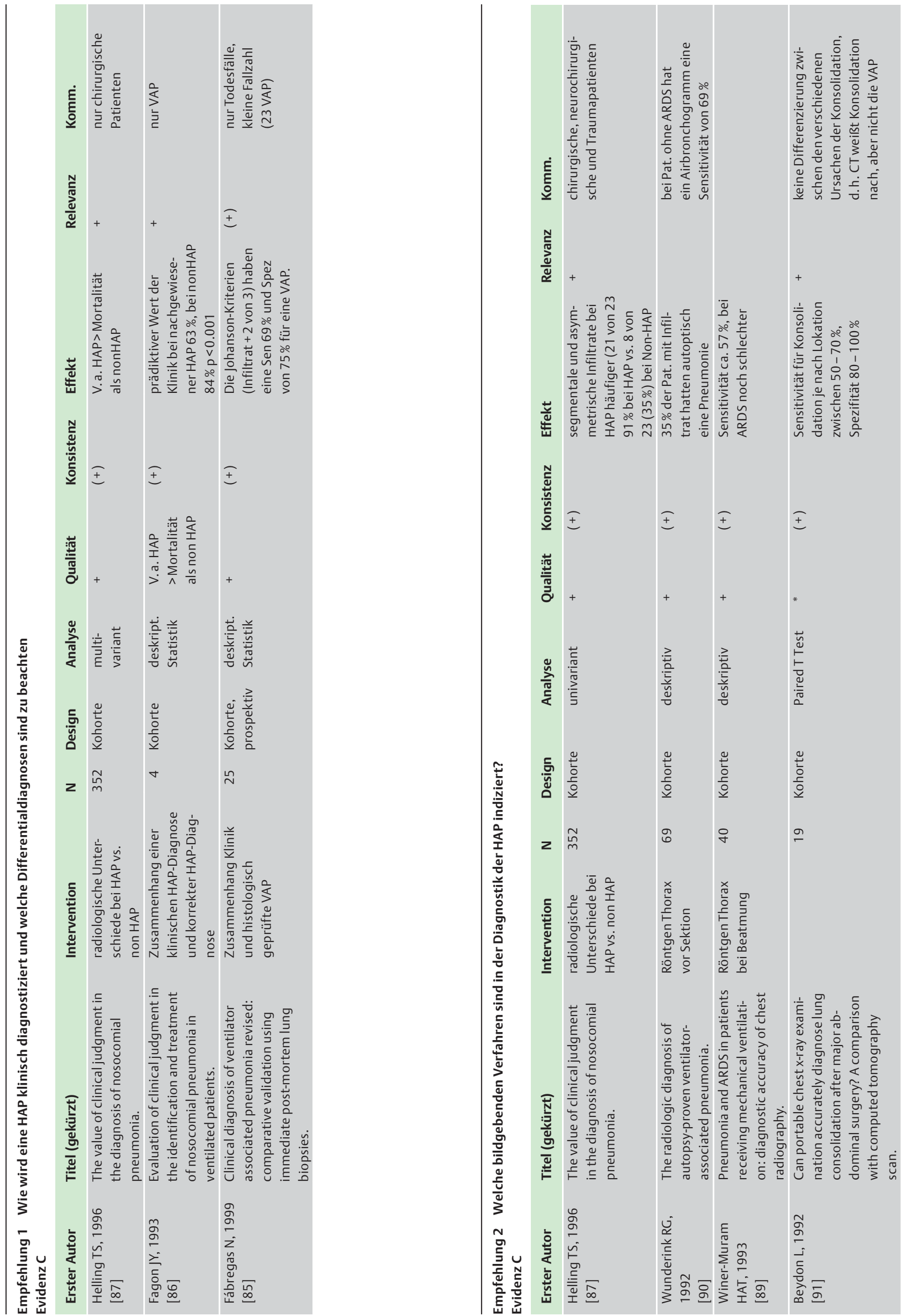


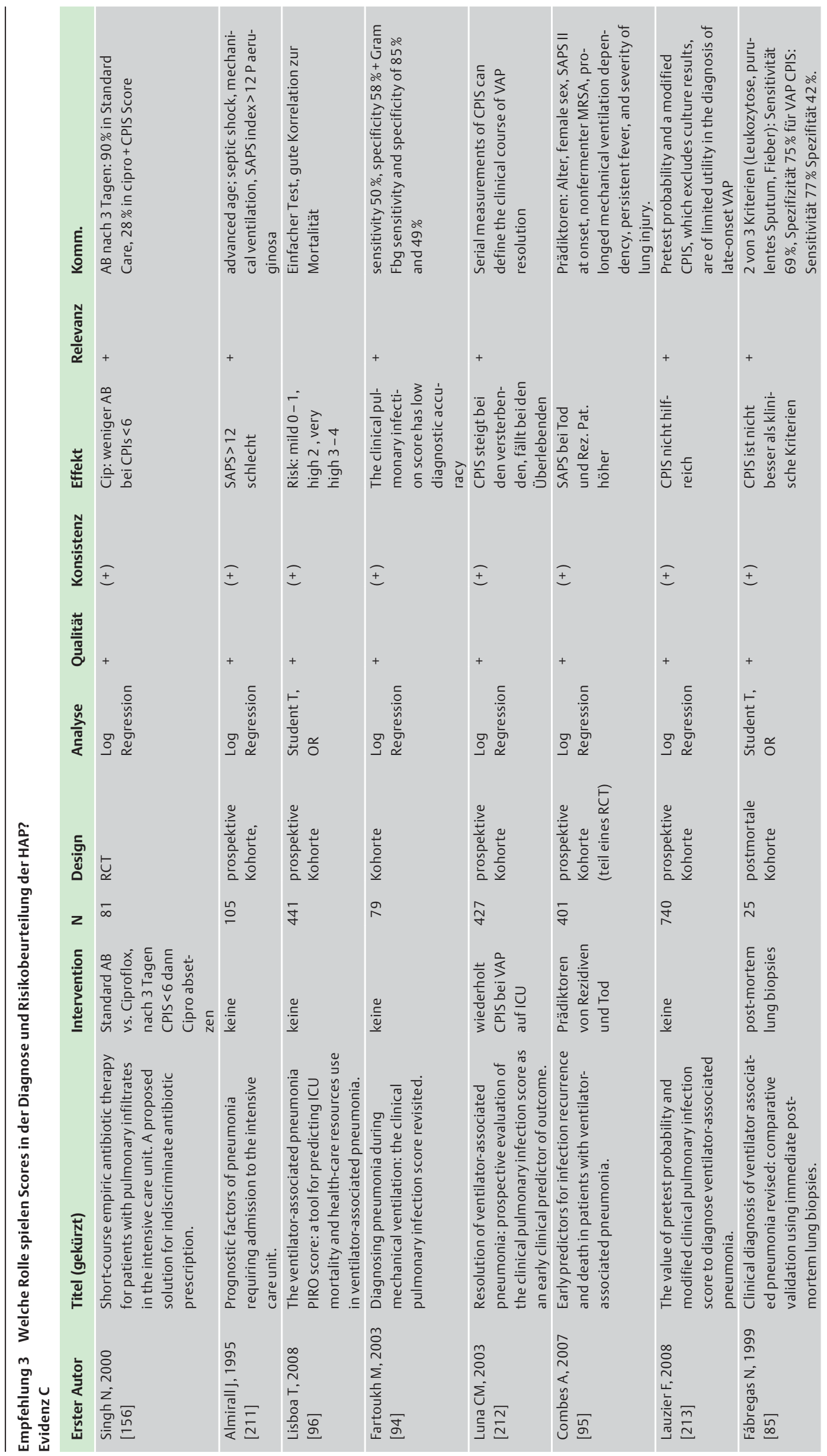




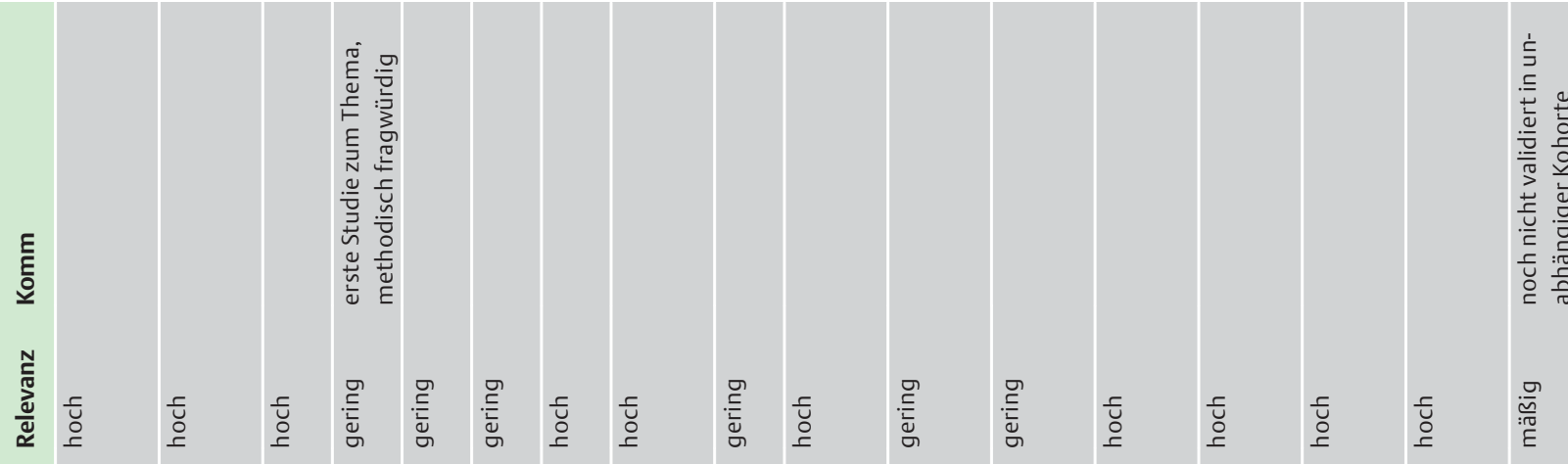

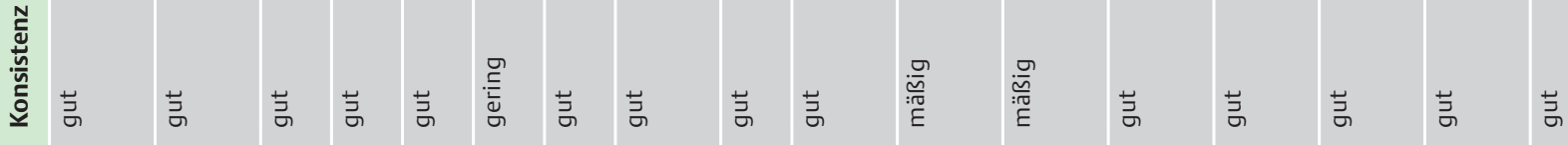

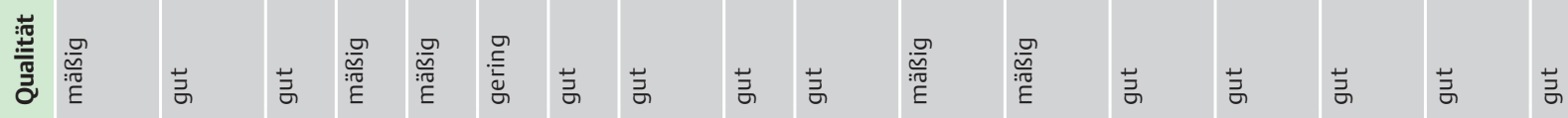

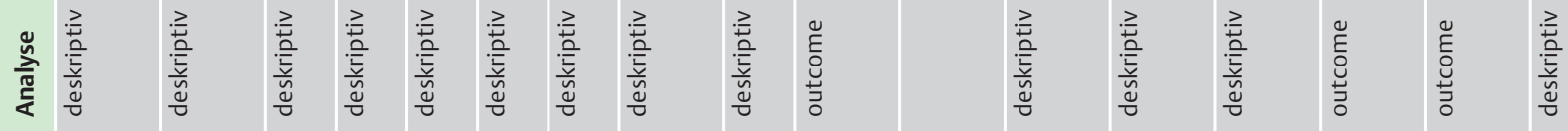

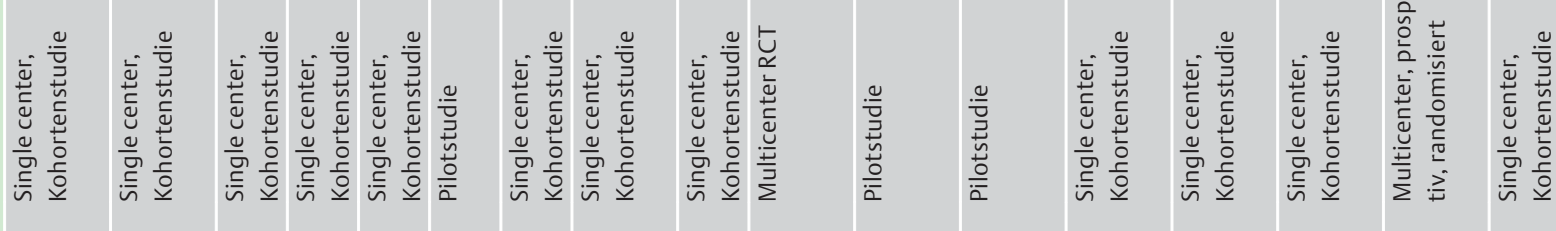

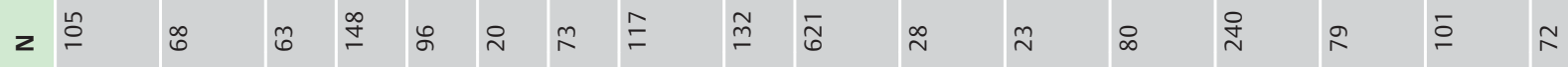

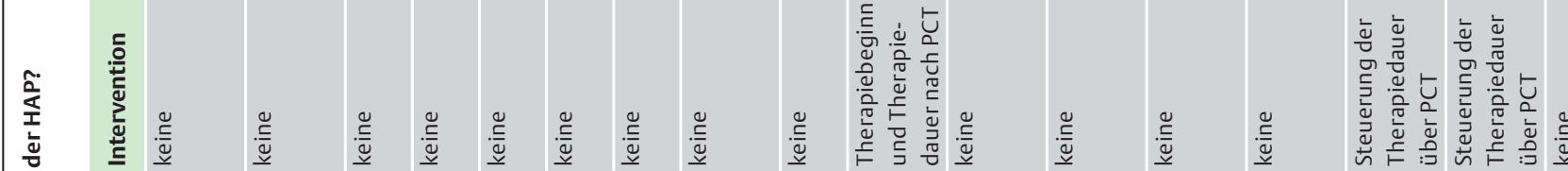

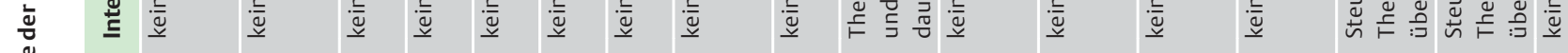

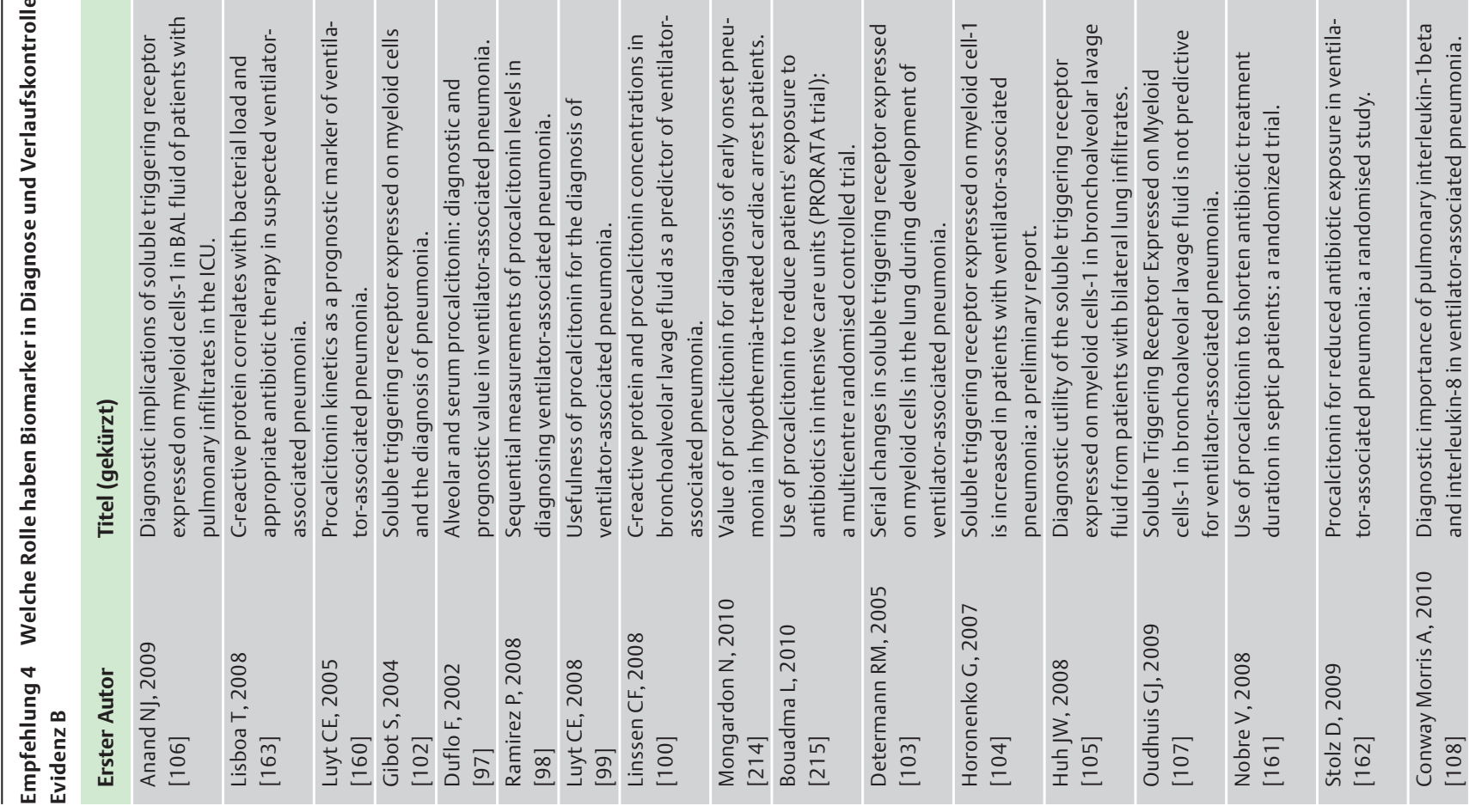




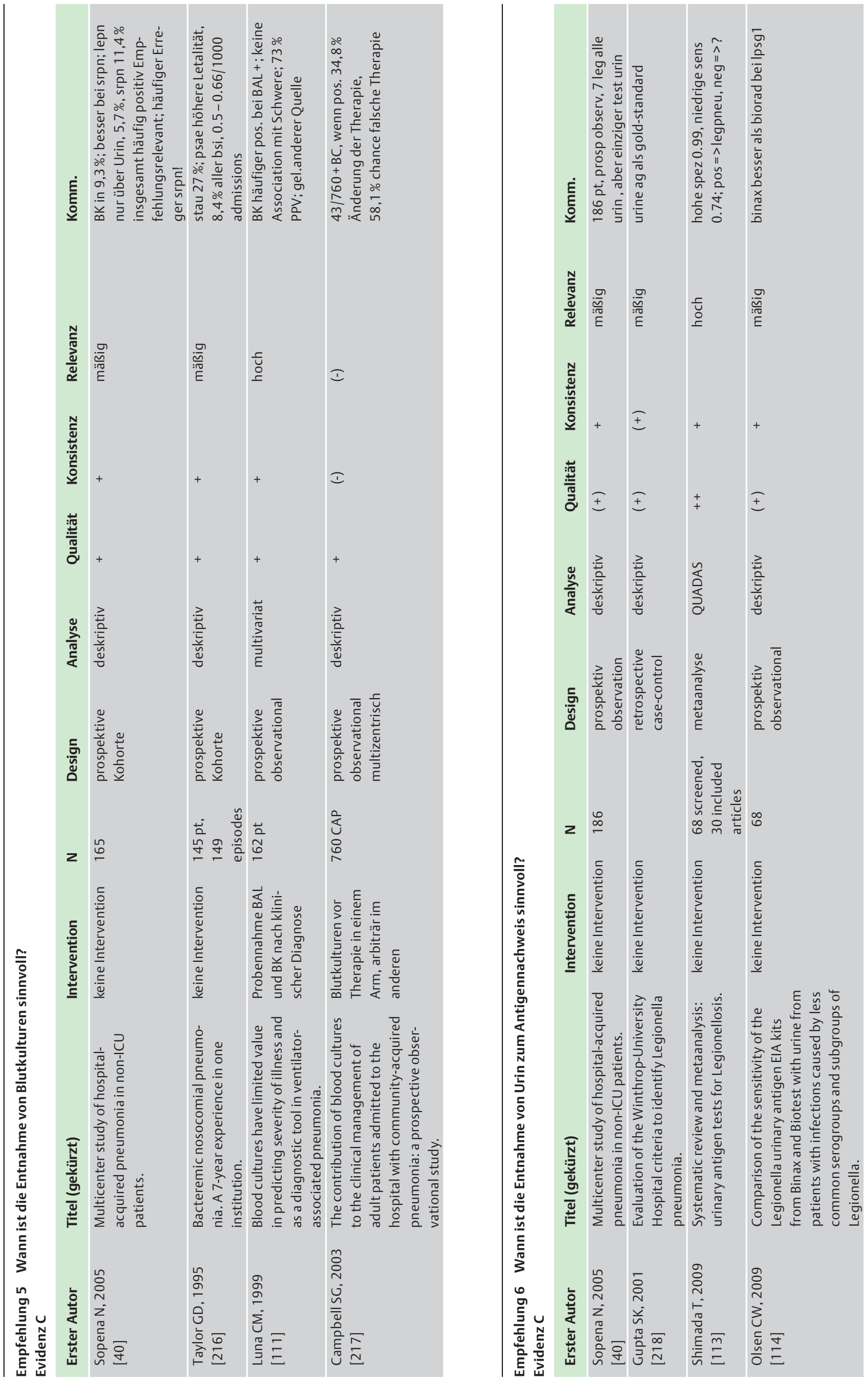




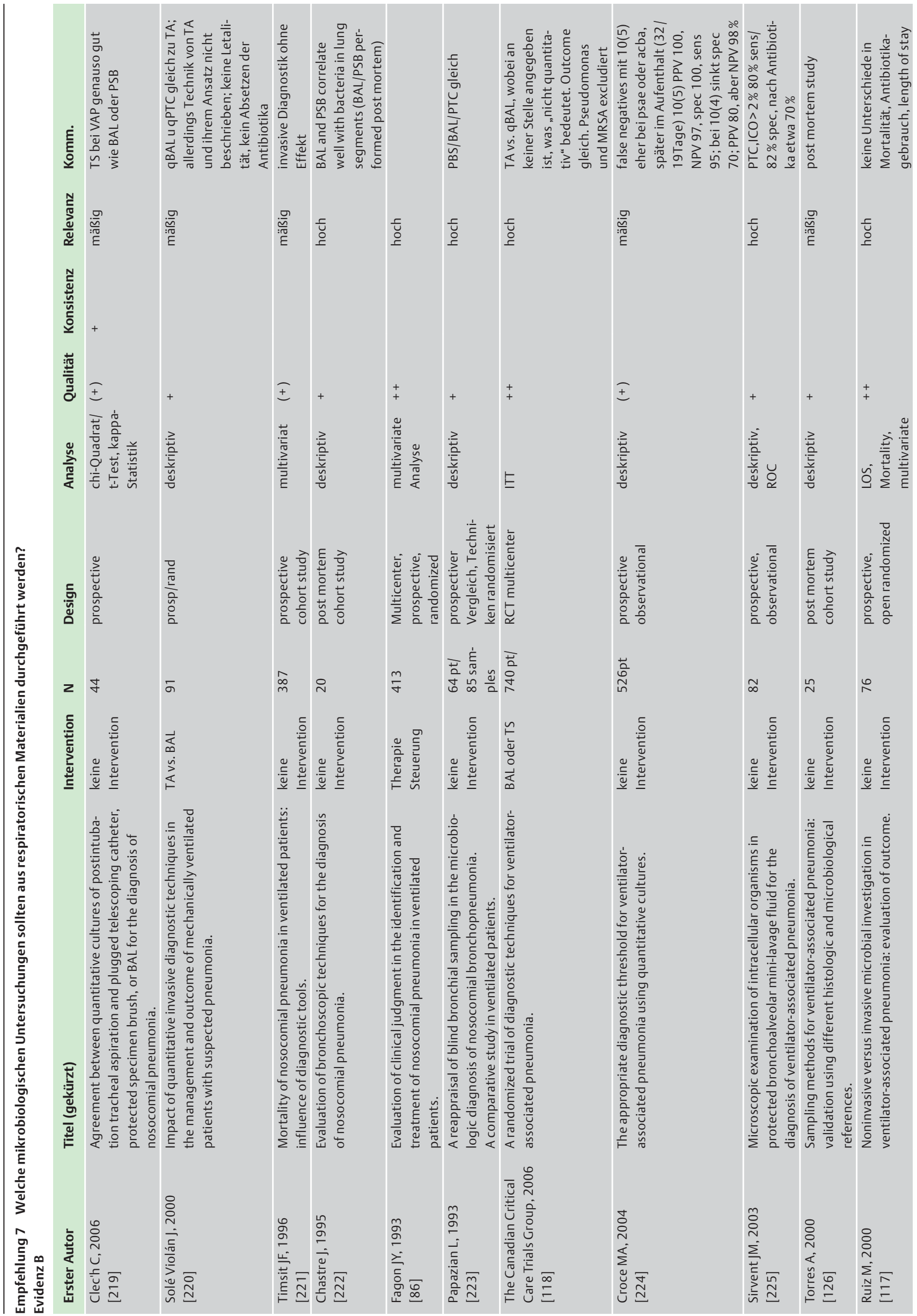



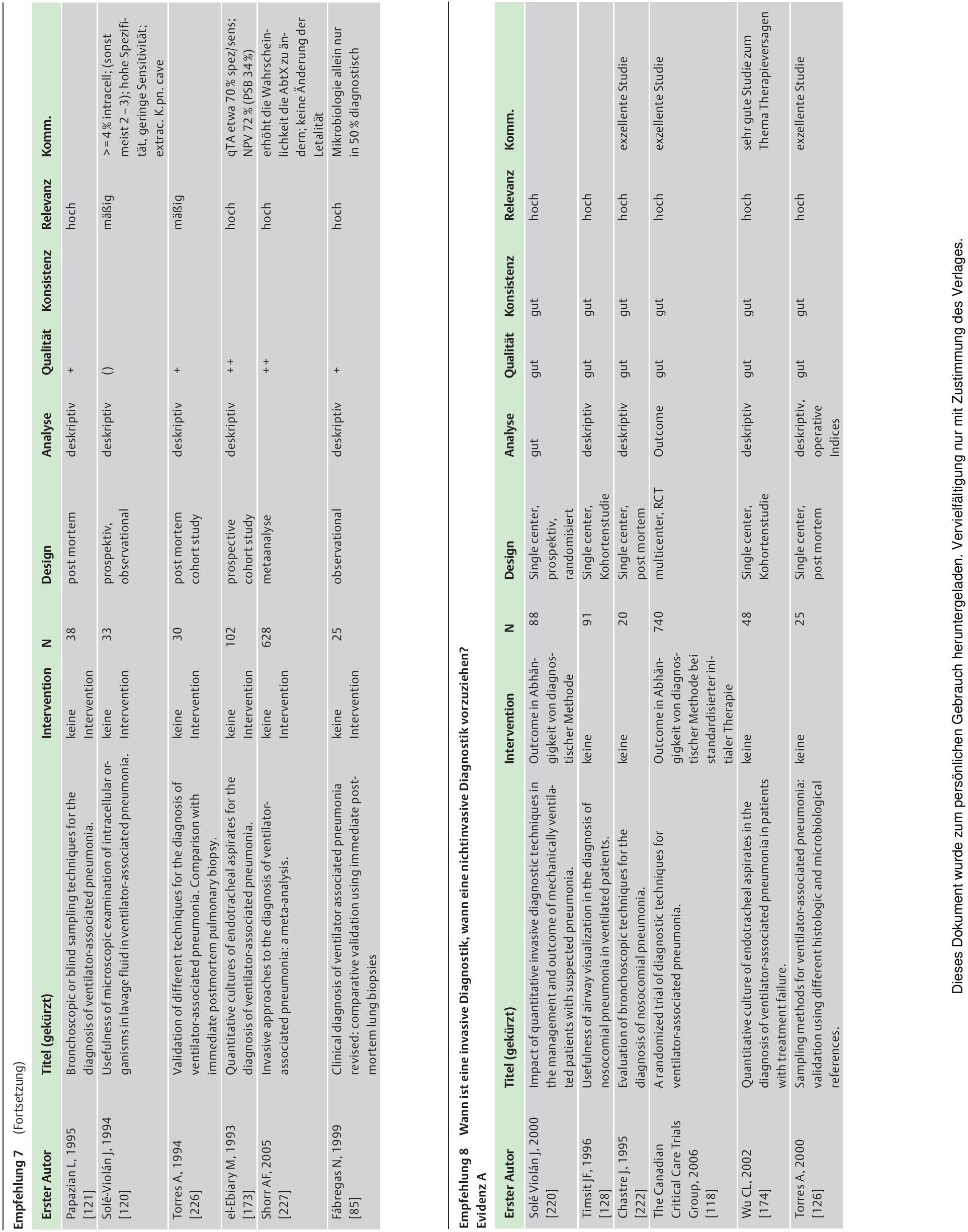


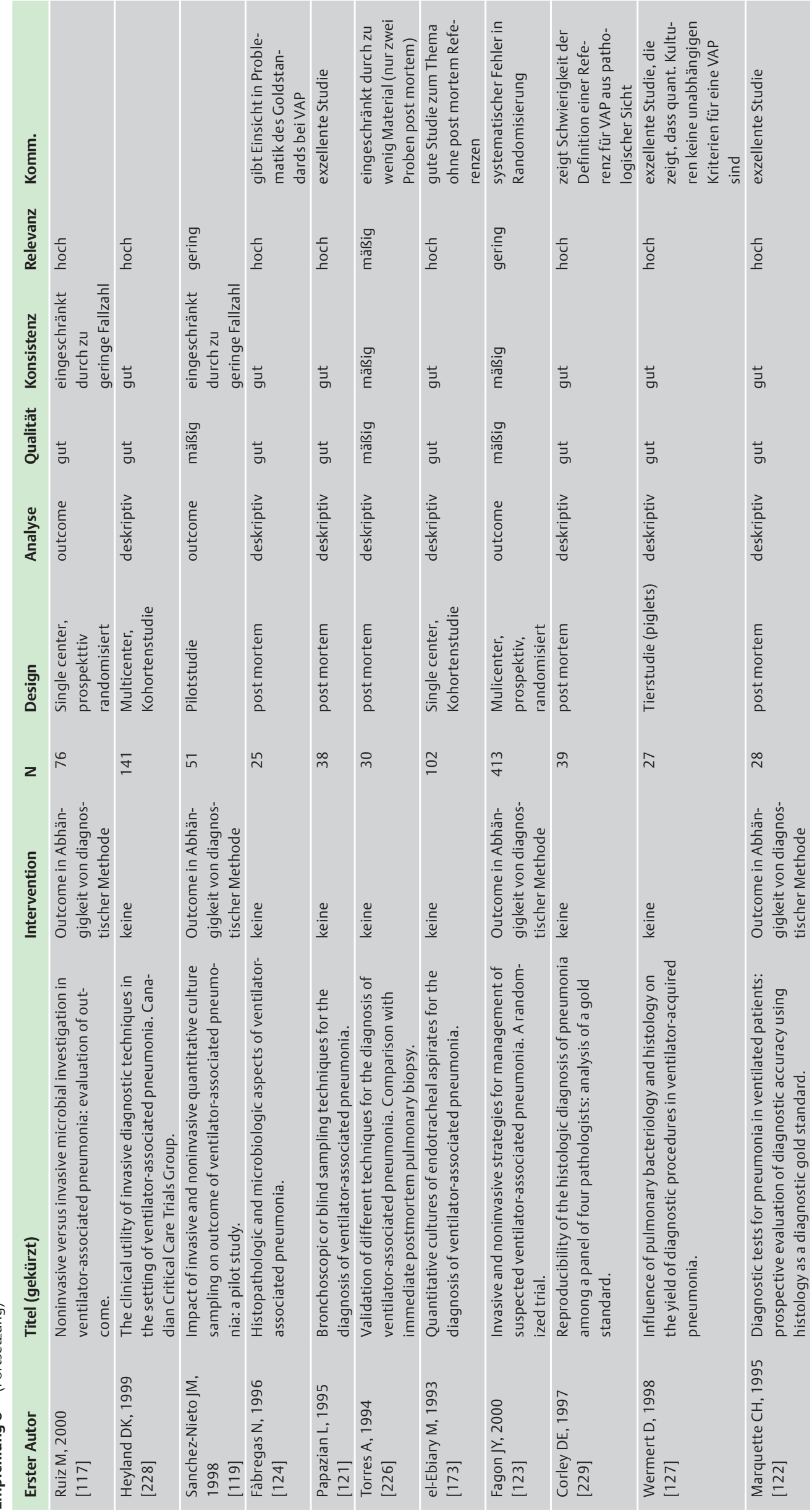



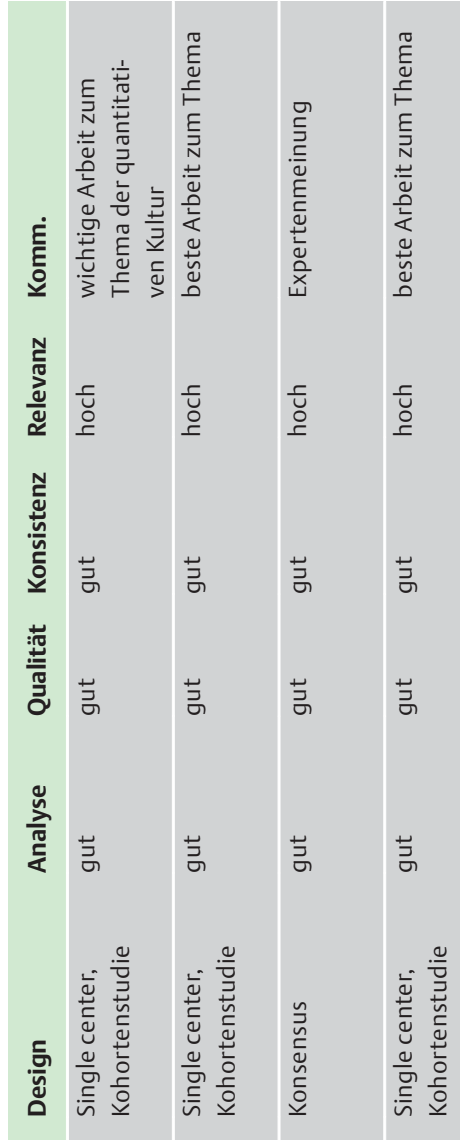

$z$ †
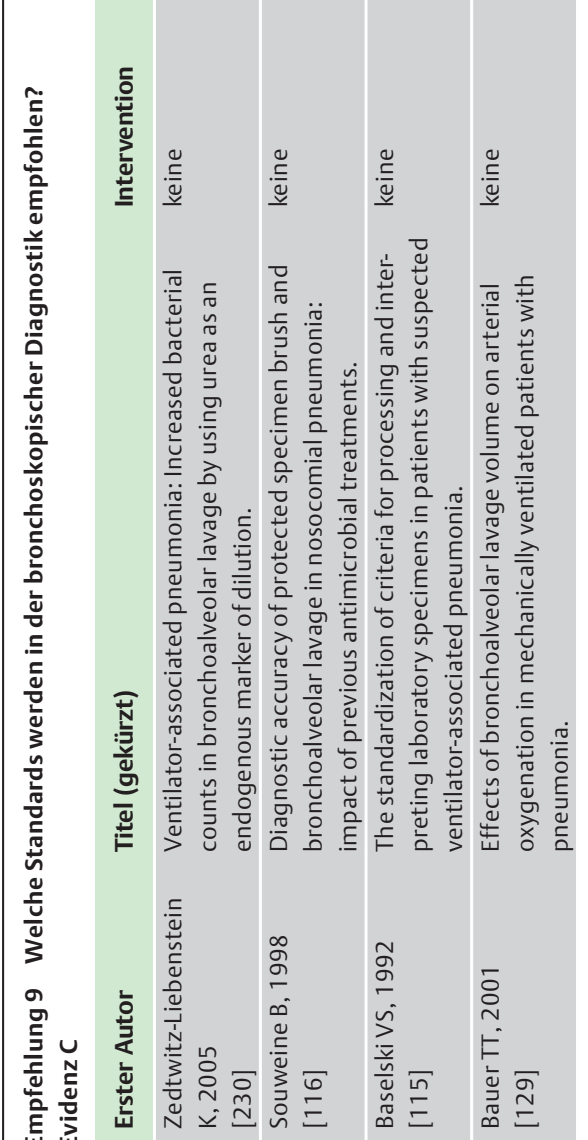

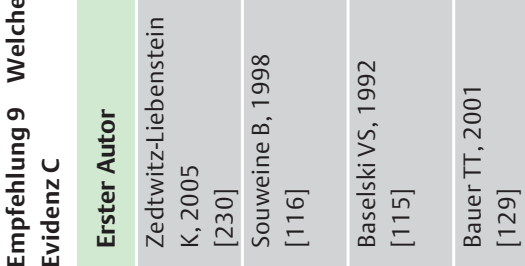

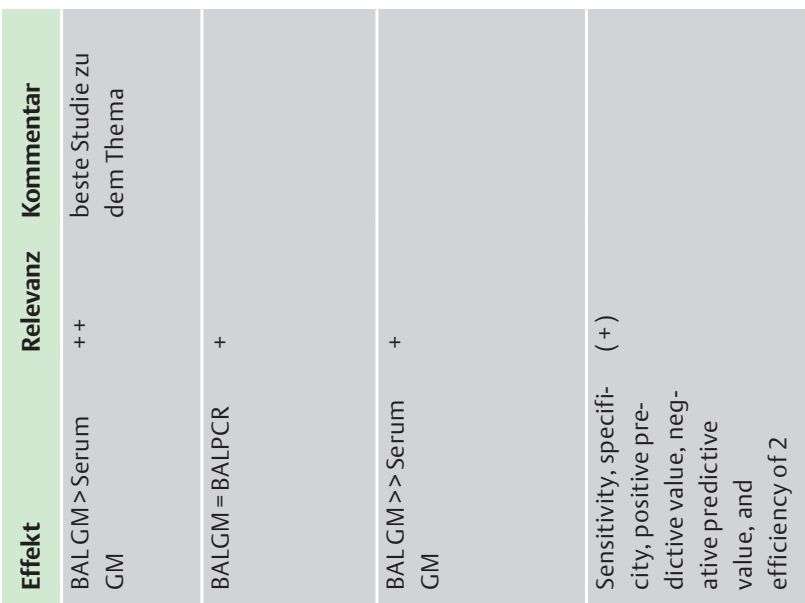

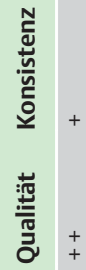

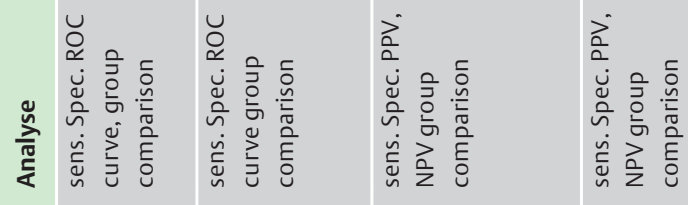

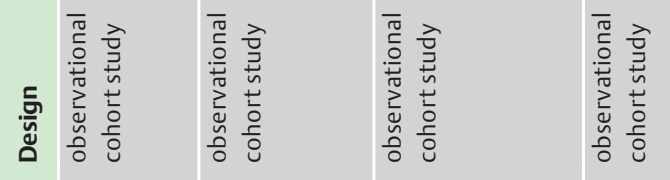

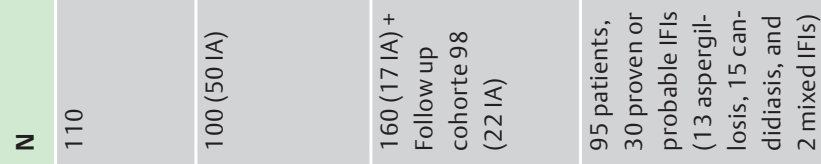

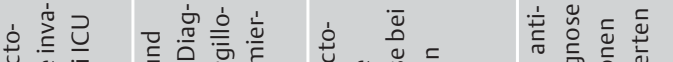

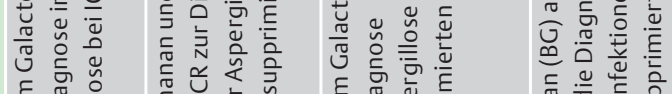

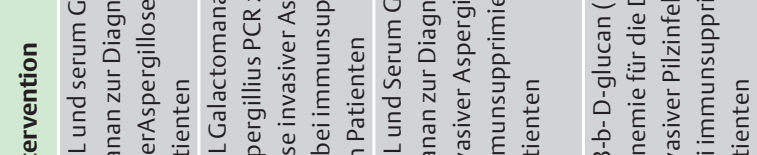

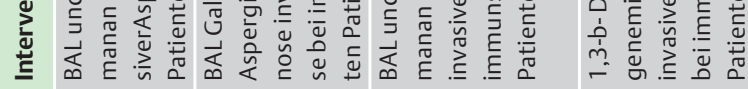

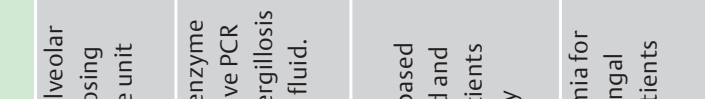

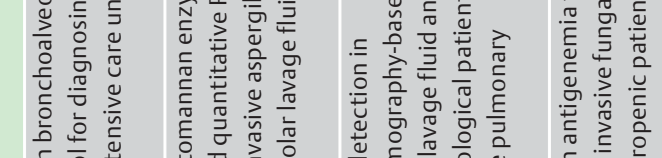

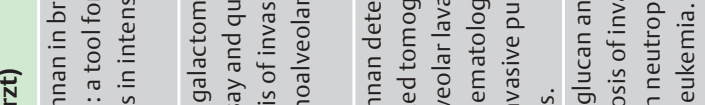

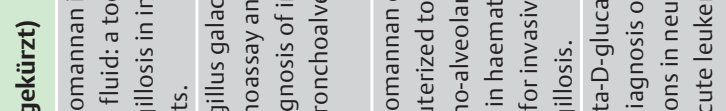

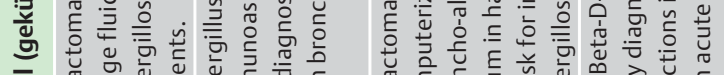

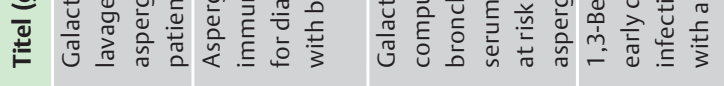




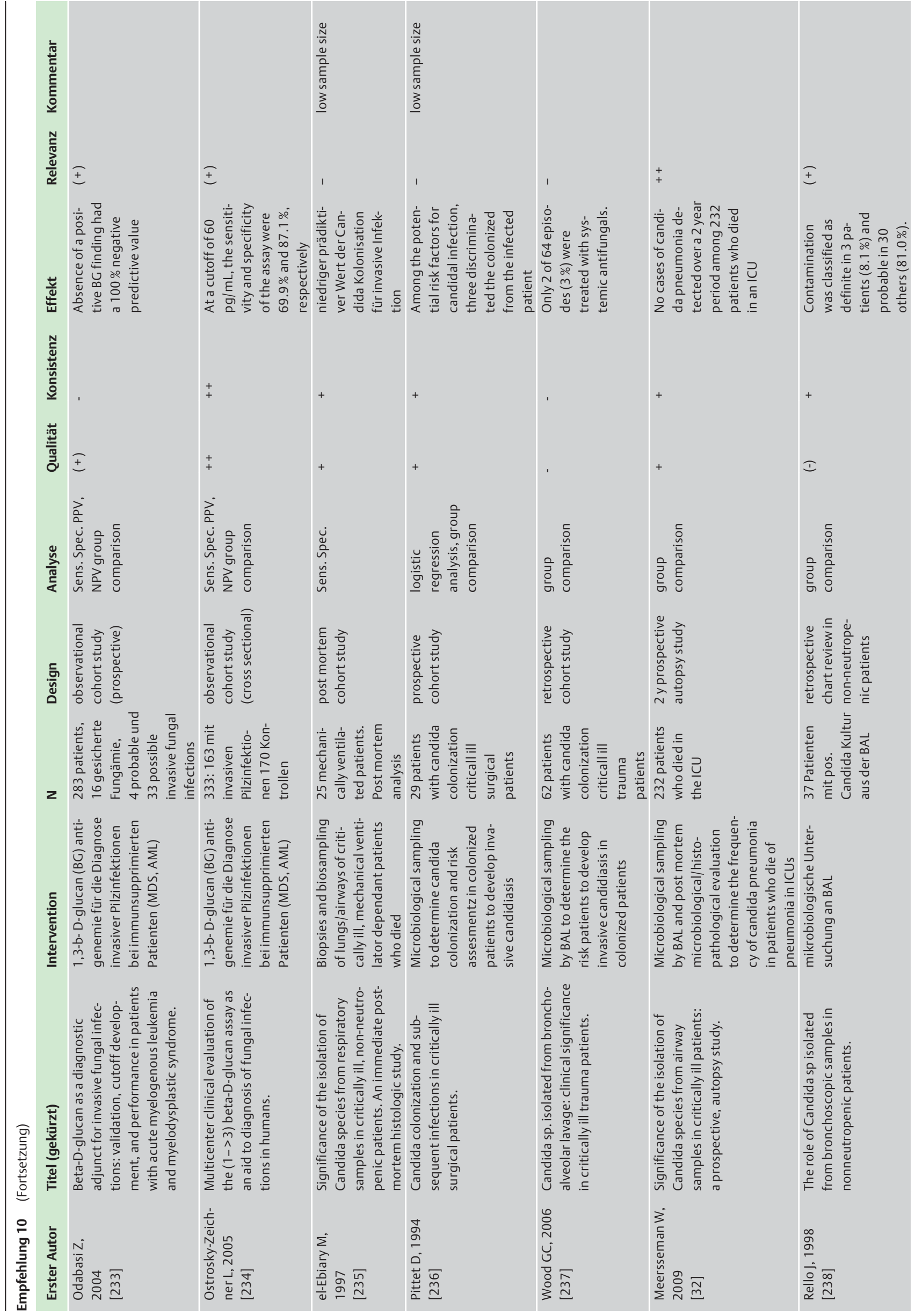



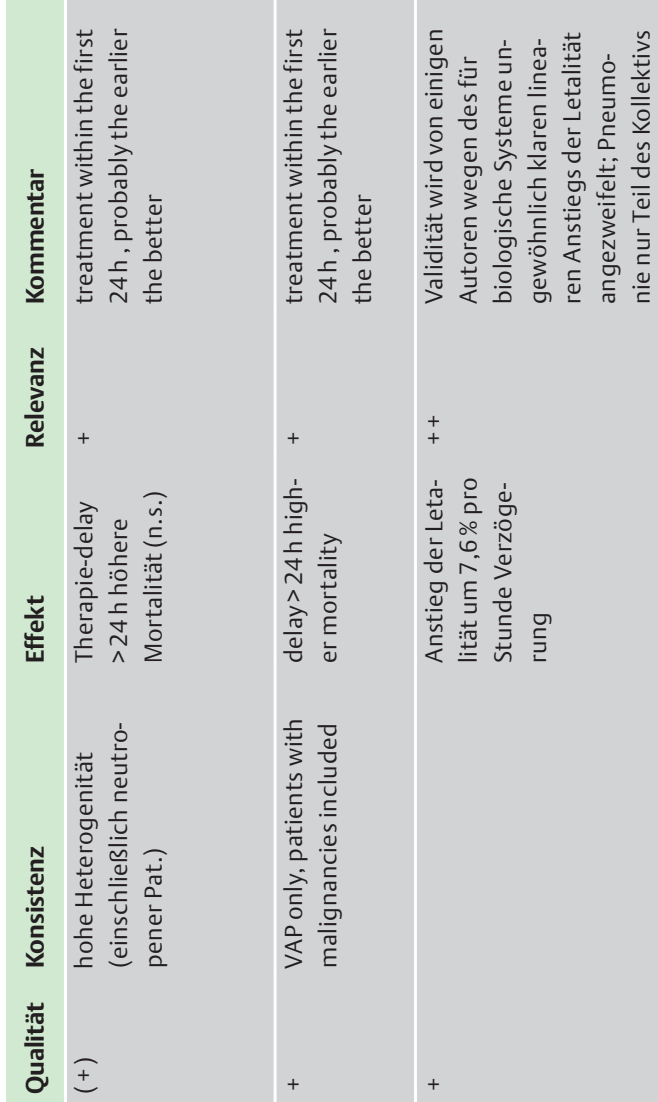

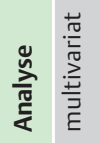
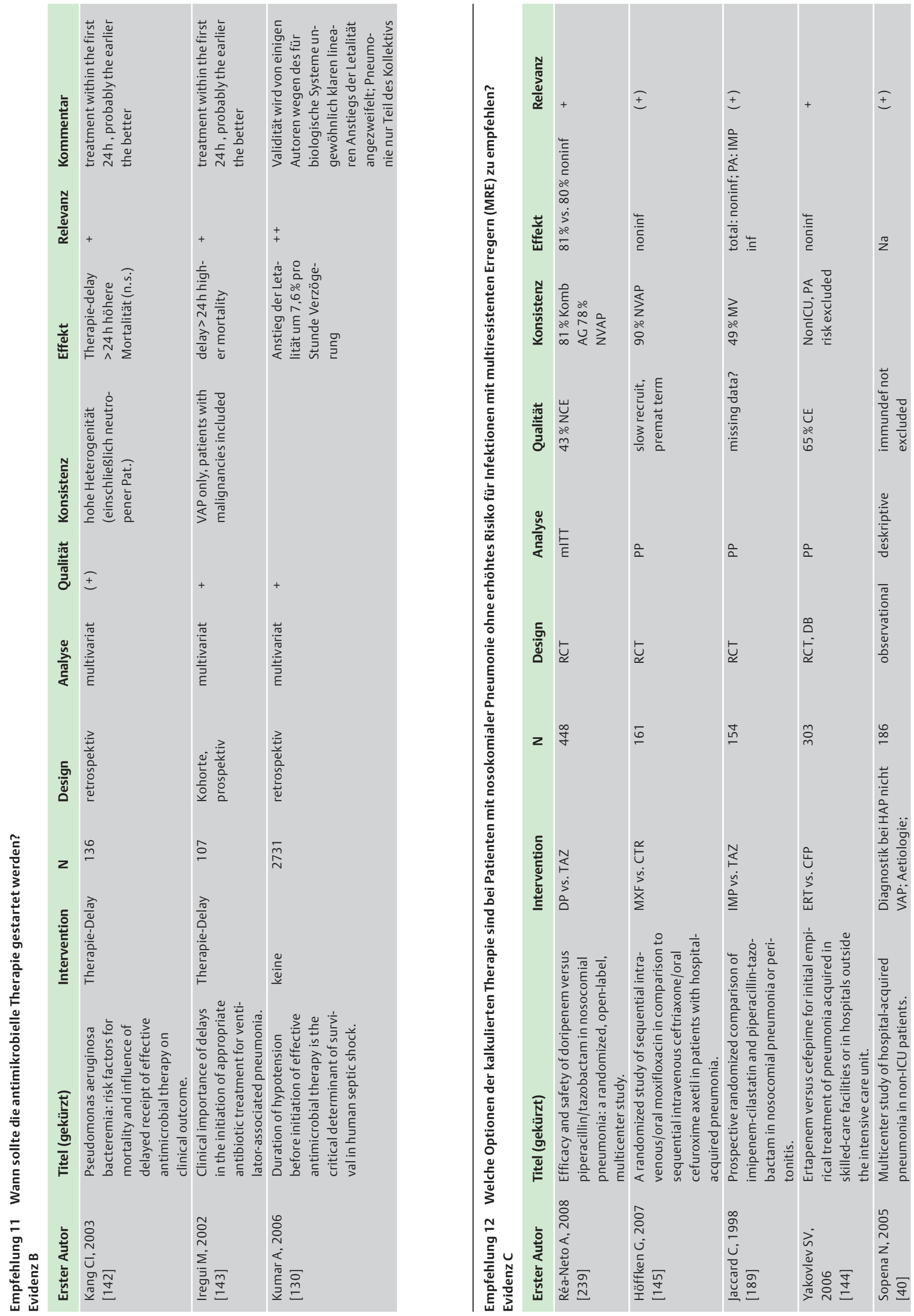


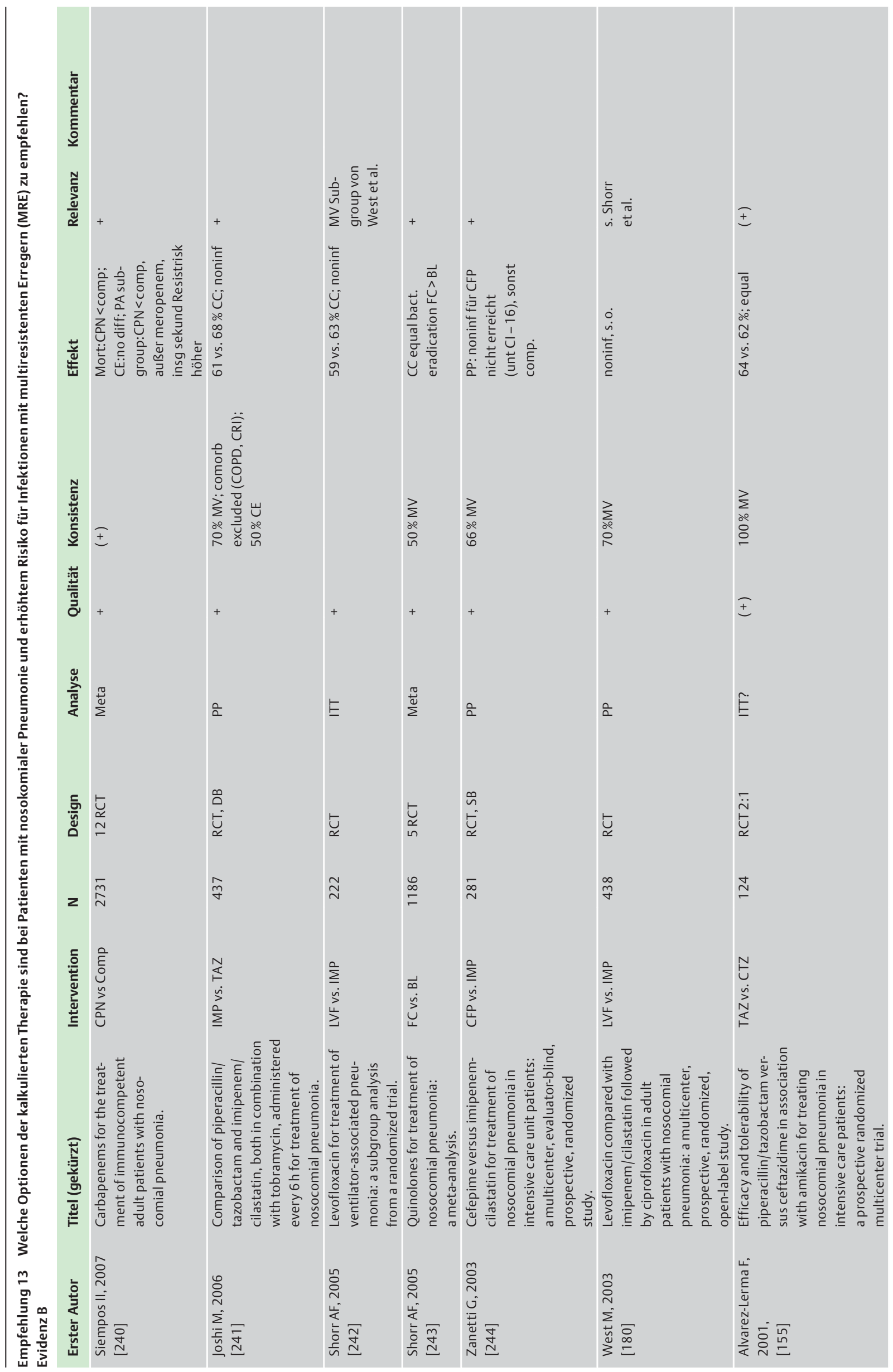




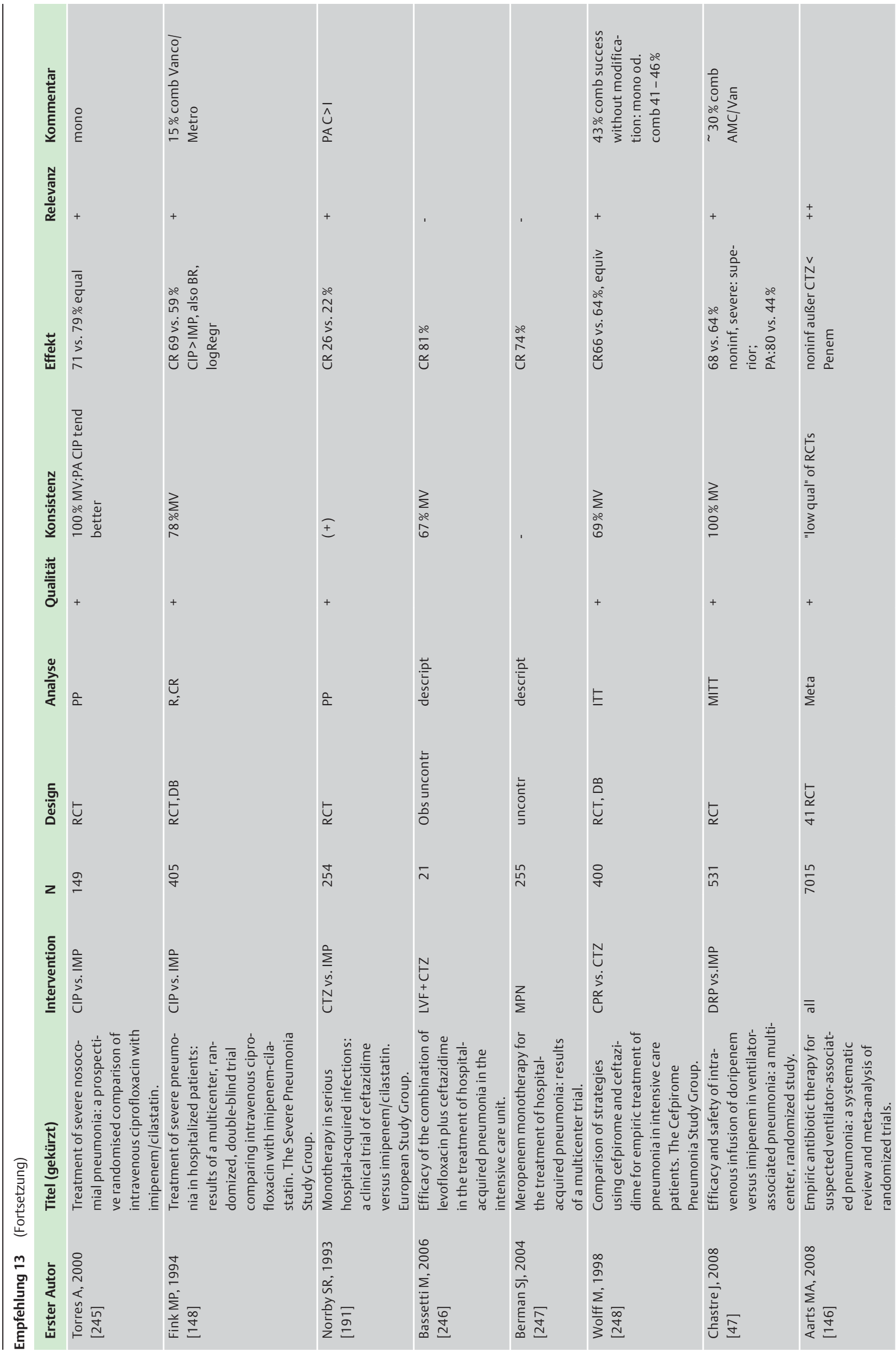



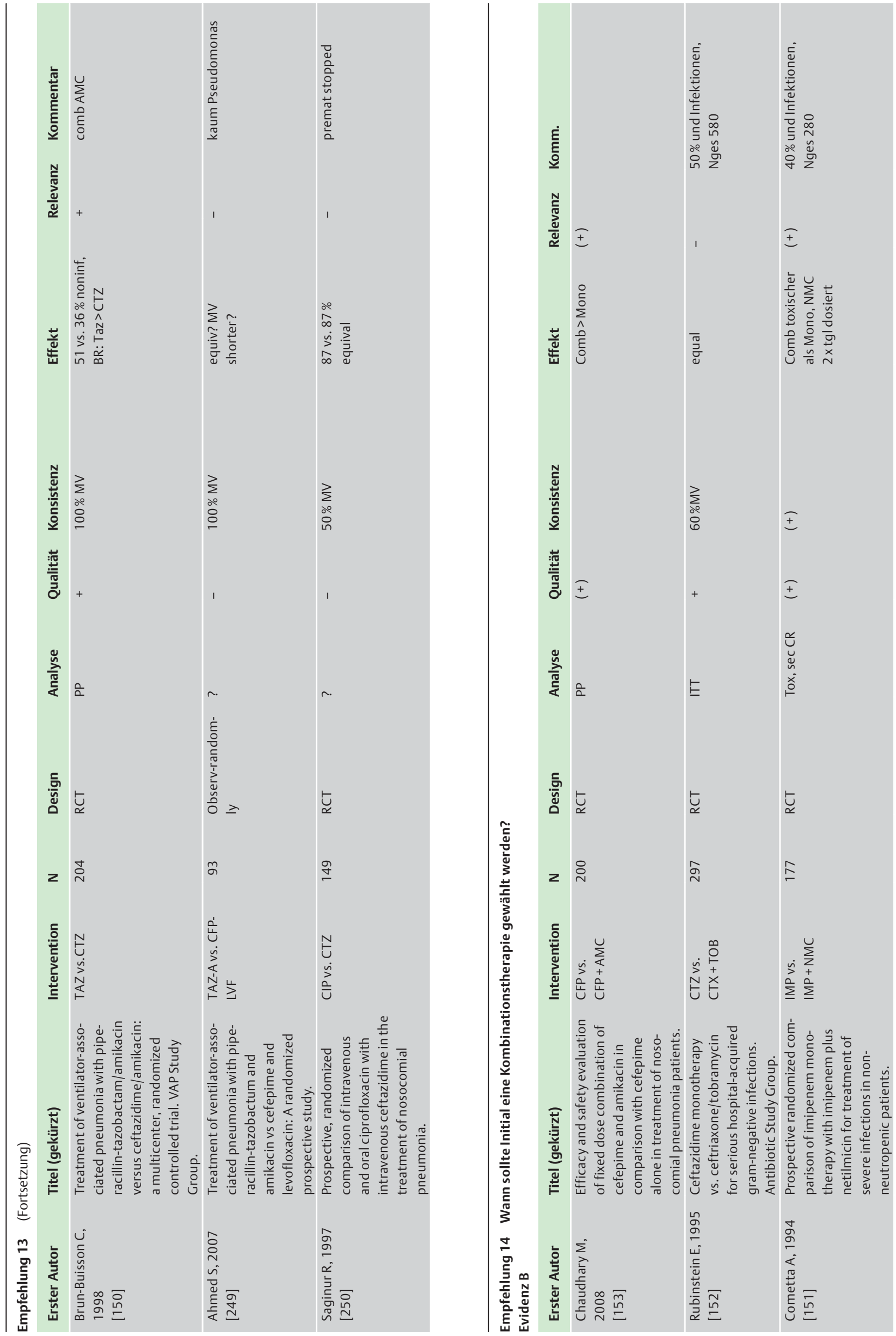


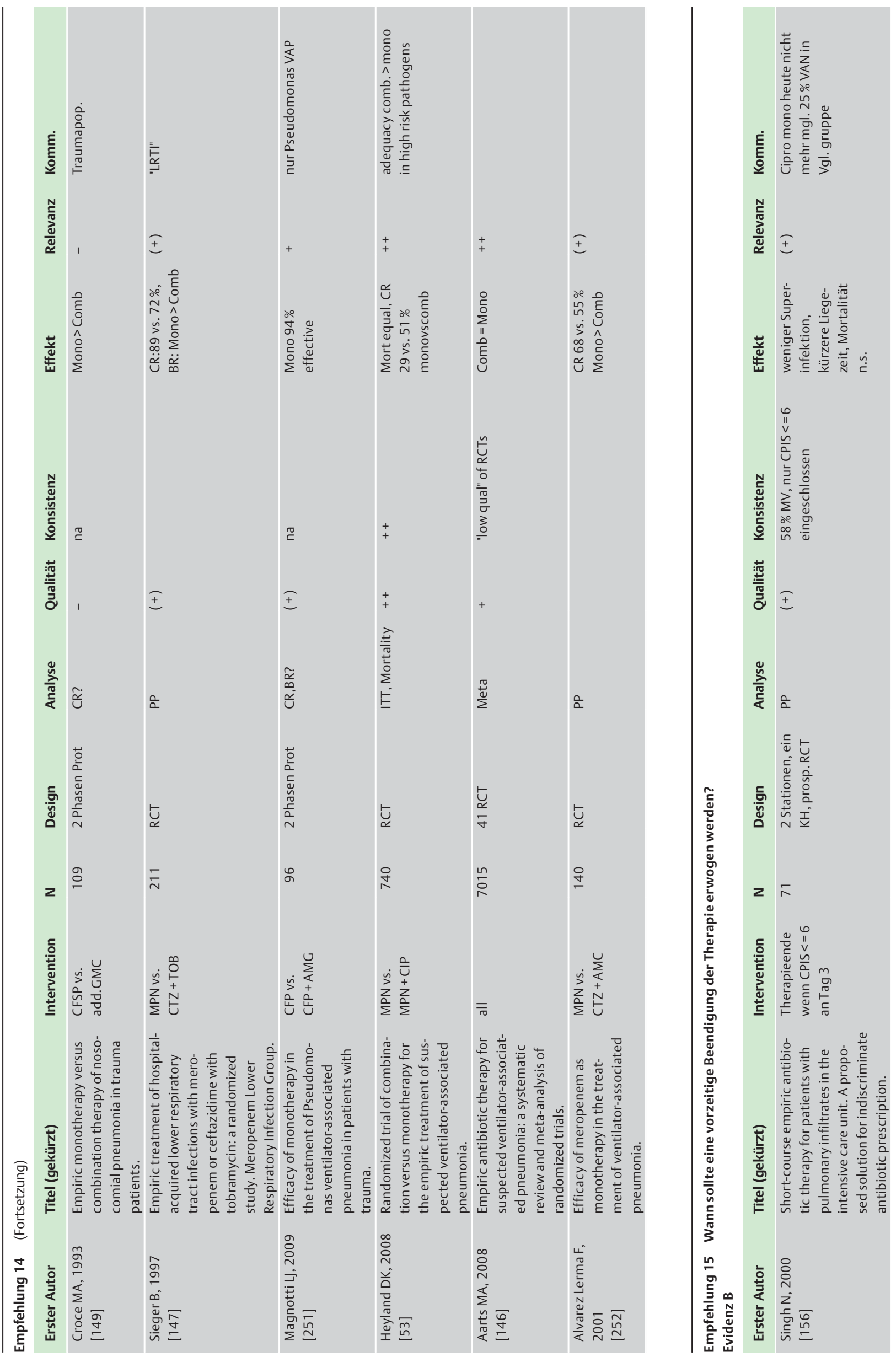




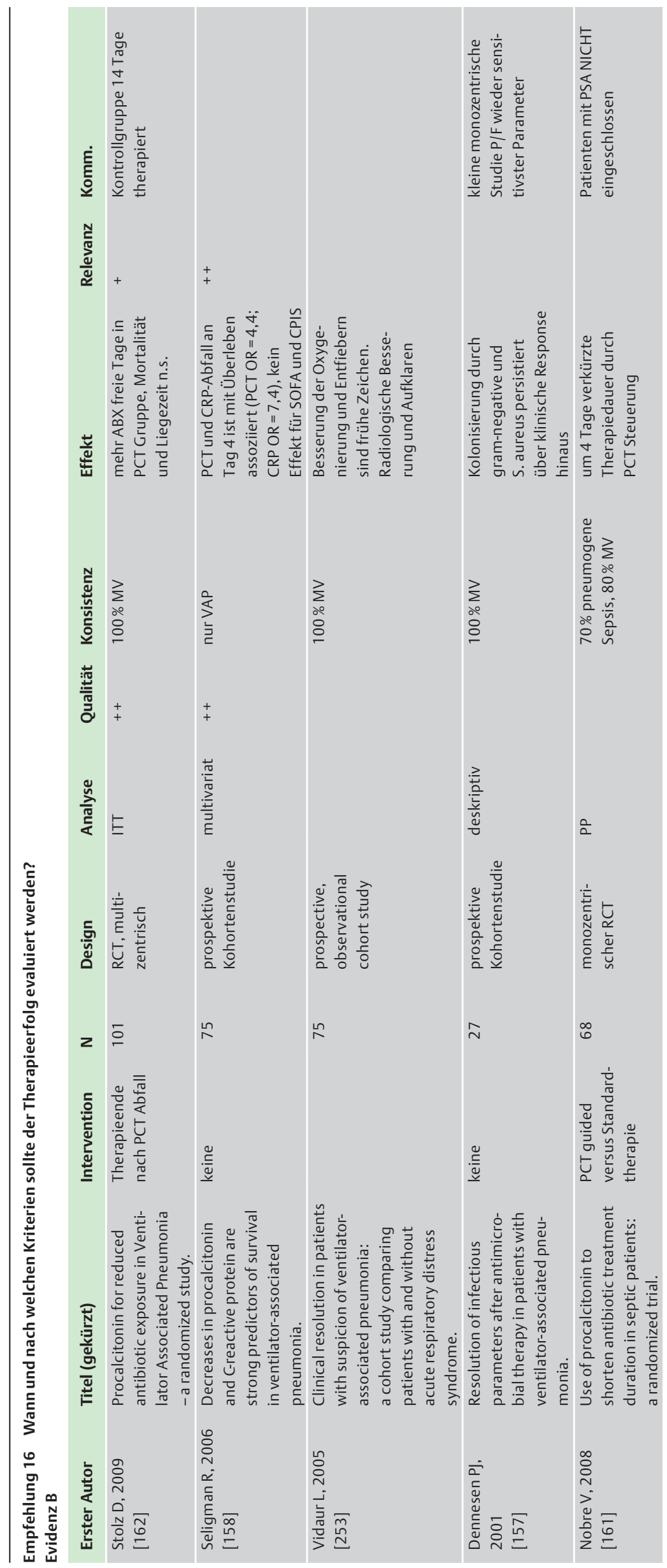




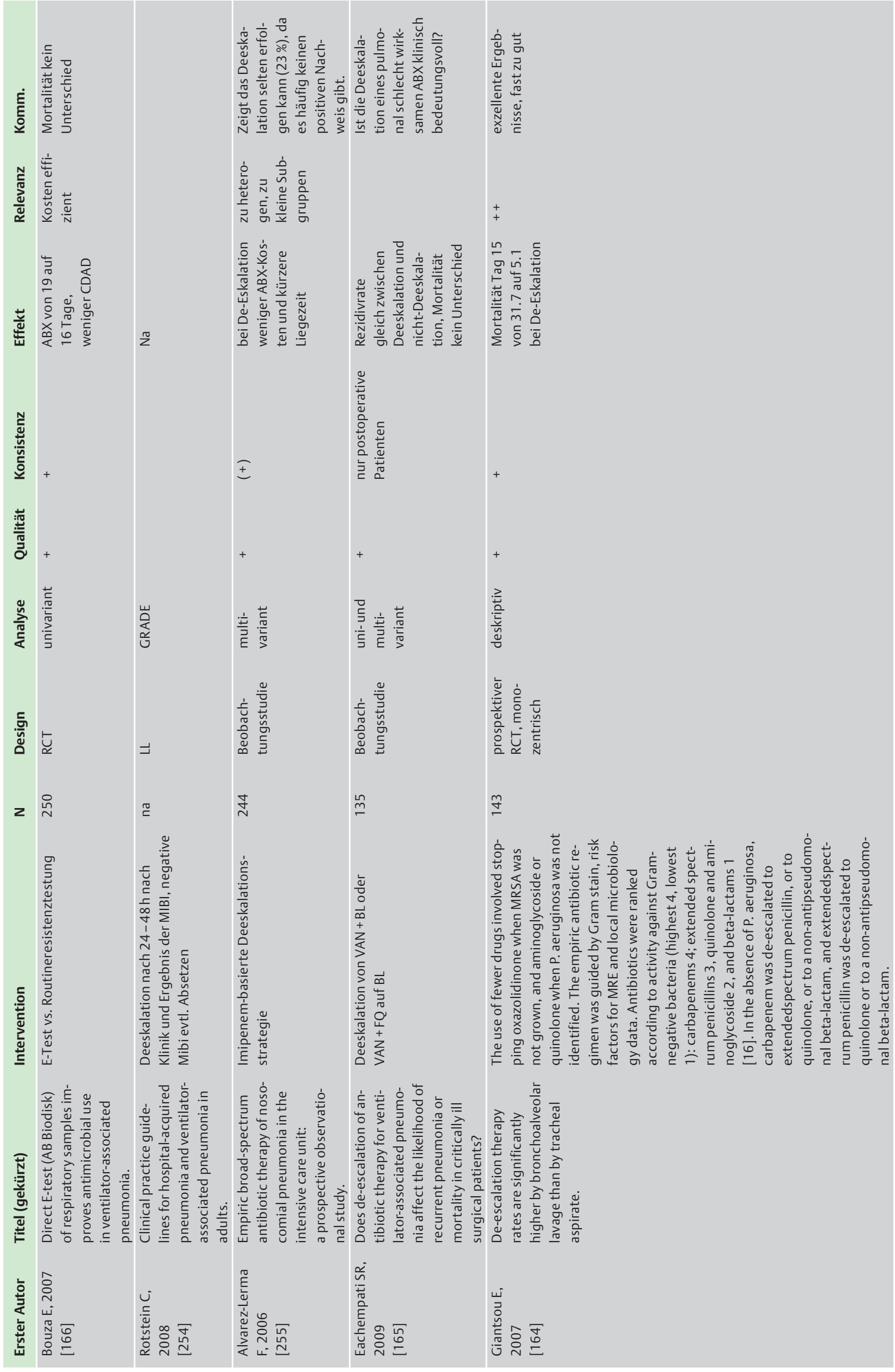




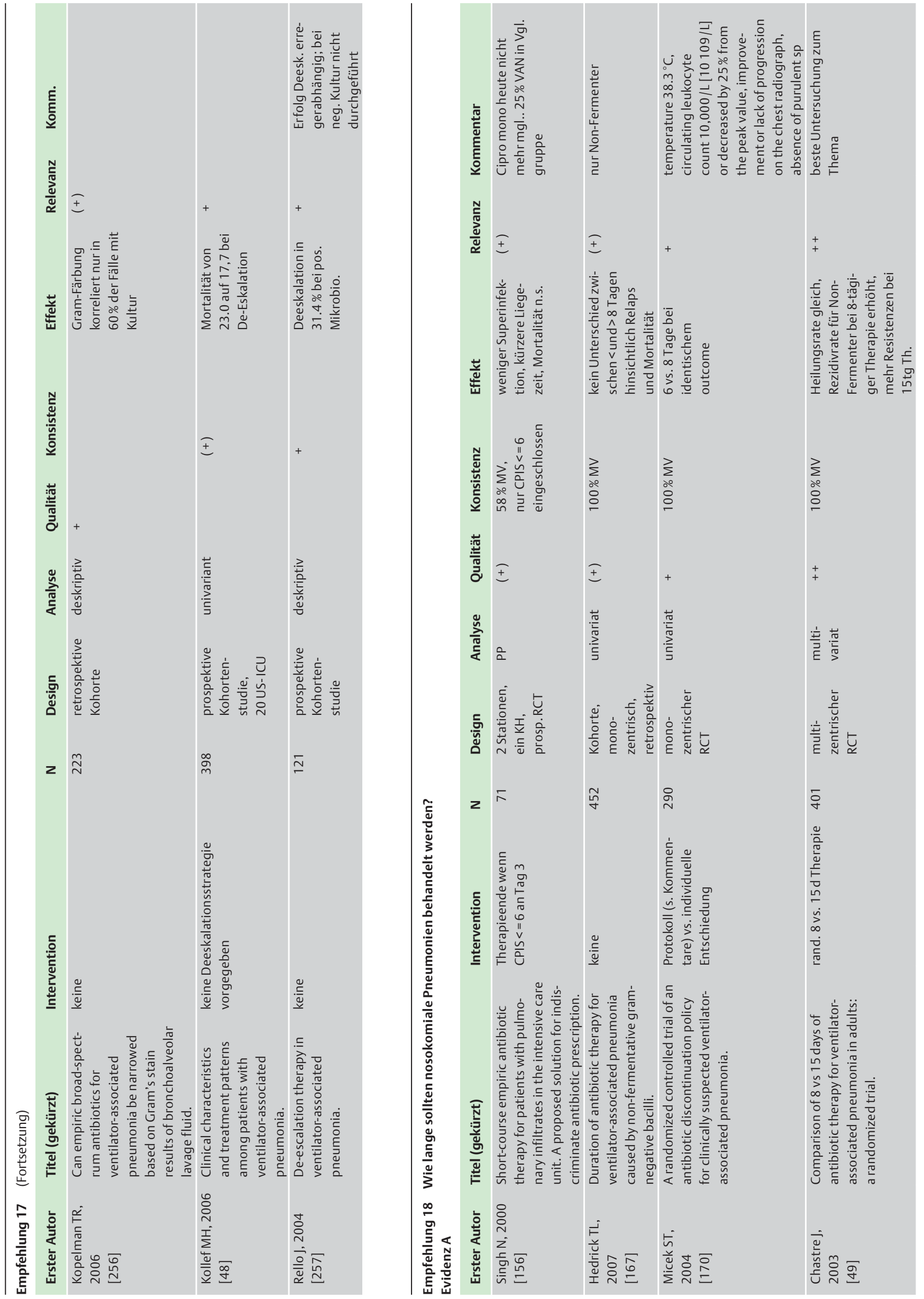

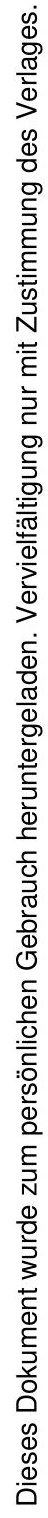




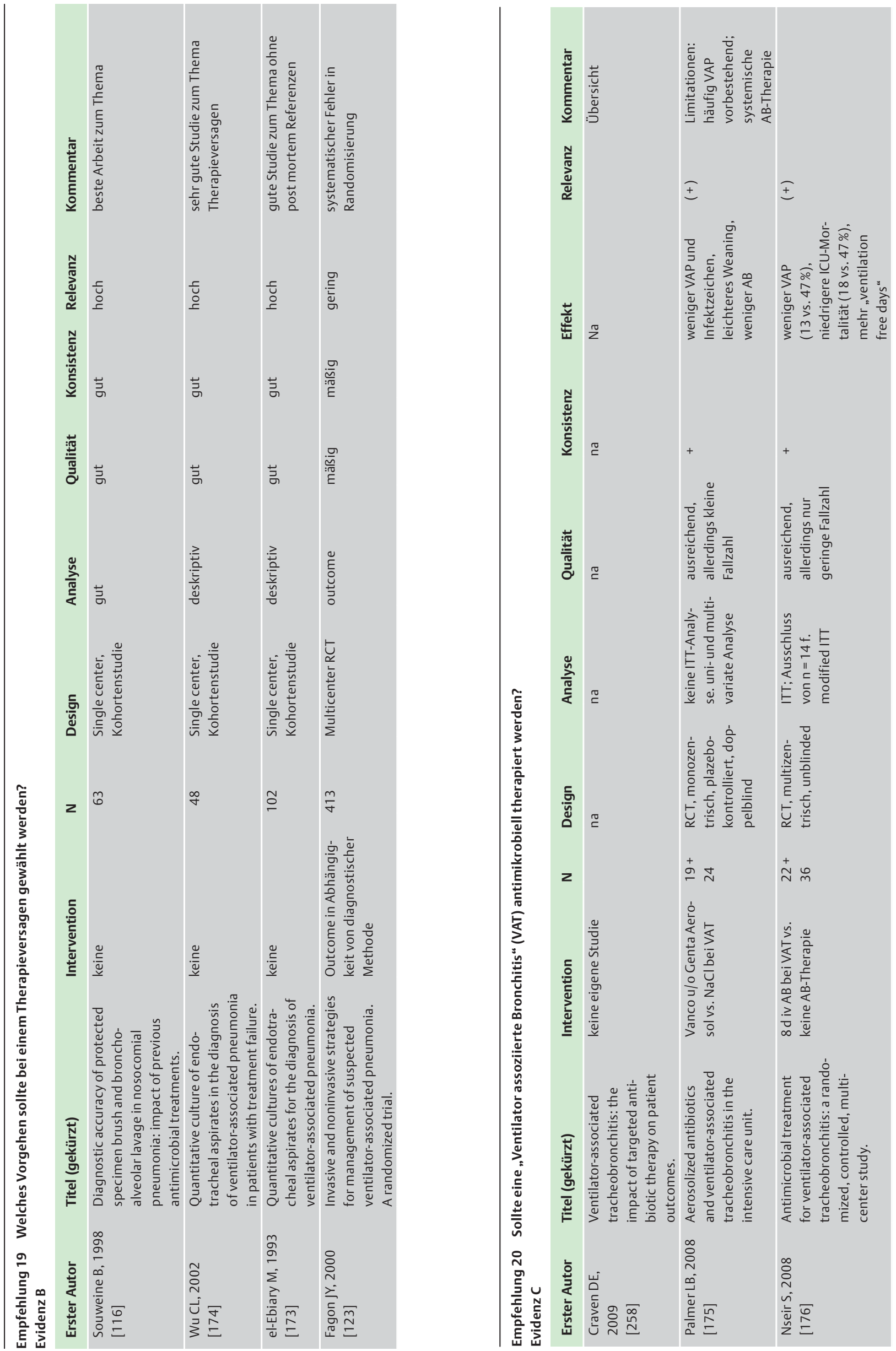



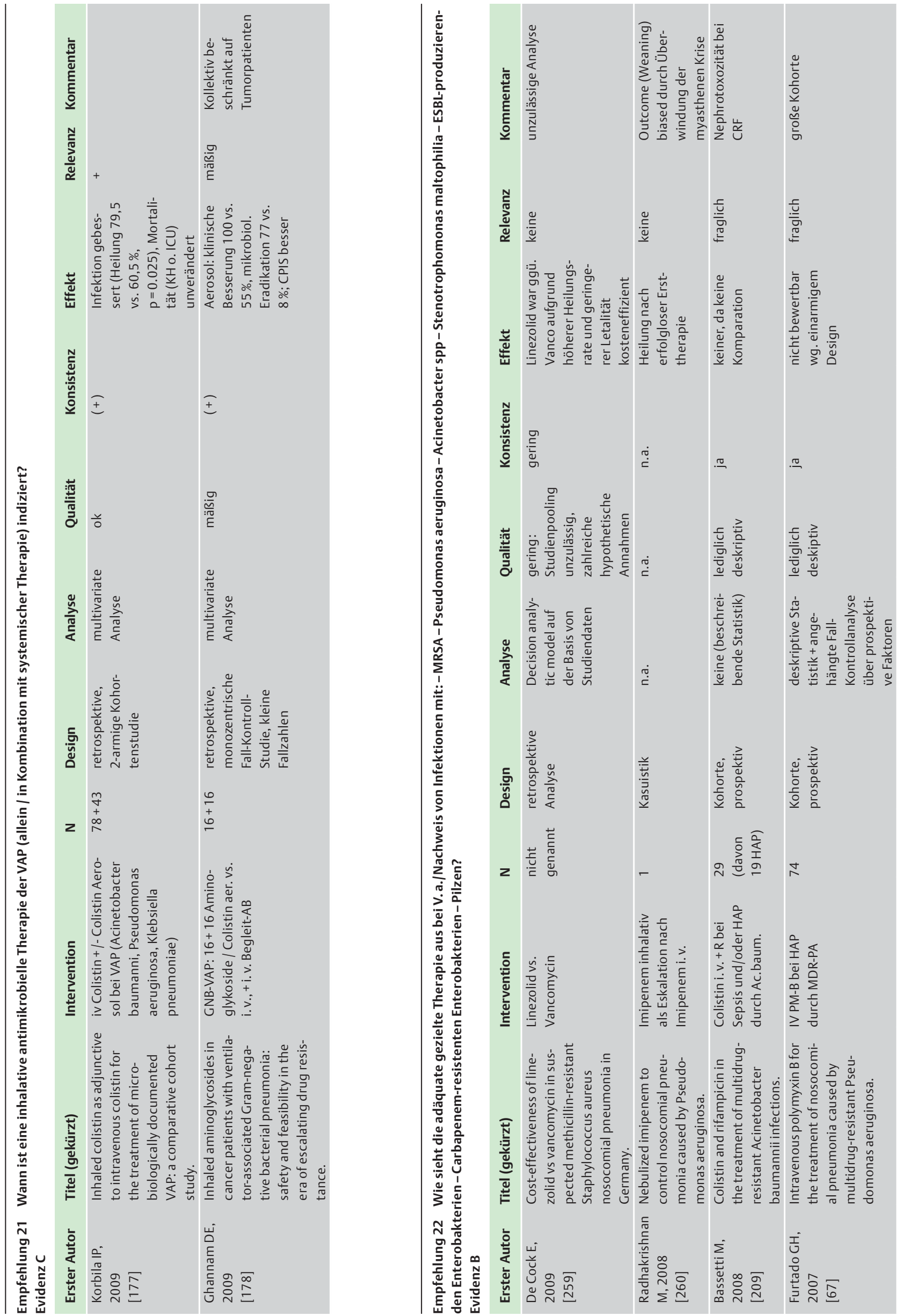


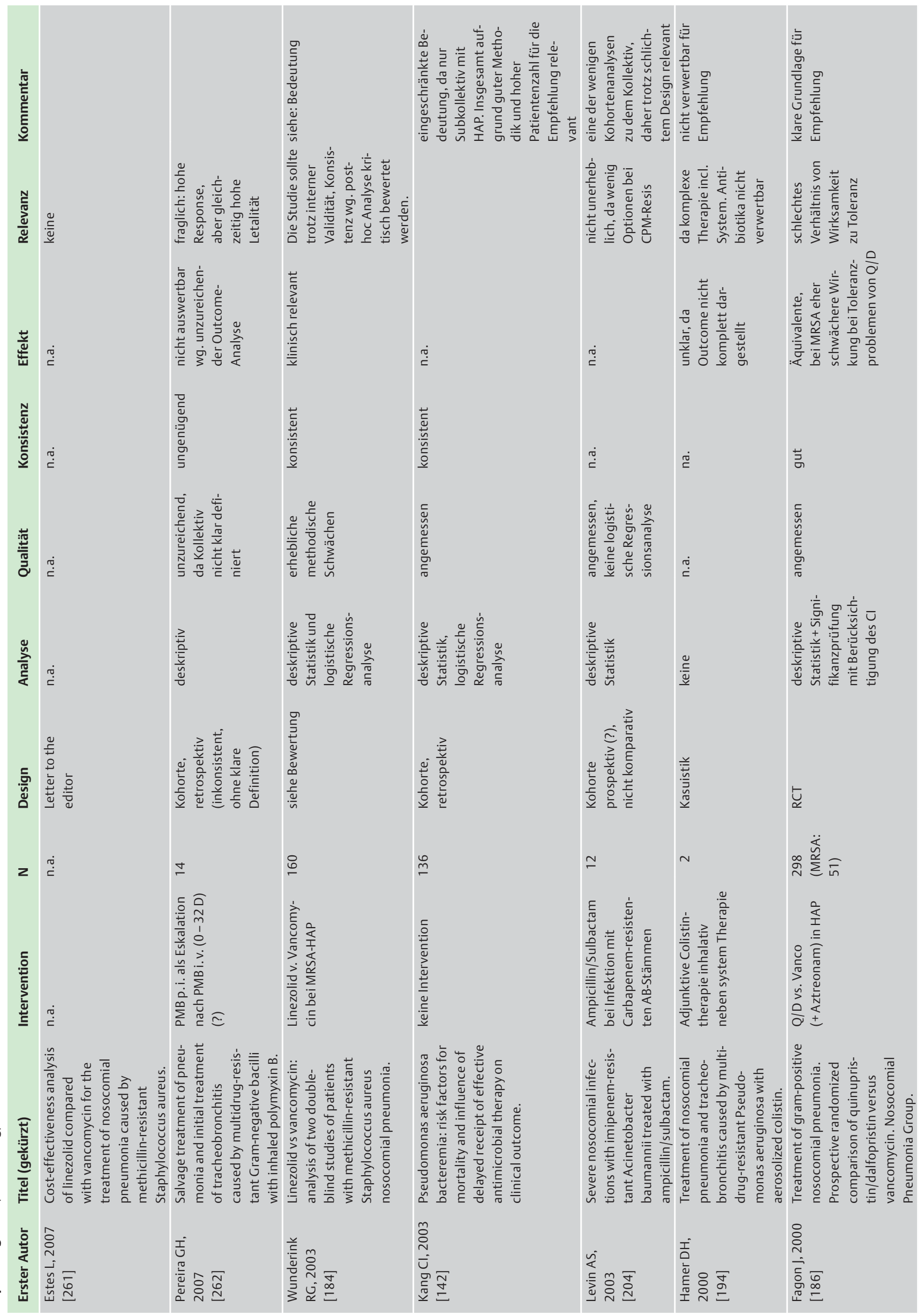




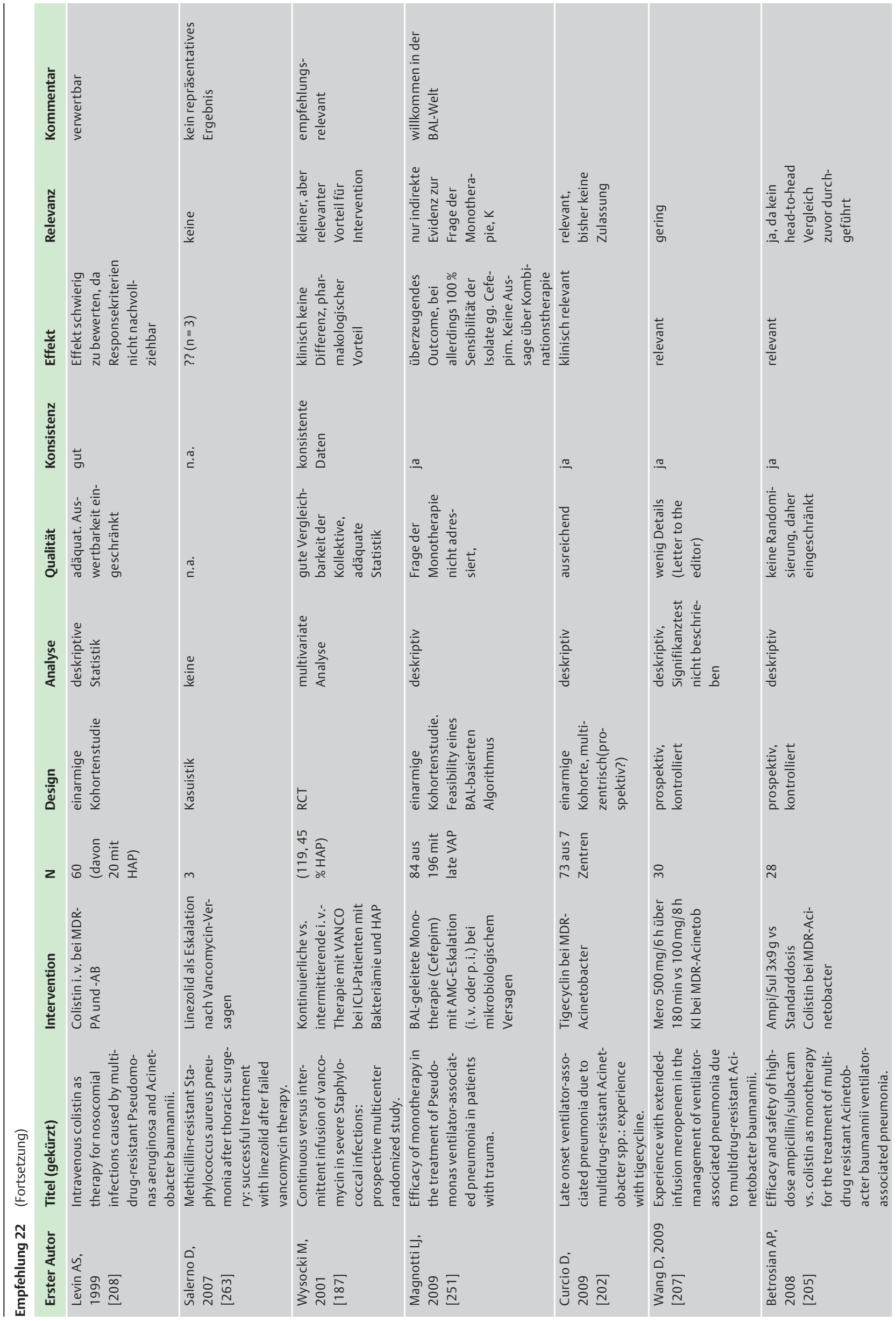




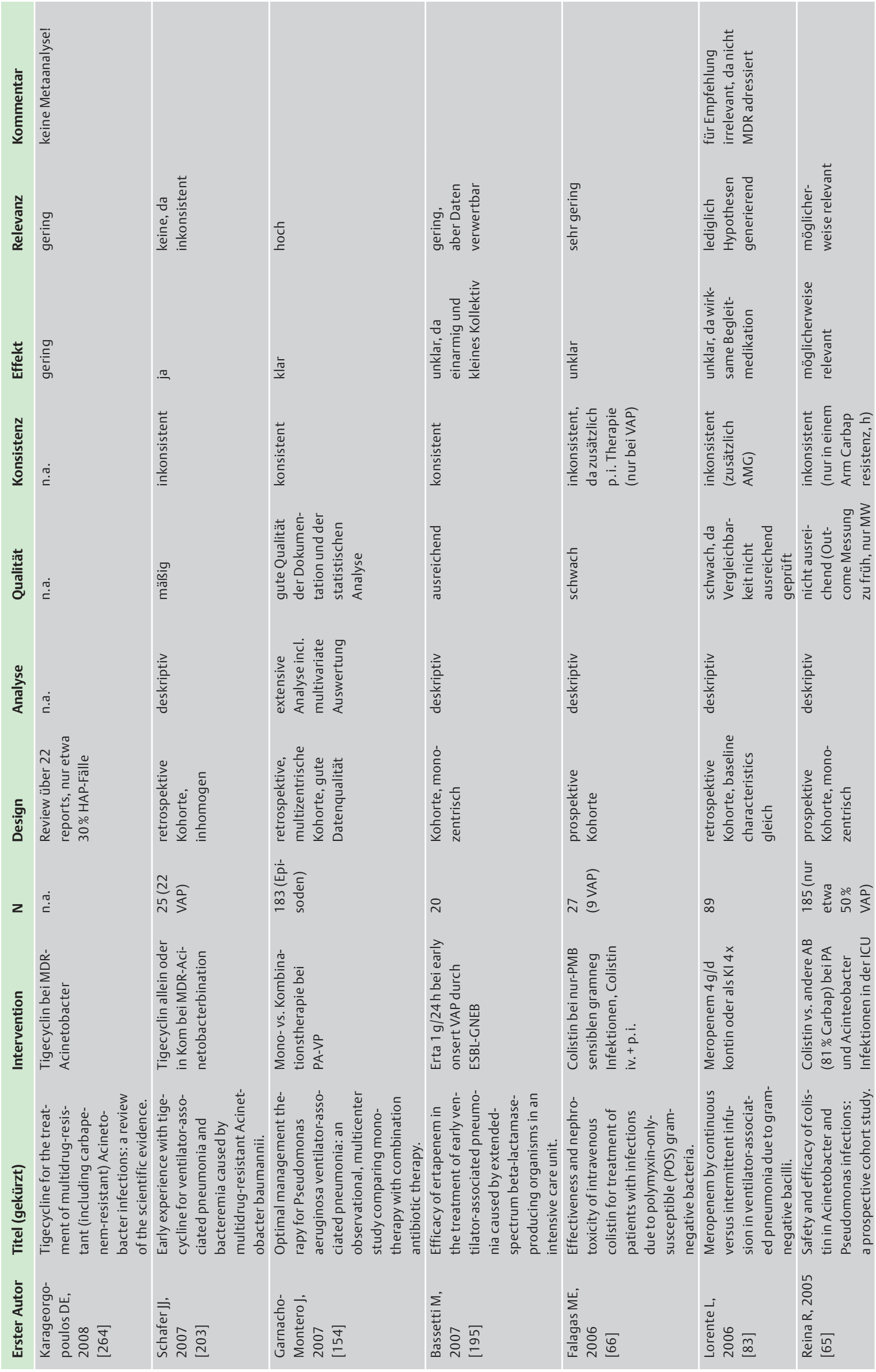




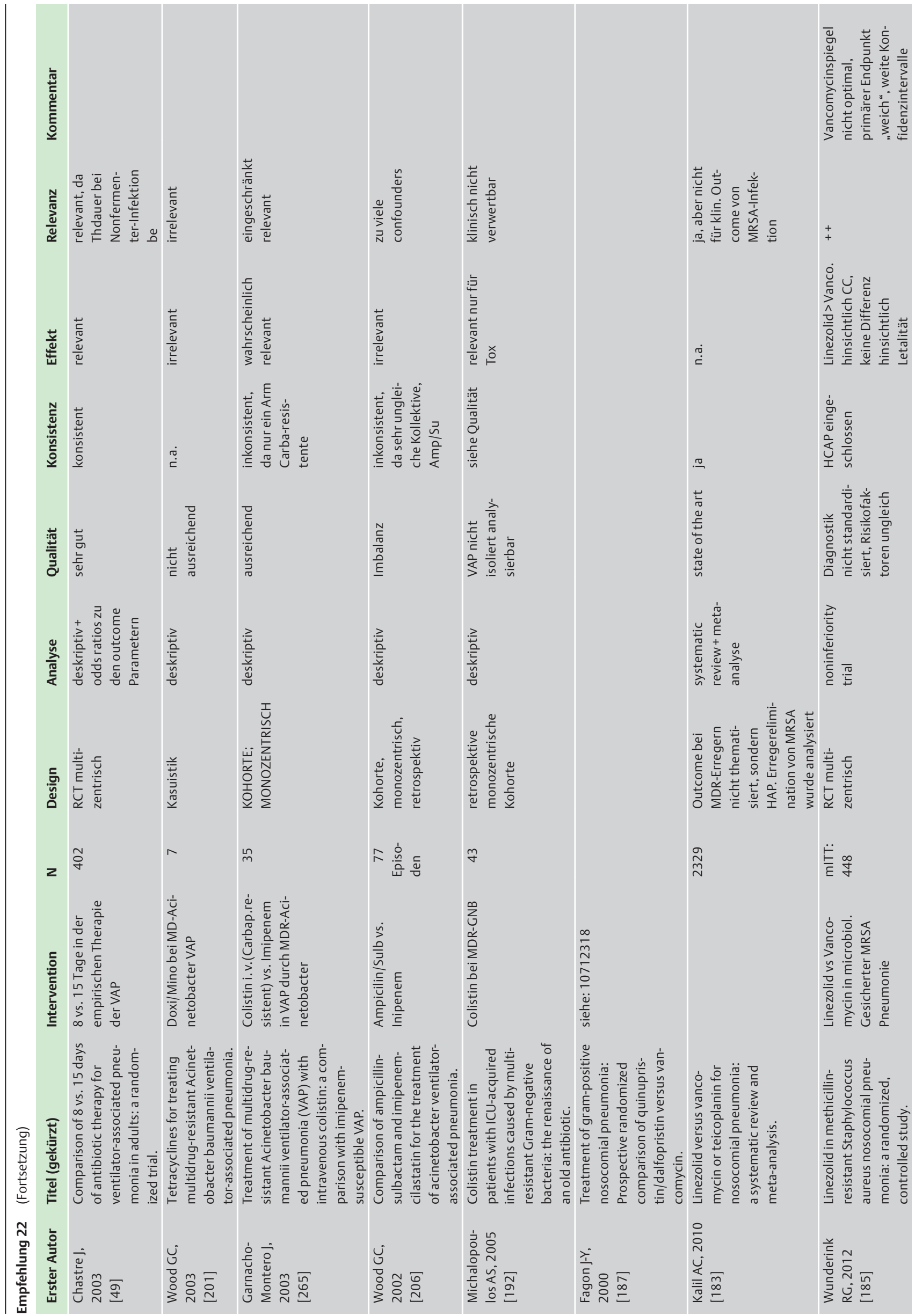

